
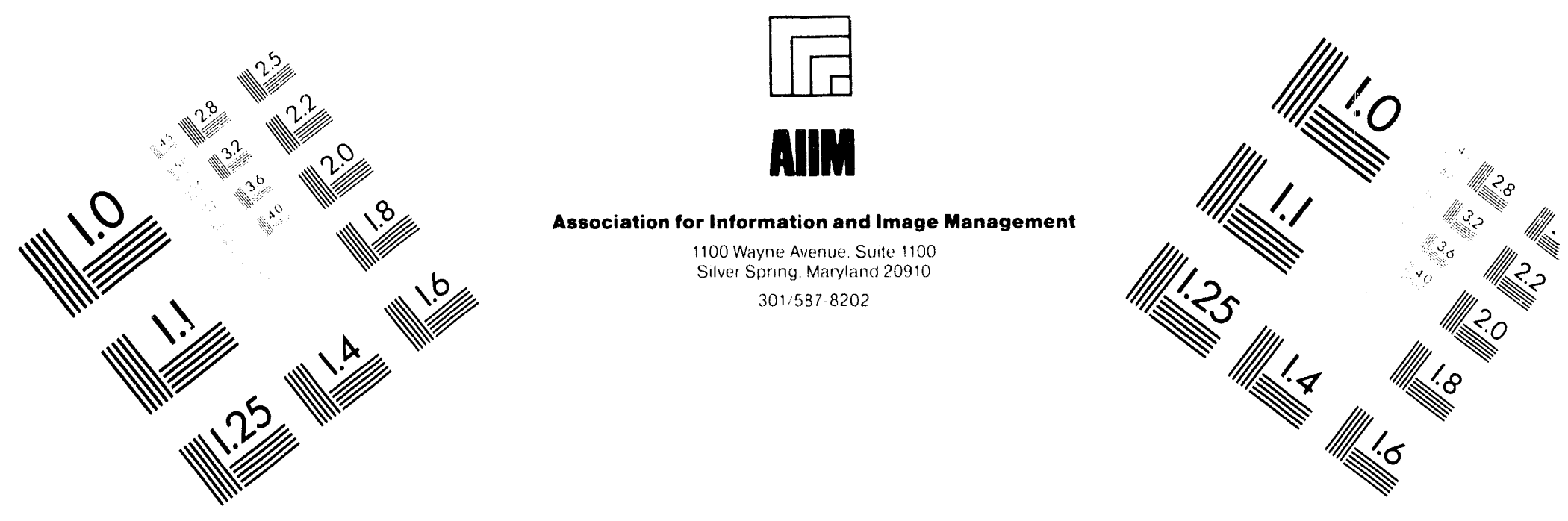

\title{
Centimeter
}

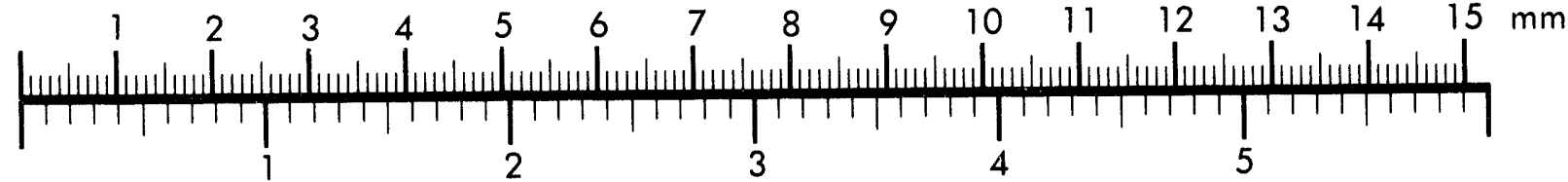

Inches
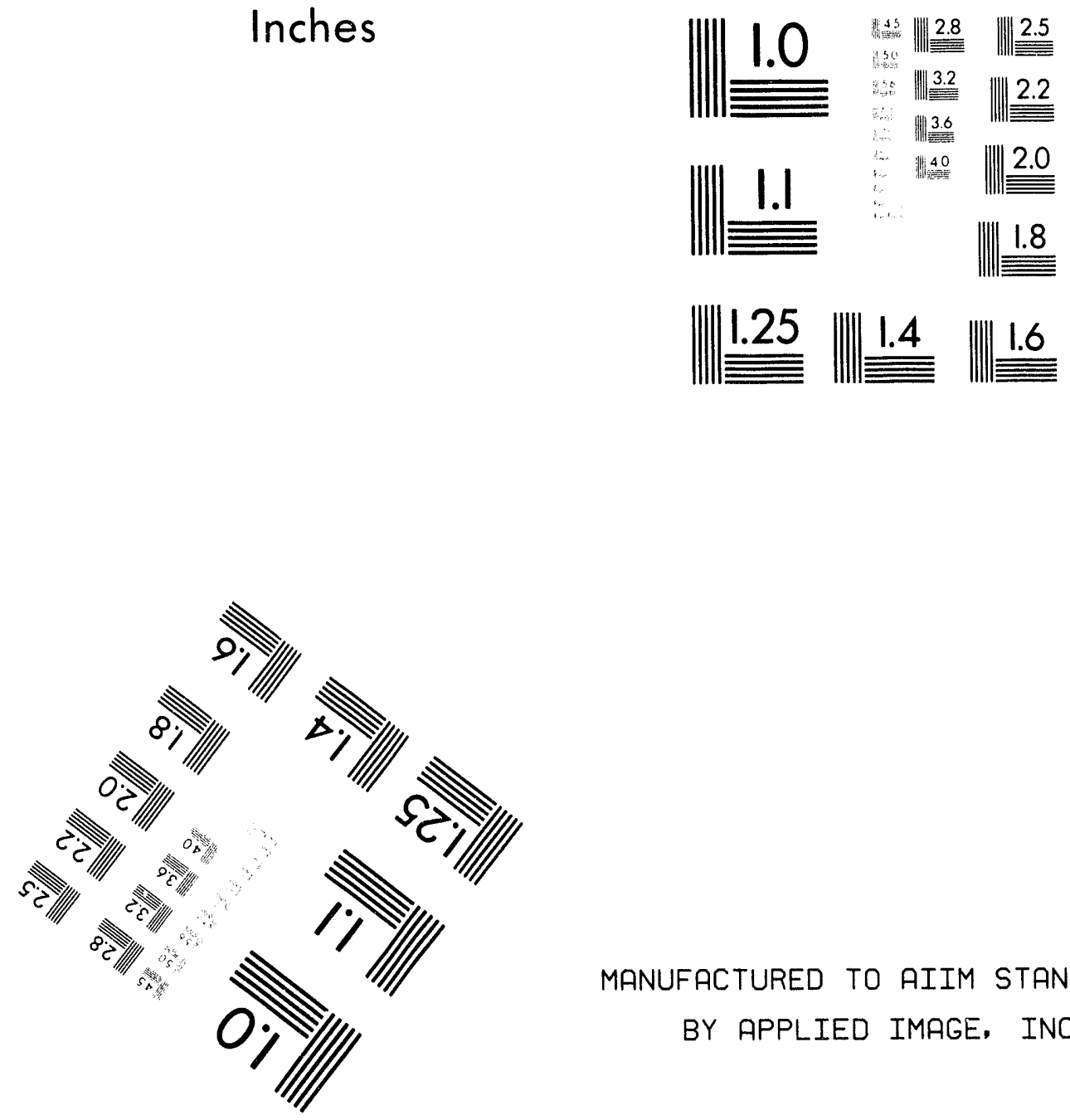

MANUFACTURED TO AIIM STANDARDS

BY APPLIED IMAGE, INC.

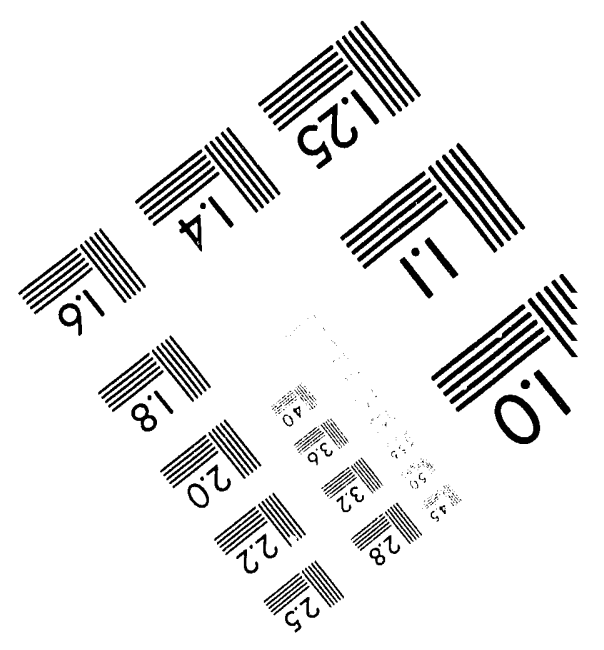



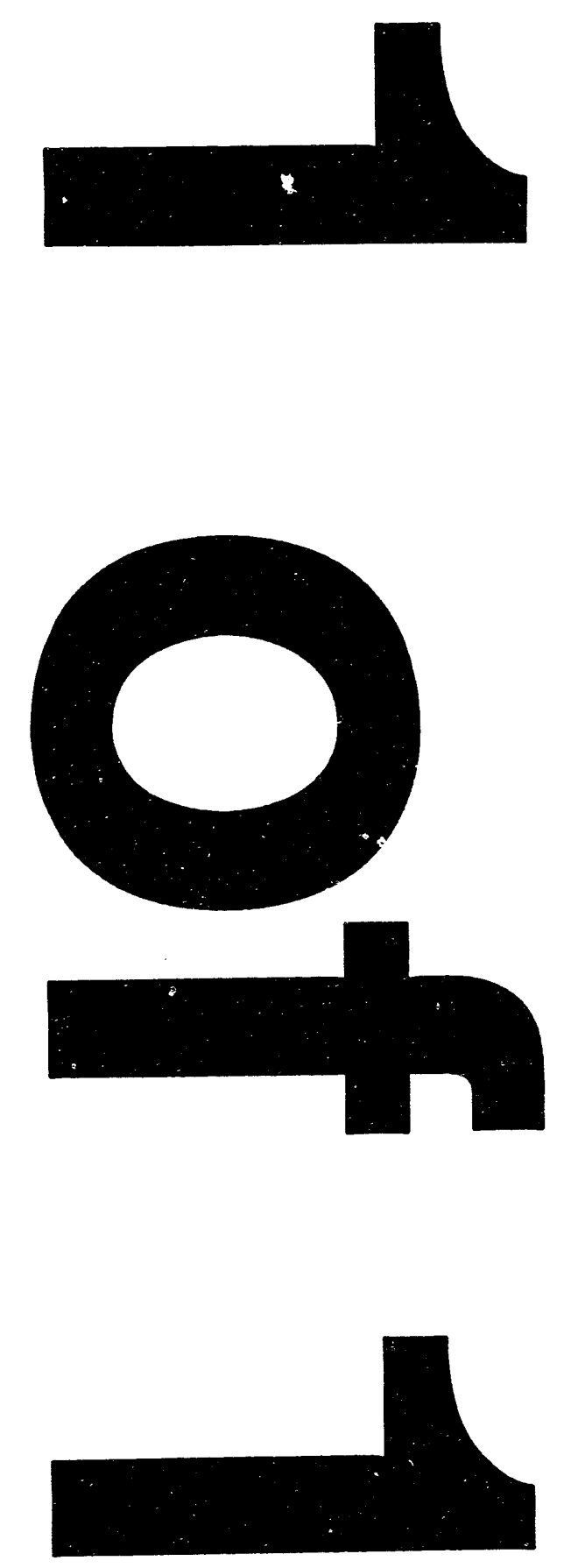
WSRC-TR-93-666

Publication Date: April 1994

\section{Hydrologic Analysis of Data from the Lower Lost Lake Aquifer at Recovery Well RWM-12 (U)}

R. A. Hiergesell

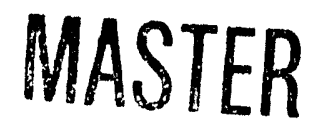

Westinghouse Savannah River Company Savannah River Site

Aiken, SC 29808

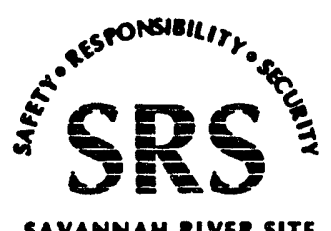

Prepared for the U. S. Department of Energy under Contract No. DE-AC09-89SR18035 


\section{Approvals}

$1 R$ Ch

Y. R. Cook, Technical Reviewer

Waste Disposal and Environmental Development Group

Interim Waste Technology Section

Waste Management and Environmental Technology DepartmentSRTC

R.W. Itan

R. H. Hsu, Manager

Waste Disposal and Environmental Development Group

Interim Waste Technology Section

Waste Management and Environmental Technology DepartmenuSRTC
Date

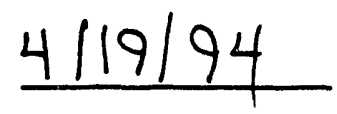

Date

$4 / 18 / 94$ 


\section{Contents}

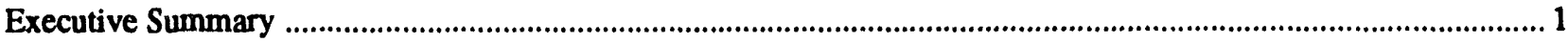

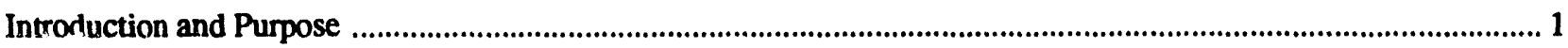

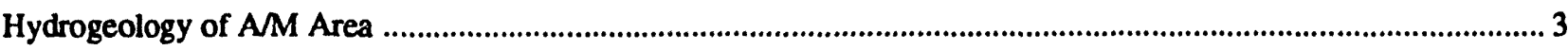

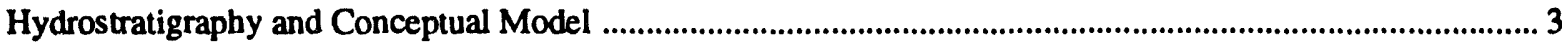

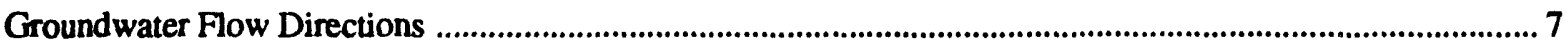

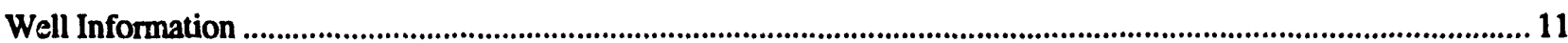

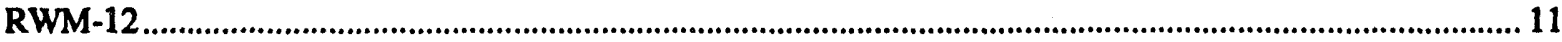

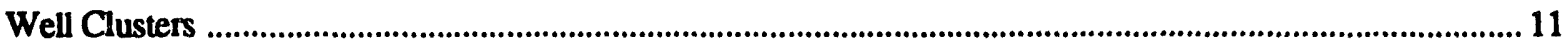

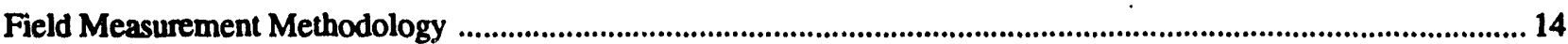

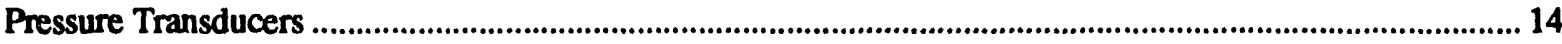

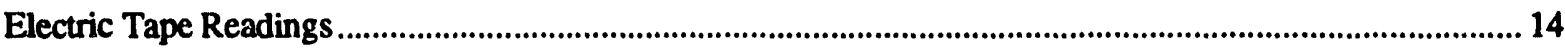

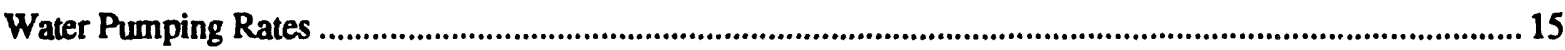

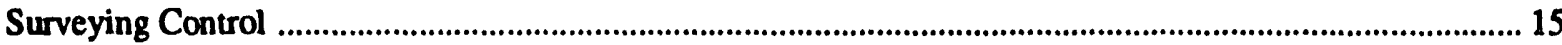

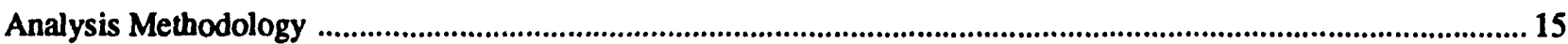

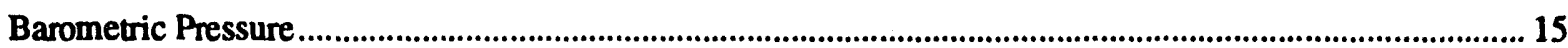

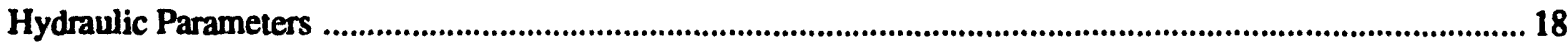

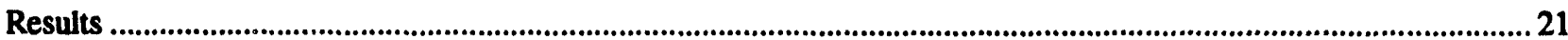

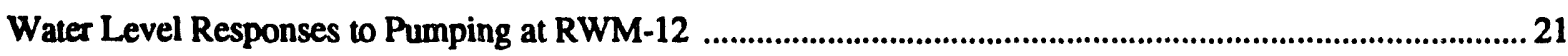

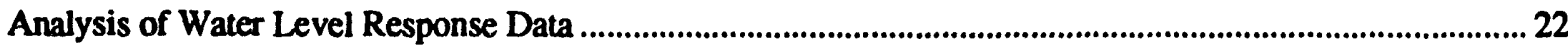

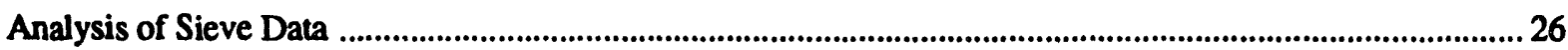

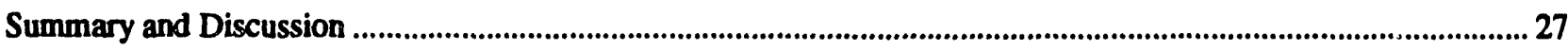

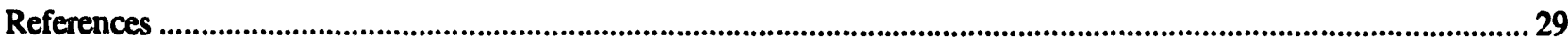

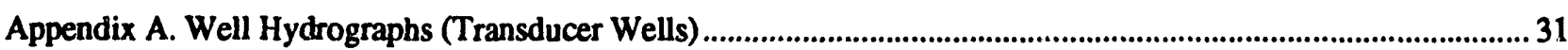

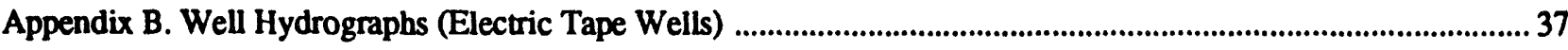

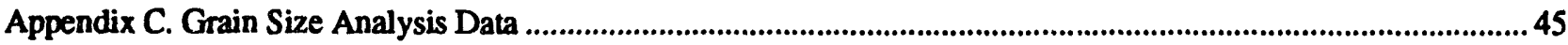

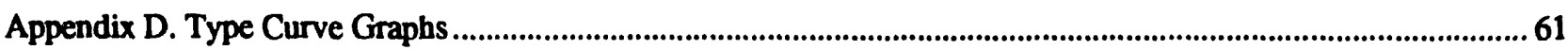

\section{List of Figures}

Figure 1. Location of RWM-12 within the AM Area ......................................................................................... 2

Figure 2. Location of Monitoring Wells in the Vicinity of RWM-12 .............................................................. 3

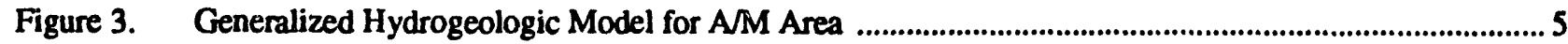

Figure 4. Idealized Hydrogeologic Cross-section with Well Screen Locations .....................................................6

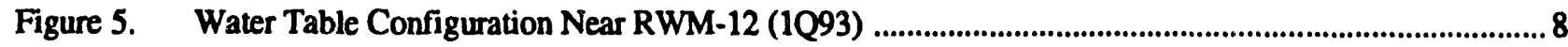

Figure 6. Lower Lost Lake Aquifer Zone Potentiometric Surface (1Q93) ...........................................................9

Figure 7. Vertical Flow Directions and Gradients at MSB-47 ....................................................................... 10

Figure 8. Geophysical Logs and Screen Zone Location for RWM-12 ..........................................................12

Figure 9. Atmospheric Pressure Variation During Test Period ........................................................................... 16

Figure 10. Correlation of Atmospheric Pressure Variation with Water

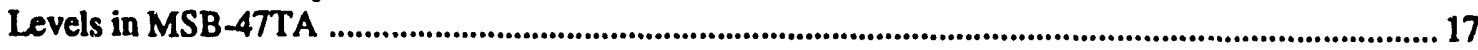




\section{List of Tables}

Table 1. Summary of Well Information for Wells in Vicinity of RWM-12 ............................................................ 13

Table 2. Summary of Calculated Hy Iraulic Parameter Values ...................................................................................2 24

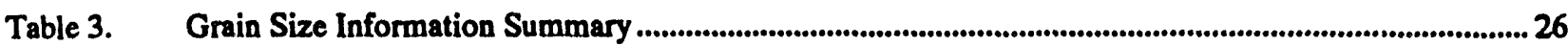

\section{Acknowledgment}

Data collection efforts in the monitoring of hydraulic responses to pumping at RWM-12 were conducted by individuals in several WSRC organizations. Bill Pidcoe, Environmental Restoration Department; John Haselow and Ralph Nichols, SRTCESS; Robert Hunter, Dan Stewart, and Jim Piercy, Environmental Protection Department-Environmental Monitoring participated in instrumenting certain wells and/or obtaining water level measurements. Pressure transducers and data loggers were supplied by EPD-EMS and SRTC-ESS. The author appreciates the efforts of all involved. 


\section{Hydrologic Analysis of Data from the Lower Lost Lake Aquifer at Recovery Well RWM-12}

\section{Executive Summary}

This report presents an analysis of water level responses that were monitored in wells near recovery well RWM-12 when it was brought online on March 23, 1992. The well is part of a system of wells used to pump and treat a groundwater contaminant plume of trichloroethylene (TCE) beneath the AMM Areas of the Savannah River Site. The purpose of obtaining measurements of water level responses was to obtain the data needed to make quantitative estimates of hydraulic conductivity in the pumped horizon(s) and to assess the hydraulic connection between adjacent layers. Field estimates of hydraulic parameters are needed to calibrate and refine groundwater flow models of the AM Area.

Estimates of transmissivity $(T)$ and storativity $(S)$ were obtained for the Lower Lost Lake Aquifer using several hydraulic methodologies and one method related to grain size distribution. One approach also provided a leakance factor $(r / B)$ which was later used to estimate vertical hydraulic conductivity $\left(\mathrm{K}_{\mathrm{v}}\right)$ in the confining zone. Estimates of $\mathrm{T}$ for the lower Lost Lake aquifer zone ranged from a high of $1.73 \mathrm{ft}^{2} / \mathrm{min}$ to a low of $6.36 \mathrm{E}-01 \mathrm{ft}^{2} / \mathrm{min}$. The most reliable method of estimating $\mathrm{T}$ is thought to be the Hantush (1955) ${ }^{4}$ method because this analytical model is the most representative of field conditions at RWM-12. However, reasonable estimates were also obtained from the other methods. Values of $S$ ranged from 1.68E-04 to 7.39E-05. At the three wells for which Hantush analyses were conducted, estimates of $K_{v}$ ranged from 2.27E-06 to $1.03 \mathrm{E}-06 \mathrm{~cm} / \mathrm{sec}$.

The most surprising development during field testing was the lack of a hydraulic response at MSB-47C to pumping at RWM-12. MSB-47C is finished in the same formation as the upper screen of RWM-12. The lack of response is probably attributable to either naturally occurring beterogeneity within the upper Lost Lake aquifer or to a decrease in hydraulic conductivity $(K)$ in the aquifer material immediately surrounding the wellbore at RWM-12. Such a reduction in $K$ could occur during the well installation process if a clay-based drilling fluid is used, invasion of the formation material by the clay-rich fluid occurs, and complete removal of the clay material from the formation matrix is not achieved during the well development process.

\section{Introduction and Purpose}

This report presents an analysis of water level responses that were monitored in wells near recovery well RWM-12 when it was brought online on March 23, 1992 as part of the system of wells used to pump and treat a groundwater contaminant plume of trichloroethylene (TCE) beneath the AM Areas of the Savannah River Site. The series of wells, all similar to RWM-12, pump groundwater and deliver it to air strippers that effectively separate and remove the TCE. Water level responses to pumping at RWM12 were monitored using both pressure transducers/data loggers, and electric tapes. The purpose of obtaining measurements of water level responses was to obtain the data that is needed to make a quantitative estimate of hydraulic conductivity in the pumped horizon, and to assess the hydraulic connection between adjacent layers. 
The $A$ and $M$ Areas are located in the northwest portion of the Savannah River Site. Within the A-Area, the location of RWM-12 is incicated on Figure 1. Well clusters that were monitored to detect hydraulic responses are presented in Figure 2. Clusters whose individual wells were instrumented with pressure transducers include MSB-47, MSB-67, and MSB-68. In addition, atmospheric pressure was monitored at the MSB-47 location. Electric tapes were utilized in the other wells to measure the depth to water.

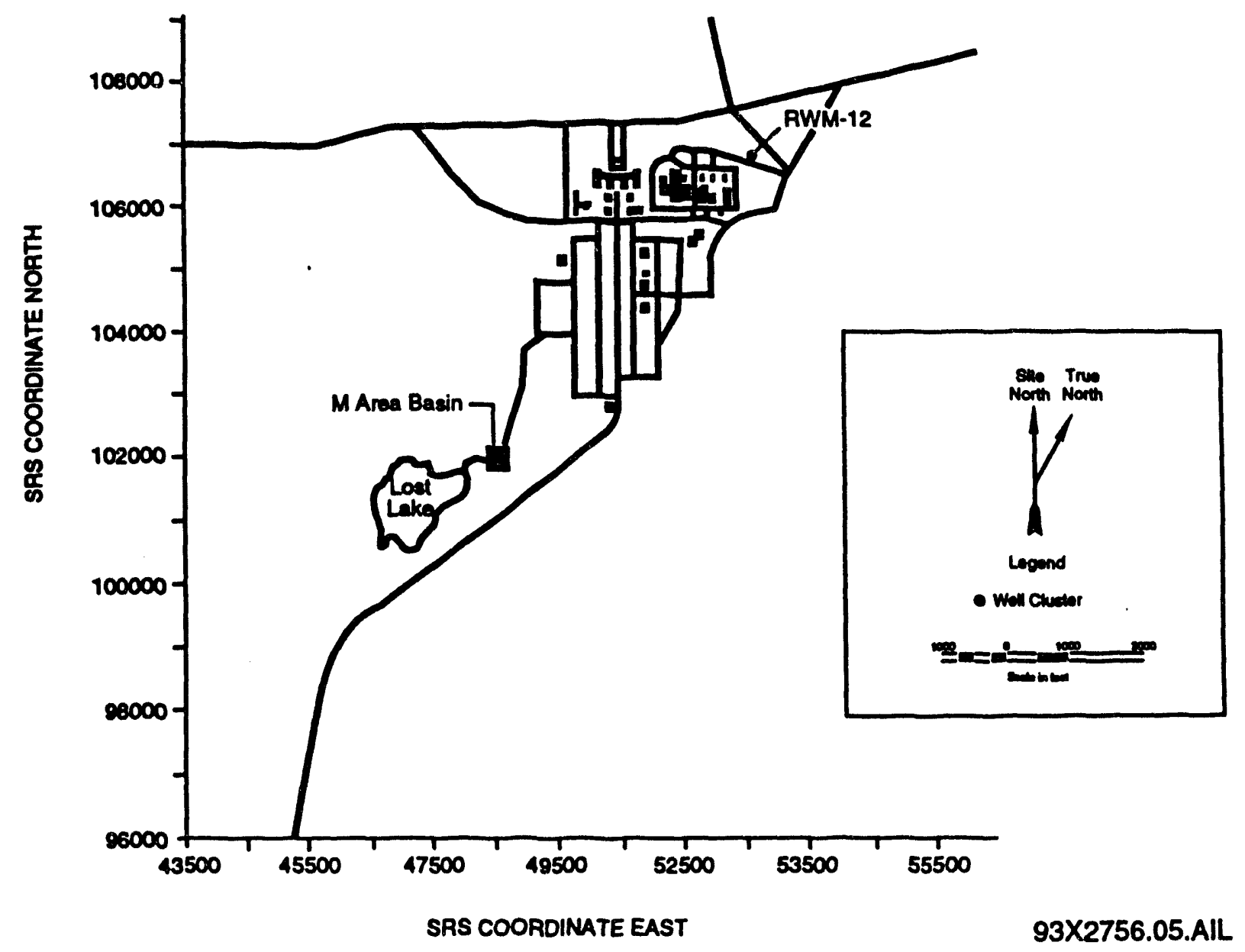

Figure 1. Location of RWM-12 within the AMArea 


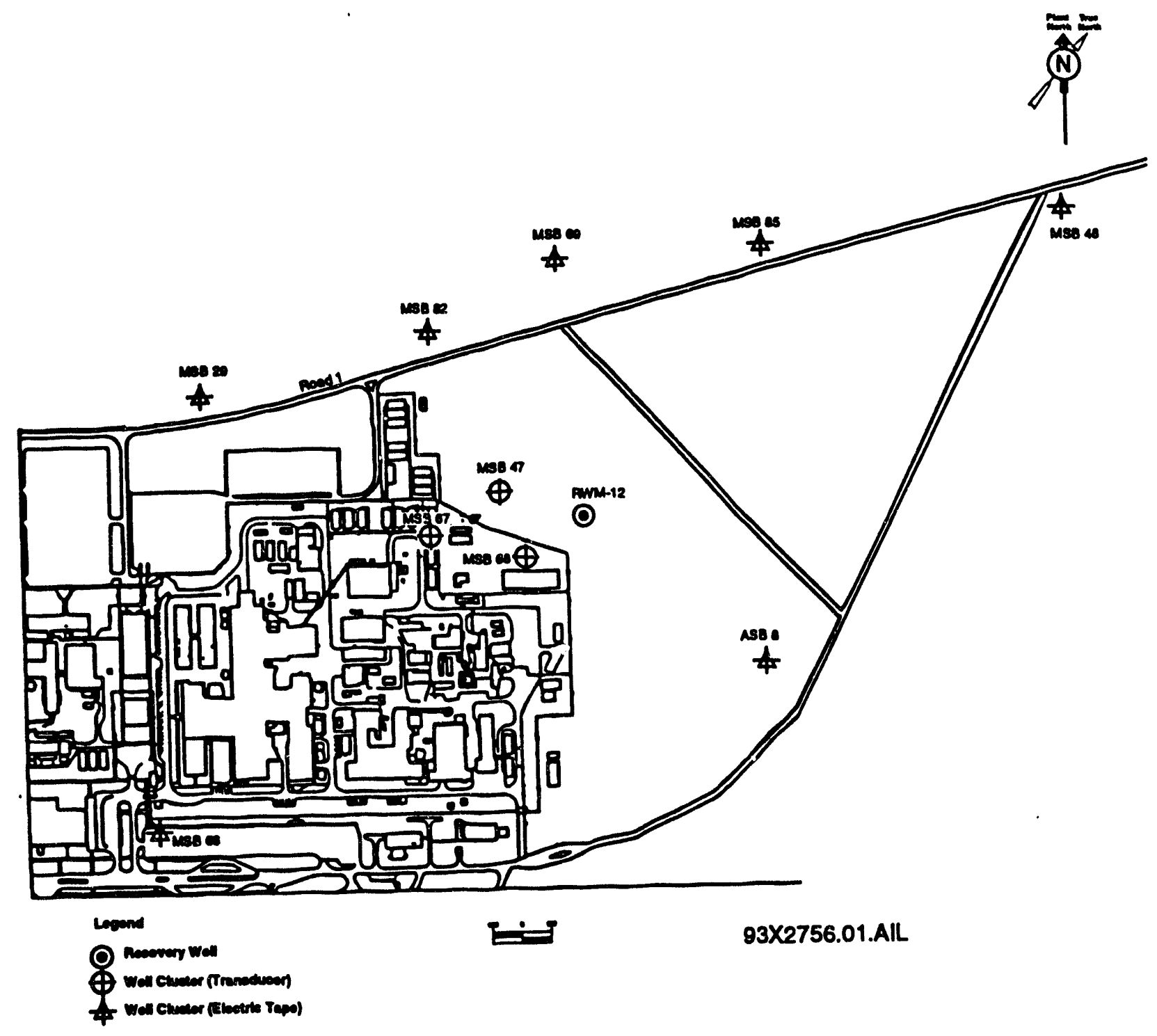

Figure 2. Location of Monitoring Well in the Vicinity of RWM-12

\section{Hydrogeology of A/M Area}

\section{Hydrostratigraphy and Conceptual Model}

Several attempts have been made to define terminology to describe the hydrostratigraphic units at SRS. The nomenclature utilized in this report is that presented in Lewis and Aadland (WSRC-TR-92-355) ${ }^{1}$ and which appears in the generalized conceptual model in Figure 3. A detailed description of hydrostratigraphy of the AM Areas is presented in that report and only a summary is provided herein. In the AMI Area, the Southeastern Coastal Plain Hydrogeologic province consists of the Floridan-Midville Aquifer System, which includes the individual "M-Area", "Lost Lake", and "middle sand" aquifer zones that comprise the Steed Pond Aquifer, the Crouch Branch Aquifer, the MCQueen Branch Aquifer, and all intervening confining 
units. The sediments were deposited in environments ranging from fluvial deltaic to shallow marine, and all tend to thin in the direction of the ancestral coastline to the northwest. This thinning and pinching out of individual hydrostratigraphic units is a persistent pattern beneath the $A M$ Area. When confining units pinch out or are discontinuous, aquifer units coalesce into singular bydrologic units.

The main hydrostratigraphic units of interest beneath the AM Area are the Steed Pond Aquifer, the underlying Crouch Branch Aquifer, and the Crouch Branch Confining Unit that separates them. In the southern portion of the A/M Area the Steed Pond Aquifer is divided into the upper "M-Area" aquifer zone and lower "Lost Lake" aquifer zone. These zones are divided by the "green clay" confining zone. Also in the southern and central AM Area, the Crouch Branch Confining Unit is divided into an "upper clay" zone and "lower clay" zone by a transmissive zone termed the "middle sand".

The "green clay" confining zone of the Steed Pond Aquifer thins northward and eventually pinches out beneath the $A M M$ Area. In the northern part of the AMM Areas the "M-Area" aquifer zone and "Lost Lake" aquifer zone coalesce into a single aquifer unit. North of the AM Area the "upper clay" and "lower clay" zones of the Crouch Branch Confining Unit successively pinch out. Where the "upper clay" pinches outh the "middle sand" coalesces with the Steed Pond Aquifer. Similarly, where the "lower clay" pinches out north of the SRS boundary, the Crouch Branch Aquifer coalesces with the Steed Pond Aquifer to form the Hollow Creek Aquifer.

Within this conceptual framework the "Lost Lake" aquifer zone is divided into upper and lower zones in some areas, which are separated by a clay layer that acts locally as an effective hydraulic seal between these zones. One such area is in the vicinity of recovery well RWM-12. The upper and lower screen zones of this well are finished within the upper and lower portions of the "Lost Lake" aquifer zone. In this report, these zones will be referred to as the "upper" Lost Lake aquifer zone and the "lower" Lost Lake aquifer zone. An idealized cross-section of the hydrogeologic units near RWM-12, indicating the location of well screen zones, is presented in Figure 4. 


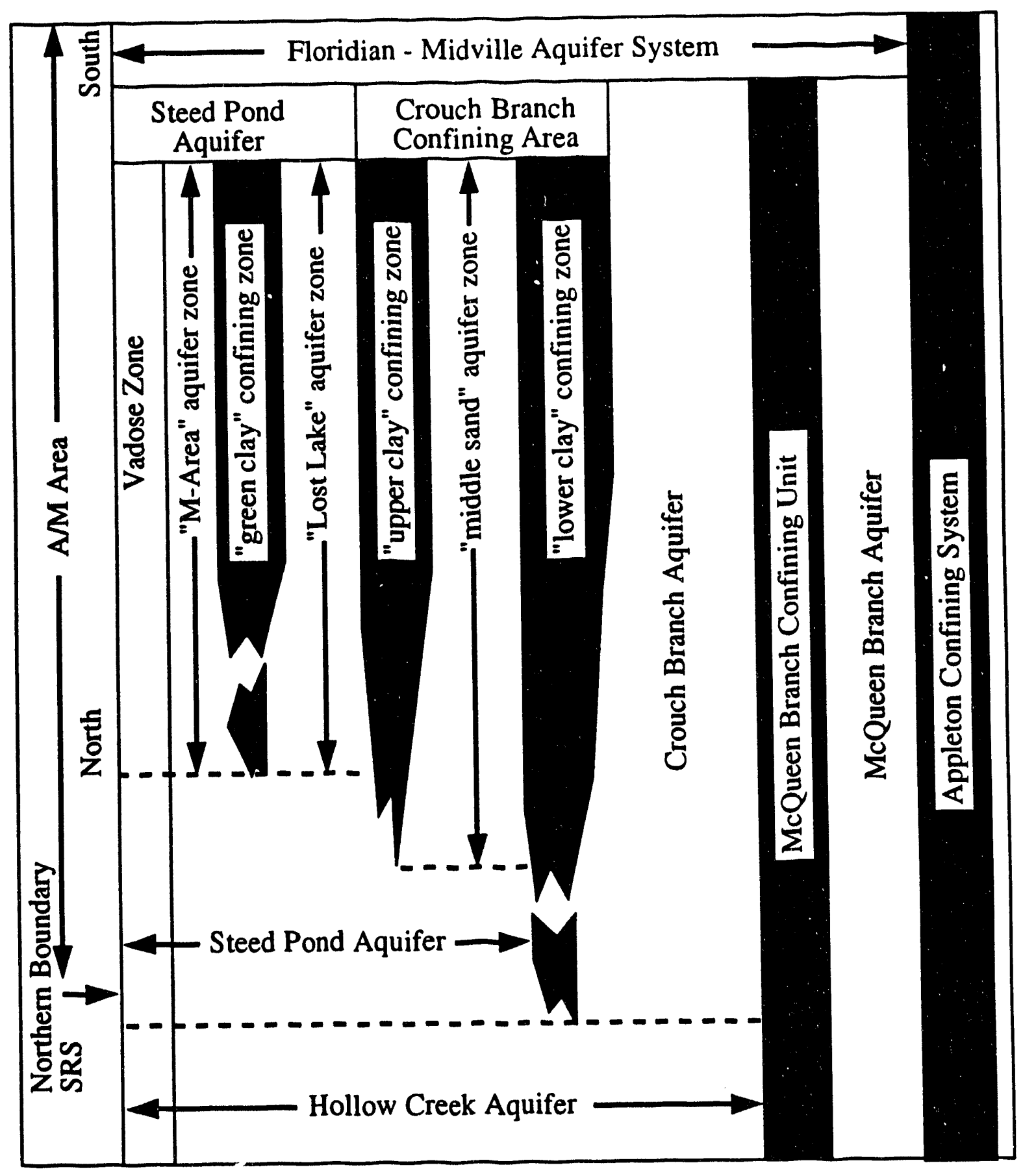

93X2756.03.AIL

Figure 3. Generalized Hydrogeologic Model for A/M Area 


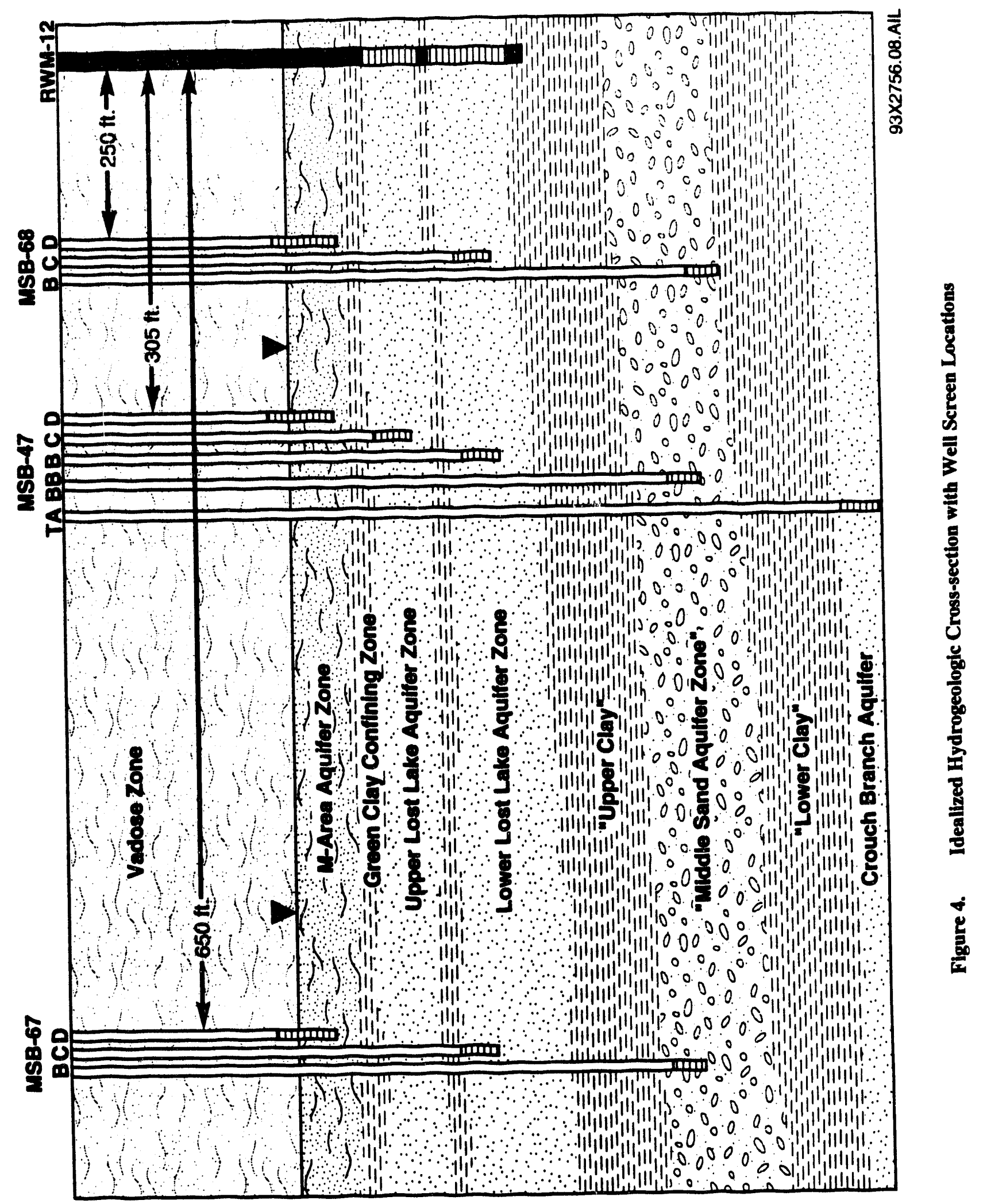




\section{Groundwater Flow Directions}

The sequence of hydrostratigraphic layers beneath the $\mathrm{A} / \mathrm{M}$ Area acts as a complex multi-aquifer groundwater system with vertical leakage occurring between layers. Deep dissection by surface streams has cut into the upper units of the groundwater flow system. Consequently, portions of the uppermost aquifer units can be isolated, horizontally, from the same aquifer units in other nearby areas. The degree of incision of surface streams into the subsurface sediments is the primary factor in determining horizontal flow directions in the groundwater sy'stem. The uppermost aquifer units flow horizontally in the direction of, and discharg? to, the nearby streams that have incised them. Deeper aquifer units flow predominantly toward more distant streams, which incise them, and discharge at those localities. The vertical movement of groundwater is controlled largely by the lateral extent, thickness, and vertical hydraulic conductivity of low permeability layers (aquitards) in the subsurface.

Near the $A / M$ Area the most deeply incised streams are Tims Branch, located to the east, Hollow Creek to the north, an unnamed creek located to the west, and a swampy portion of the Savannah River flood plain located to the south. All of these drainageways constitute discharge zones for the aquifer units beneath the AMM Area. Maps depicting horizontal flow directions in the vicinity of RWM-12 are presented for the water table and the lower Lost Lake aquifer zone in Figures 5 and 6. The horizontal flow direction for the upper Lost Lake aquifer zone is not presented because there are an insufficient number of wells finished within this unit near RWM-12. Its horizontal flow direction is likely to be sub-parallel to the lower Lost Lake aquifer zone. The vertical component of groundwater flow beneath the A/M Area is downward. In the vicinity of RWM-12 this downward gradient is illustrated in Figure 7, where water level relationships from the MSB -47 cluster wells indicate decreasing hydraulic head with progressively deeper screen zones. Calculation of vertical gradients between screen zones of the different wells indicates that the highest gradients are between wells MSB-47C and -47B and between MSB-47B and -47BB, these being 0.18 and 0.14 , respectively. These higher gradients likely reflect a reduced vertical hydraulic conductivity in the sediments between the respective screen zones in the vicinity of this cluster.

While subregional flow patterns are generally understood, characterization of groundwater flow patterns on a local scale is complicated in the A/M Area because of the pattern of low-permeability unit pinchouts. Also, borebole data is currently under study which indicates that high-angle faulting may be present beneath parts of $A / M$ Area. This may further complicate the deciphering of local flow patterns if faults offset confining units by more than their thickness, causing breaches of their hydraulic seals. If such breaches exists, they may provide pathways that allow contaminants to migrate downward more rapidly than they could travel through the low permeability confining units. 


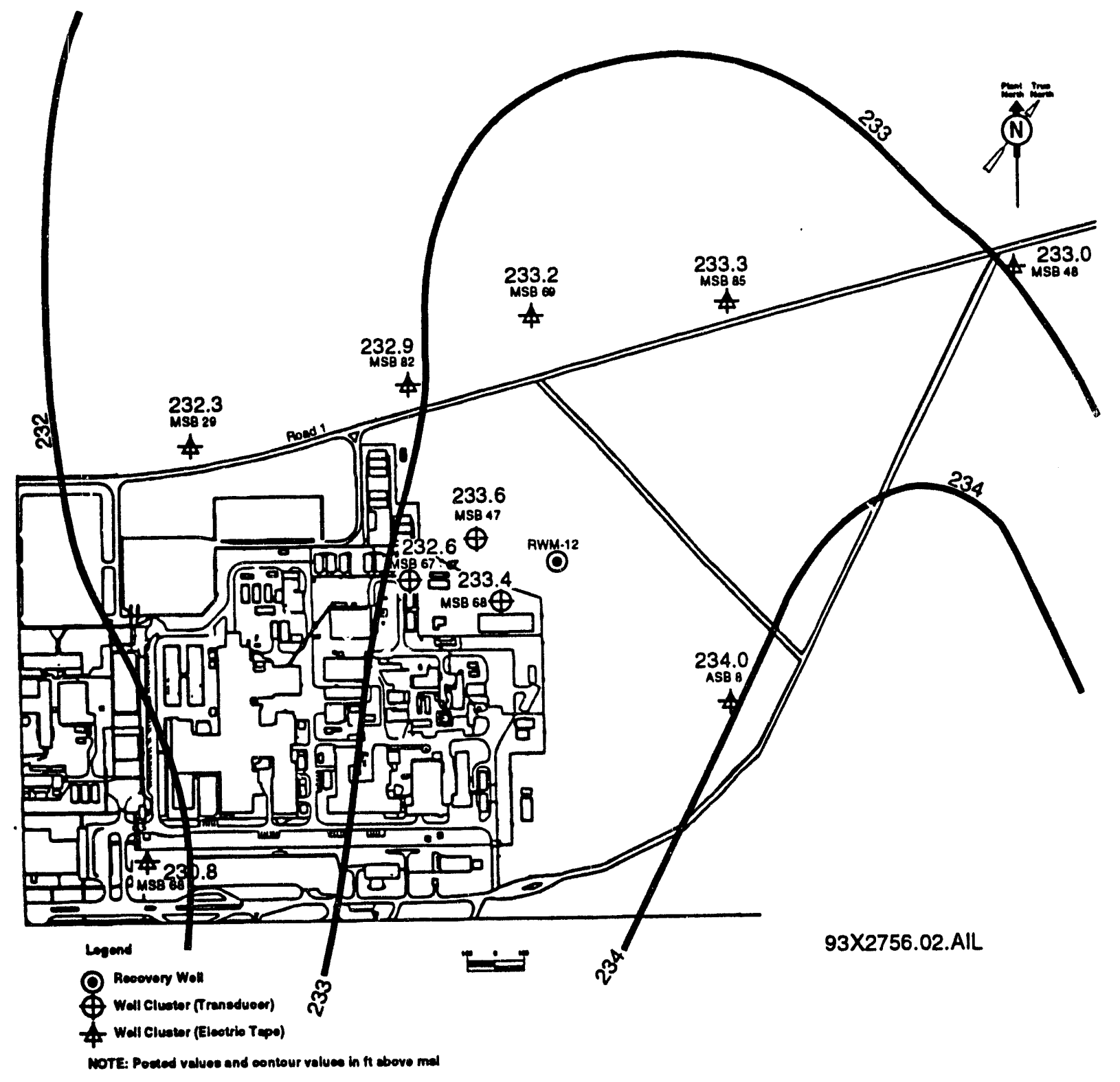

Figure 5. Water Table Configuration Near RWM-12 (1Q93) 


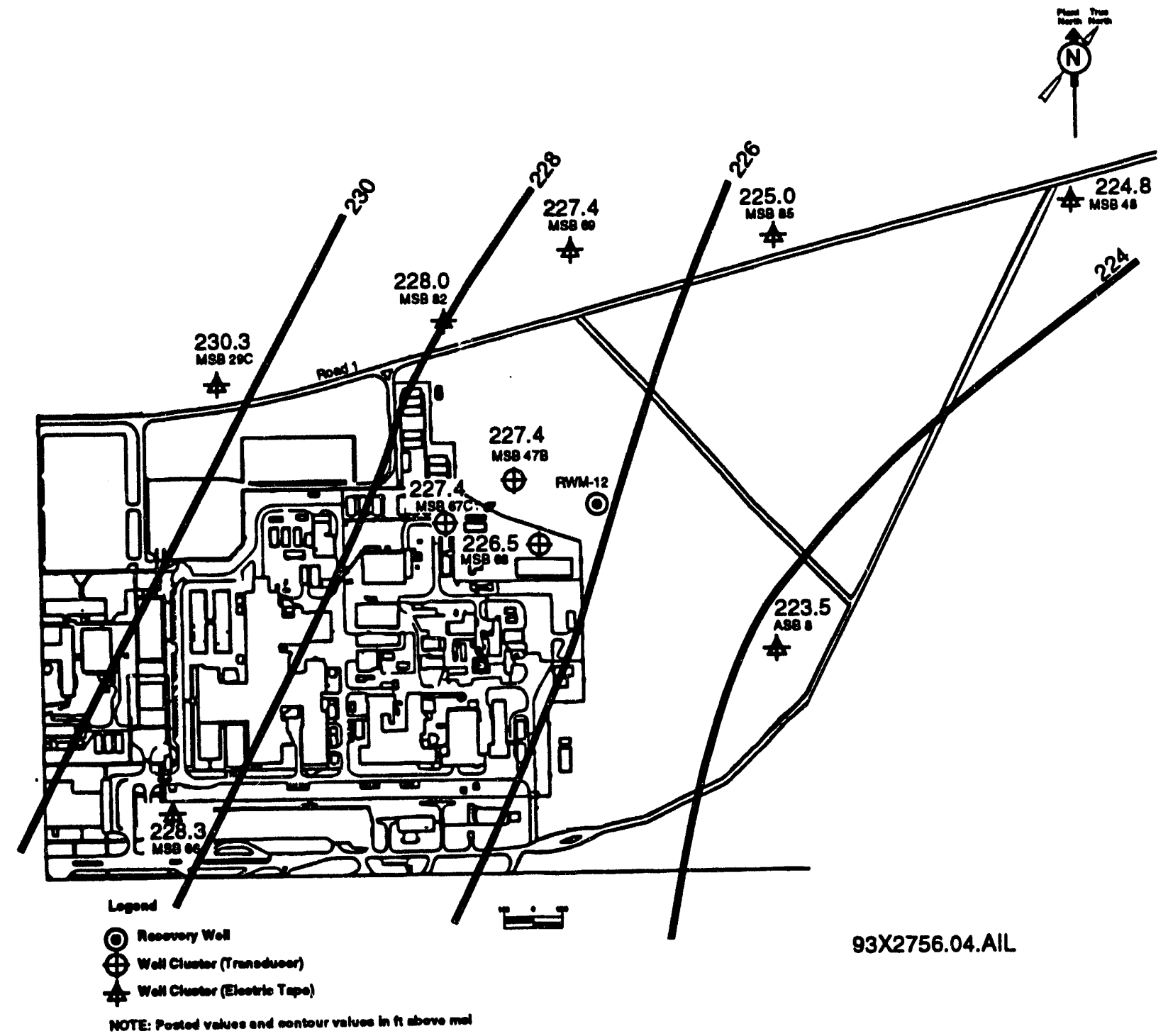

Figure 6. Lower Lost Lake Aquifer Zone Potentiometric Surface (1Q93) 


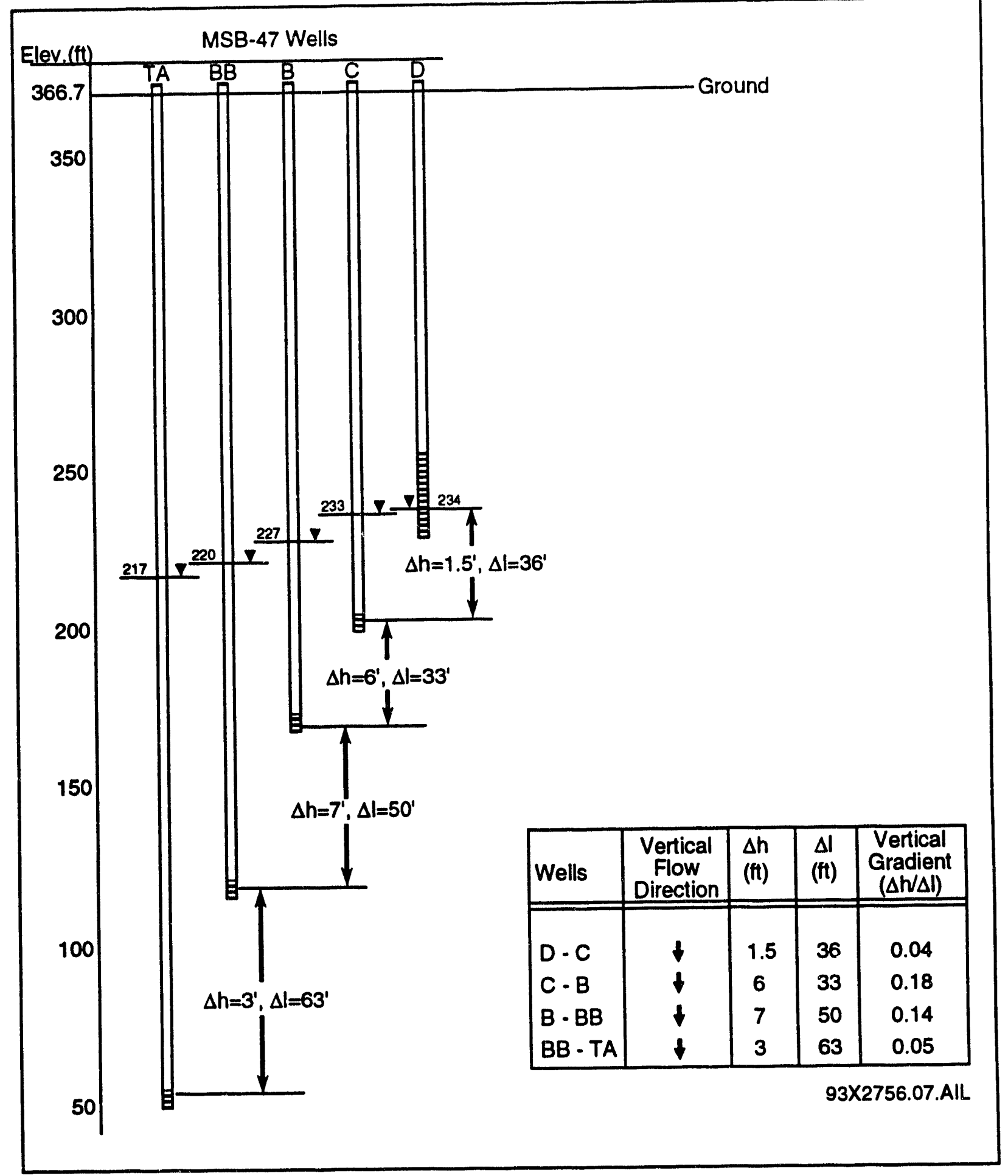

Figure 7. Vertical Flow Directions and Gradients at MSB-47 


\section{Well Information}

RWM-12

Well Clusters

The screen zones in pumping well RWM-12 are located adjacent to the twe separate aquifer zones within the "Lost Lake" aquifer zone. Screen zones are indicated on Figure 8 and are superimposed on the borehole geophysical logs obtained during well construction. The left hand track of the borehole log contains natural gamma and spontaneous potential logs, while the right hand track contains single-point, 16-inch and 64-inch long normal electrical resistivity logs. The vertical column of numbers represents the depth, in feet, below land surface. Deflections of the natural gamma log to the right are indicative of the presence of clay in adjacent borizons, and deflections of electrical resistivity logs to the right are indicative of porous sands in this hydrogeologic setting. The long-normal resistivity logs have their electrodes spaced at 16- and 64-inch increments. The wider spacing of 64 inches provides a "deeper" look into the formation away from the wellbore.

Selection of the screen zones was conducted at the time of well installation utilizing geophysical logs, core samples from the borehole, and core plug VOC analyses indicating vertical concentration distribution. Clearly, the two zones having the highest electrical resistivity bave been selected for screening. The low-permeability zone that separates these zones is well defined by the natural-gamma log.

RWM-12 is constructed of 6-inch diameter, black carbon steel, schedule 40 casing, and the screen zones are constructed of stainless steel. The screen is constructed of continuous wrap stainless steel, having a 0.018-inch slot. A 5.2-foot sump is located directly beneath the lower screen.

Monitor wells are constructed using 4-inch polyvinyl chloride (PVC) casing and screens. Screen zones in the monitor wells are generally 5 feet in length, except for water table wells, which usually have a 20-foot screen length. All monitor wells are constructed with a 5-foot sump immediately beneath each well screen length. Each monitor well is equipped with a dedicated submersible pump for periodic collection of water samples to be analyzed for the presence of contaminants. Each well is also constructed with a 1-inch diameter standpipe that is used to measure the depth to water in the well. Information regarding construction and surveying for all wells monitored as part of this investigation is presented in Table 1. Distance of each well from RWM-12 is also included therein. 

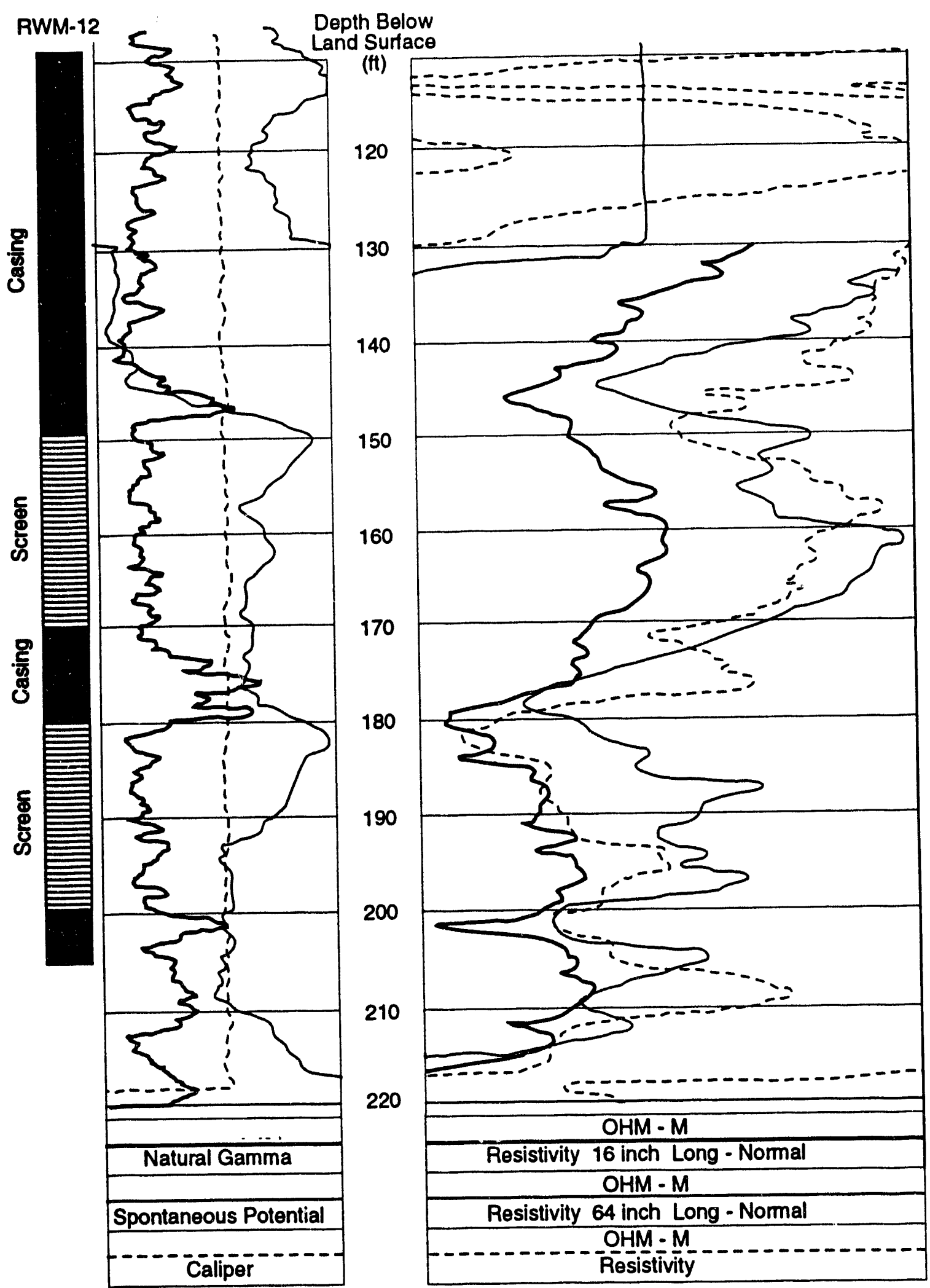

93X2756.06.AIL

Figure 8. Geophysical Logs and Screen Zune Locations for RWM-12 
Table 1. Summary of Well Information for Wells in Vicinity of RWM-12

\begin{tabular}{|c|c|c|c|c|c|c|c|c|}
\hline \multirow[b]{2}{*}{ WELL } & \multicolumn{8}{|c|}{ WELL INFORMATION FOR AQUIFER TEST AT RWM-12 } \\
\hline & $\begin{array}{c}\text { SRP } \\
\text { COORD } \\
\text { N. } \\
\text { (ft) }\end{array}$ & $\begin{array}{c}\text { SRP } \\
\text { COORD } \\
\text { E } \\
\text { (fi) }\end{array}$ & $\begin{array}{l}\text { Dist. } \omega \\
\text { RWM-12 } \\
\text { (ft) }\end{array}$ & $\begin{array}{c}\text { Elev } \\
\text { top of } \\
\text { Casing } \\
\text { (fi) }\end{array}$ & $\begin{array}{l}\text { Elev } \\
\text { Top of } \\
\text { Screen } \\
\text { (fi) }\end{array}$ & $\begin{array}{l}\text { Water } \\
\text { Level } \\
\text { Elev } \\
\text { (ft) }\end{array}$ & $\begin{array}{c}\text { Elev } \\
\text { Top of } \\
\text { Standpipe } \\
\text { (fi) }\end{array}$ & $\begin{array}{l}\text { Total } \\
\text { Screen } \\
\text { Length } \\
\text { (ft) }\end{array}$ \\
\hline \multirow[t]{2}{*}{ RWM-12 } & 106879.2 & 52500.1 & 0.0 & 359.4 & 210.4 & 225.6 & & 20.5 \\
\hline & & & & & 179.7 & 225.6 & & 205 \\
\hline ASB-8A & 106369.3 & 53117.5 & 800.7 & 349.3 & 835 & 219.4 & 349.5 & 5.6 \\
\hline ASB-8B & 106362.3 & 53109.6 & 799.2 & 349.8 & 128.4 & 220.6 & 345.0 & 5.6 \\
\hline ASB-8C & 106354.4 & 53101.0 & 797.8 & 349.7 & 188.3 & 223.9 & 349.9 & 5.6 \\
\hline ASB-8TA & 106375.8 & 53124.7 & 802.2 & 349.6 & 24.6 & 215.8 & 349.8 & 5.2 \\
\hline MSB-29A & 107326.8 & 51236.4 & 1340.6 & 365.4 & 124.5 & 220.3 & 365.6 & 5.6 \\
\hline MSB-29B & 107319.3 & 51217.5 & 1356.0 & 365.2 & 153.3 & 224.7 & 365.4 & 5.6 \\
\hline MSB-29C & 107315.0 & 51206.6 & 1364.9 & 365.2 & 181.2 & 231.0 & 365.4 & 5.6 \\
\hline MSB-29D & 107323.3 & 51226.9 & 1348.4 & 365.1 & 229.4 & 232.3 & 365.3 & 20.6 \\
\hline MSB-29TA & 107330.4 & 51245.7 & 1333.1 & 365.0 & 63.9 & 212.5 & 365.2 & 5.3 \\
\hline MSB-47B & 106978.5 & 52207.2 & 309.3 & 369.0 & 171.1 & 228.1 & 369.2 & 5.6 \\
\hline MSB-47BB & 106999.7 & 52234.4 & 291.7 & 369.1 & 120.6 & 220.2 & 369.3 & 4.7 \\
\hline MSB-47C & 106969.2 & 52195.5 & 317.6 & 369.3 & 202.3 & 233.4 & 369.5 & 5.6 \\
\hline MSB-47D & 106960.1 & 52184.0 & 326.3 & 369.2 & 246.1 & 234.3 & 369.4 & 20.6 \\
\hline MSB-4TTA & 106987.7 & 52219.0 & 301.3 & 369.0 & 55.2 & 217.2 & 369.2 & 5 \\
\hline MSB-48A & 107936.6 & 54099.8 & 1917.6 & 362.2 & 129.9 & 223.2 & 362.4 & 4.7 \\
\hline MSB-48B & 107945.0 & 54112.2 & 1932.6 & 361.9 & 158.8 & 224.4 & 362.1 & 4.7 \\
\hline MSB-48C & 107917.5 & 54077.0 & 1888.0 & 362.9 & 180.8 & 225.0 & 363.1 & 4.8 \\
\hline MSB-48D & 107914.4 & 54056.3 & 1869.1 & 362.6 & 243.5 & 222.0 & 362.8 & 21.5 \\
\hline MSB-48TA & 107925.8 & 54089.2 & 1902.8 & 361.9 & 107.8 & 223.6 & 362.1 & 5.3 \\
\hline MSB-66B & 105842.0 & 51064.6 & 1771.0 & 383.5 & 144.0 & 219.3 & 383.8 & 4.7 \\
\hline MSB-66C & 105842.1 & 51053.5 & 1780.0 & 383.5 & 171.0 & 228.7 & 383.8 & 4.7 \\
\hline MSB-66D & 105841.8 & 51044.0 & 1787.9 & 383.3 & 249.5 & 267.6 & 383.4 & 30.1 \\
\hline MSB-66TA & 105842.6 & 51096.7 & 1744.7 & 382.8 & 37.5 & 206.5 & 383.1 & 4.7 \\
\hline MSB-67B & 106842.0 & 51989.6 & 511.9 & 362.7 & 134.9 & 201.4 & 365.6 & 4.8 \\
\hline MSB-67C & 106819.8 & 51988.6 & 514.9 & 362.7 & 174.9 & 228.2 & 365.1 & 4.8 \\
\hline MSB-67D & 106830.7 & 51971.5 & 530.8 & 363.1 & 241.0 & 233.6 & 365.6 & 19.5 \\
\hline MSB-68B & 106744.9 & 52308.5 & 234.0 & 356.9 & 133.0 & 219.9 & 357.2 & 4.7 \\
\hline MSB-68C & 106730.5 & 52304.9 & 245.4 & 356.7 & 171.7 & 227.1 & 357.2 & 4.7 \\
\hline MSB-68D & 106741.4 & 52293.6 & 248.3 & 357.0 & 239.9 & 233.8 & 357.5 & 20.5 \\
\hline MSB-69B & 107776.1 & 52432.9 & 899.4 & 381.7 & 144.7 & 221.3 & 381.9 & 4.7 \\
\hline MSB-69C & 107780.1 & 52447.5 & 902.4 & 381.8 & 175.7 & 228.6 & 382.1 & 4.7 \\
\hline MSB-69D & 107784.3 & 52462.0 & 905.9 & 382.2 & 239.9 & 233.5 & 382.4 & 19.5 \\
\hline MSB-69TA & 107772.5 & 52418.4 & 897.0 & 381.5 & 80.4 & 214.9 & 382.1 & 5.7 \\
\hline MSB-82A & 107529.5 & 51978.4 & 833.7 & 374.5 & 126.3 & 227.6 & 374.7 & 4.7 \\
\hline MSB-82B & 107533.4 & 51993.3 & 827.5 & 374.4 & 148.4 & 220.6 & 374.6 & 4.8 \\
\hline MSB-82C & 107521.9 & 51949.4 & 846.4 & 374.0 & 177.9 & 229.4 & 374.3 & 4.8 \\
\hline MSB-82D & 107518.1 & 51934.6 & 853.2 & 373.7 & 237.1 & 233.0 & 374.0 & 20.1 \\
\hline MSB-82TA & 107525.7 & 51964.2 & 839.7 & 373.8 & 94.0 & 214.6 & 374.1 & 5.4 \\
\hline MSB-85B & 107827.0 & 53122.7 & 1134.0 & 380.8 & 137.8 & 222.2 & 381.0 & 4.7 \\
\hline MSB-85C & 107835.2 & 53151.4 & 1156.8 & 381.4 & 174.1 & 225.6 & 381.6 & 4.8 \\
\hline MSB-8SD & 107822.8 & 53108.8 & 1122.9 & 381.4 & 236.8 & 233.5 & 381.6 & 210.1 \\
\hline MSB-85TA & 107831.2 & 53137.2 & 11455 & 381.0 & 88.7 & 221.7 & 381.2 & 5.4 \\
\hline
\end{tabular}




\section{Field Measurement Methodology}

Pumping of RWM-12 commenced at approximately 12:52 p.m. on March 23, 1992. To monitor responses to this pumping, certain well clusters close to the pumping well were instrumented with pressure transducers to obtain water level measurements at relatively closely spaced time increments, such that adequate characterization of any responses could be realized. Other, more distant, well clusters were monitored with electric tapes since hydraulic responses to pumping were expected to be minimal or non-existent; hence, adequate characterization could be realized with occasional tape measurements.

Pressure Transducers

Pressure transducers were dedicated in eleven wells located at three different well clusters. Instrumented wells include: MSB -47B, $-47 \mathrm{BB},-47 \mathrm{C},-47 \mathrm{D},-47 \mathrm{TA},-67 \mathrm{~B}$, $-67 \mathrm{C},-67 \mathrm{D},-68 \mathrm{~B},-68 \mathrm{C}$, and $-68 \mathrm{D}$. Water level measurements were in itiated and recorded in each of these wells prior to the initiation of pumping at RWM-12, but for different periods of time. The MSB-67 cluster wells were monitored from 120 minutes prior to the start of pumping until 4550 minutes after. The MSB -47 cluster wells were monitored from 2803 minutes prior to the start of pumping until 10,178 minutes after. The MSB-68 cluster was monitored from 4550 minutes prior to the start of pumping until 10,146 minutes following startup. Transducer water levels were initialized to electric tape readings acquired for each of the wells prior to the initiation of pumping. Data loggers were programmed to capture measurements on closely spaced time increments immediately following initiation of pumping, and to progressively expand these intervals as time proceeded. Hydrographs of these water level measurements obtained with transducers are presented in Appendix A.

\section{Electric Tape Readings}

Electric tapes were utilized to monitor water levels in wells located farther away from RWM-12 than those monitored with transducers. Wells monitored using this methodology included: ASB-8A, -8B, -8C, -TA; MSB-29A, -29B, -29C, -48A, -48B, $-48 \mathrm{C},-48 \mathrm{TA},-66 \mathrm{~B},-66 \mathrm{C},-60 \mathrm{D},-66 \mathrm{TA},-82 \mathrm{~A},-82 \mathrm{~B},-82 \mathrm{C},-82 \mathrm{TA},-85 \mathrm{~B},-85 \mathrm{C},-85 \mathrm{D}$, and -85TA. Measurements were taken twice each day during the five days following the initiation of pumping, and then twice again on the eighth day. Depths to water were measured by lowering the electrical tapes down the stand pipe located in each well, and measuring the distance from the fluid level to a marked point on the top of the casing. The depth of the fluid level just prior to start of pumping was used as a reference to determine if there was any response to pumping. Technicians from EPD/EMS were utilized to conduct these measurements and record the data. Hydrographs of water levels measured with electric tapes at each of these clusters are presented in Appendix B. 
Water Pumping Rates

The pumping rate of RWM-12 was monitored utilizing an online flow meter at the well head. These rates were monitored periodically by observing the digital output of the flow meter. Rates were quite steady, varying between 54 and 55 gallons per minute during the week that water levels were monitored.

\section{Surveying Control}

Vertical and horizontal control are obtained for each well installed at SRS through the EMS's ongoing program to have wells surveyed. Surveying records are kept in the EMS data library. Vertical control is Third Order surveying accuracy, which is defined as +1.0 .04 times the square of the length of the circuit of the surveying loop. The surveyors report that this minimum criterion is usually surpassed to a significant degree. In the $A$ and $M$ Areas, most of the surveying loops are less than two miles in length, consequently, vertical control is at worst $+1.0 .06 \mathrm{ft}$ and probably in the $+1-$ 0.03-to 0.04-ft range. Determination of horizontal position includes the use of an instrument that emits a source of infrared light and measures the phase shift after the light is reflected from a remote point. Horizontal accuracy is within $+/-1 \mathrm{ft}$ per 10,000 $f t$ distance from a control monument. Distances to the surveying monument utilized for the wells monitored during this test are approximately 6500 feet, thus horizontal accuracy is estimated at $+/-0.65 \mathrm{ft}$.

\section{Analysis Methodology}

\section{Barometric Pressure}

Changes in atmospheric, or barometric, pressure were obtained from measurements made with an atmospheric pressure sensor, and recorded on the data logger. Atmospheric pressure was recorded every 15 minutes in the period prior to the start of pumping up until the time that the shorter intervals were required for measuring hydraulic responses in the wells. Monitoring of atmospheric pressure was conducted from 2803 minutes prior to the start of pumping, until 10,178 minutes after the start of pumping. A plot of atmospheric pressure measurements, in equivalent feet of water, is presented in Figure 9.

Atmospheric pressure fluctuation frequently has a distinct influence upon water level in wells, and is primarily due to the weight of the air column on the fluid column in the well. Atmospheric pressure, in feet of water, is plotted on the same graph with the uncorrected water elevation for monitor well MSB-47TA in Figure 10. The clear inverse relationship can be seen visually. Statistical correlation calculated with the data used to generate these graphs is -0.901 , indicating a strong inverse relationship. The magnitude of influence upon groundwater levels resulting from the usual range of pressure variation can range up to 0.5 feet during the course of an aquifer test. Because of this, subtle hydraulic responses to pumping in overlying or underlying units, or in wells located far away from the pumping well, can be masked by this effect. 
ATMOSPHERIC PRESSURE VARIATION WITH TIME

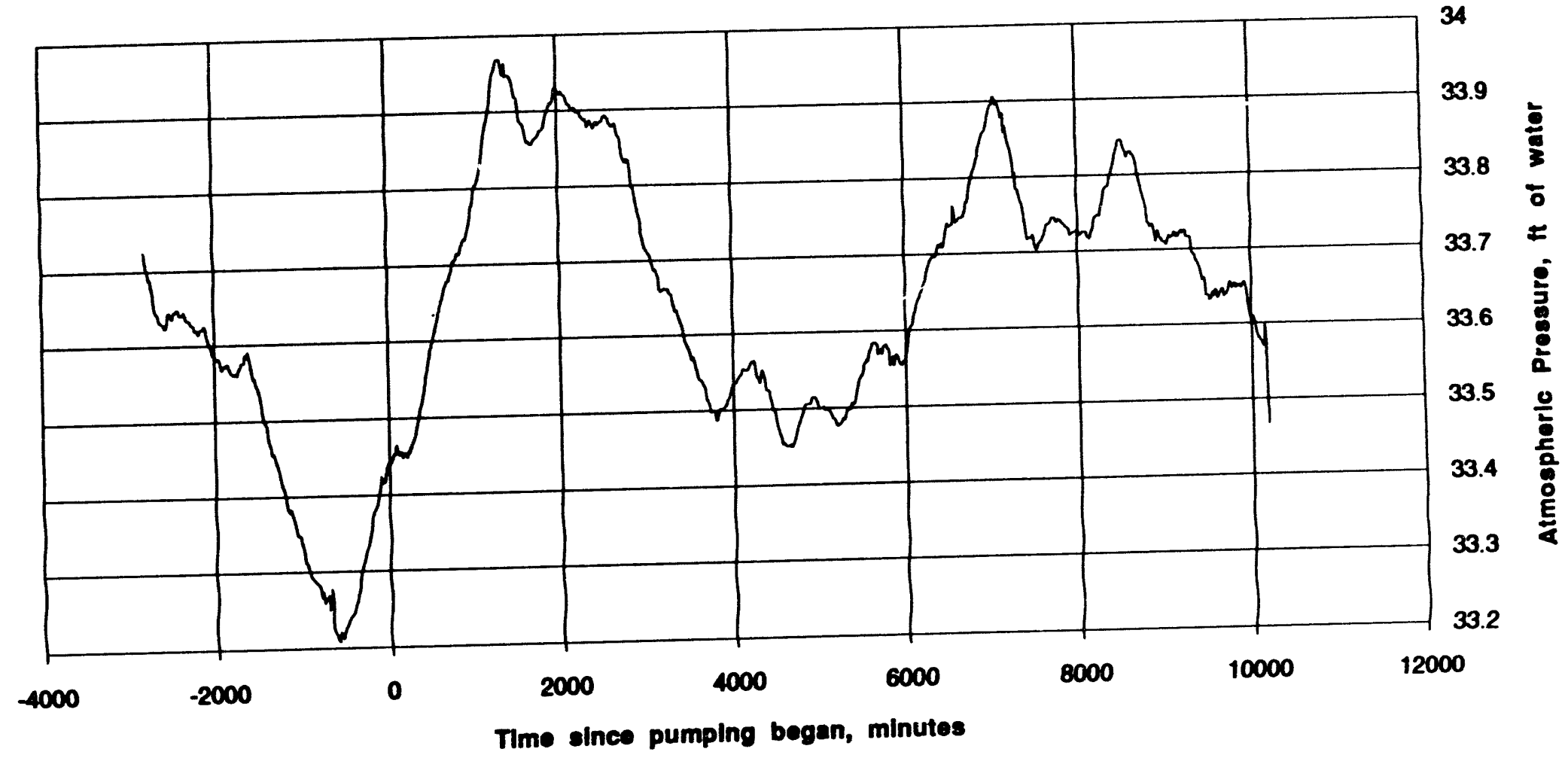

Figure 9. Atmospheric Pressure Variation During Test Period 


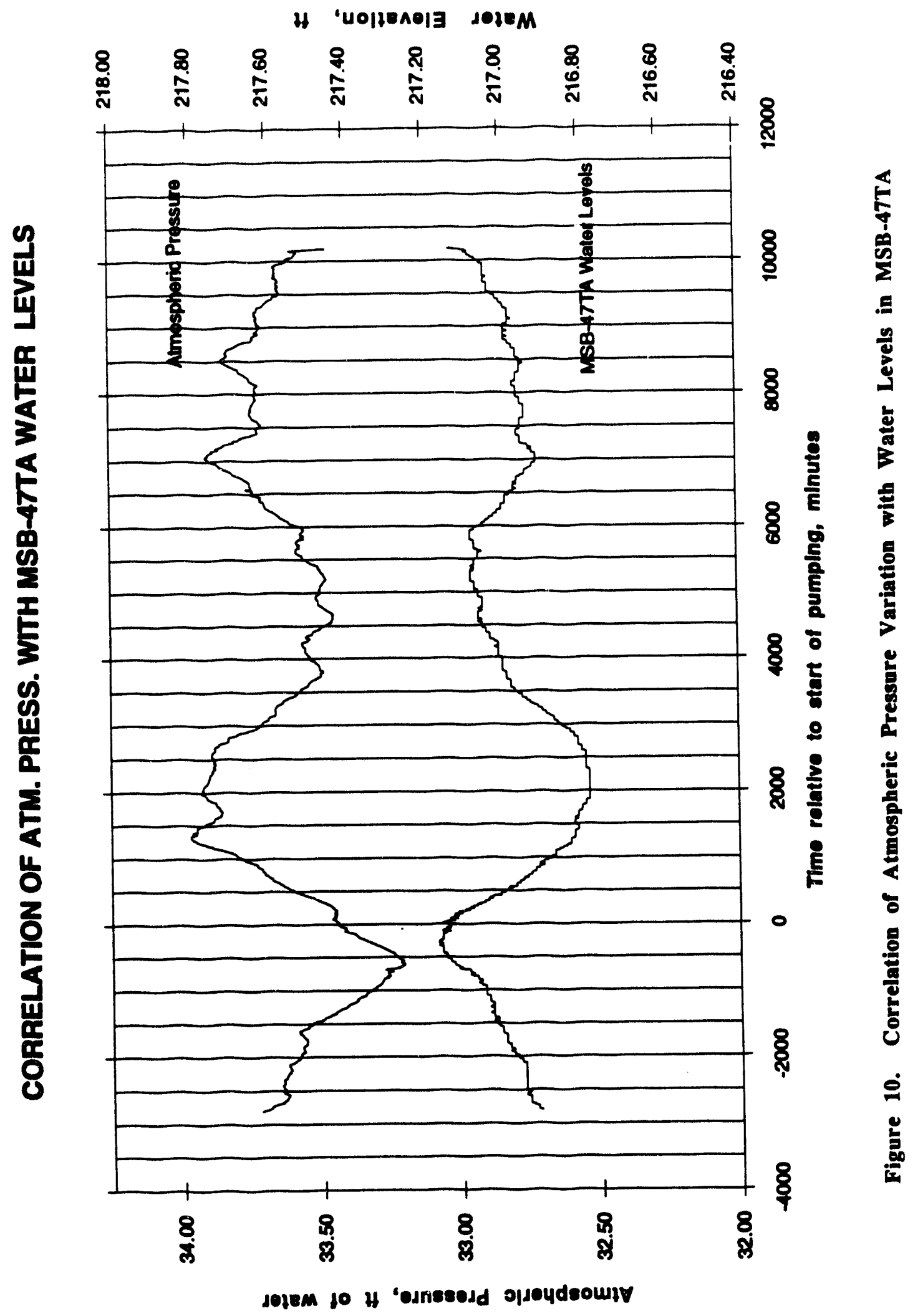


Drawdown curves generated from data that has been corrected for this extraneous effect result in more accurate calculations of bydraulic parameters.

Corrections were made to the raw measurements by using the following equation:

$\Delta w \mathrm{w}=(\mathrm{BE}) \times(\Delta \mathrm{Bp}) / 100$. (Ferris et. al. 1962) $)^{2}$

In this equation:

$\Delta w l=$ the change in water level relative to the reference water level

$\mathrm{BE}=$ the barometric efficiency of the well

$\Delta \mathrm{Bp}=$ the change in barometric pressure relative to the reference pressure

where, $B E=(\Delta w l) \times(100) /(\Delta B p)$

The reference atmospheric pressure was taken to be that pressure at the time pumping started, while the reference water level was the electric tape measurement that was taken just before pumping was initiated. Water level measurements taken prior to and after this instant, $t=0$, were corrected with respect to that reference atmospheric pressure. Determination of Barometric Efficiency (BE) was made for each well that was instrumented with a pressure transducer, but were not made at well clusters monitored solely with electric tapes. Calculations were made on a spreadsheet program having dynamic update interaction with its graphs. Optimum BE values were identified by observing which value produced the straightest line in the antecedent periods, and also the smoothest curve in the drawdown portions of the hydrograph. In the wells monitored with pressure transducers, MSB-47BB, -47B, -47C, -47D, -47TA, $-68 \mathrm{~B},-68 \mathrm{C}-68 \mathrm{D}$, and $-67 \mathrm{C}$, these percentage factors were determined to be $65,67.2$, $93.1,89.3,65,65,80,90,90$, respectively.

\section{Hydraulic Parameters}

The principal parameters that describe an aquifer's capacity to store and transmit water are transmissivity (T) and storativity, or storage coefficient, (S). Leakance $(r / B)$ is another parameter that describes the capacity of a confining unit to transmit water between overlying and underlying aquifer units. Values for each of these parameters were estimated at each of the monitor wells having transducers dedicated in them, and which were finished in the same horizon as that of the lower screen zone in RWM-12. These wells are MSB-47B, MSB-68C, and MSB-67C as shown in Figure 2, and were the only transducer monitored wells that exhibited any appreciable hydraulic response to pumping during the 7 days in which water levels weie monitored. No hydraulic response was observed in MSB-47C, which is finished in the same unit as the upper screen zone in RWM-12.

Determinations of these parameters were made using the drawdown data and two different analytical methodologies, each baving application in slightly different hydrogeologic settings. The Theis $(1935)^{3}$ method describes the method for estimating $T$ and $S$ from drawdown data in a confined setting. In this approach the solution assumes that no leakage from adjacent formations is induced by drawdown in the 
pumped formativin. Another method, Hantush and Jacob (1955) ${ }^{4}$, describes the theoretical approach to determining $T, S, x / B$ in settings where leakage into the pumped formation from adjacent formations is induced. The parameter $r / B$ is defined later in the report, but is proportional to the amount of leakage contributed to the pumped formation from adjacent formations. The greater the magnitude of $r / B$, the greater the proportion of water contributed from adjacent formations.

Basic assumptions common to both methods are:

- the aquifer has an infinite areal extent

- the aquifer is homogenous, isotropic, and of uniform thickness

- the aquifer has a horizontal potentiometric surface

- the aquifer is confined

- the pumping rate is steady

- the pumping well is fully penetrating

- Low to the pumping well is horizontal

- water is released instantaneously from storage with a decline in hydraulic head

- the diameter of the pumping well is very small so that storage volume in the well can be neglected

The following additional assumptions apply to the (Hantush and Jacob, 1955) method:

- the confining bed has an infinite areal extent, uniform vertical hydraulic conductivity, and uniform thickness

- the confining bed is overlain by an infinite constant head plane source

- flow in the confining bed is vertical

While these assumptions can never be completely satisfied in application of the theory to field conditions, this analytical approach still has practical value. If efforts are made to instrument a site to meet as many of the assumptions as possible, and if other assumptions are not grossly deviated from, the approach can still provide valid and useful results. More complete discussion of the referenced methods can be found in many standard textbooks on the subject.

The parameters mentioned above $(T, S$, and B) are defined as follows:

$T=[Q / 4 \pi s] W(u)$ where

$W(u)$ is the "well function of $u$ " and represents an exponential integral, and

$u=\left(r^{2} S\right) /(4 T t)$ where

$r=$ radial distance between the pumping and observation well, $[L]$

$S=$ storage coefficient (dimensionless)

$T=$ transmissivity, $[\mathrm{L}]^{2} /[\mathrm{t}]$

$t=$ time, $[t]$

$s=$ drawdown in the observation well, $[\mathrm{L}]$ and 
$Q=$ pumping rate, in $[L]^{3} /[t]$

$S=4 T\left(U r^{2}\right) u$ (terms are defined above)

$B=\left(\mathrm{Tb}^{\prime} / \mathrm{K}^{\prime}\right)^{1 / 2}$ where

$T=$ transmissivity of the pumped formation

$\mathbf{b}^{\prime}=$ thickness of the leaky layer, and

$\mathrm{K}^{\prime}$ = vertical hydraulic conductivity of the leaky layer

Analysis of drawdown data using the above methods utilizes the approach of matching the theoretical type curve with a time-drawdown curve of field data. The process is automated in this analysis by using the PC program AQTESOLV, version 1.0, developed by Geraghty and Miller, Inc.

As mentioned, drawdown data were initially corrected for barometric pressure fluctuation during the time period of field data collection. These files were then read into AQTESOLV. The program matches the type curves of the analytical solutions with graphs of the drawdown data. Matching can be done manually, by the user, or with an automatic routine that employs a nonlinear least-square algorithm. The latter is a systematic method that usually results in as good a fit as is possible for the theoretical and field curves, and is the method used in this analysis.

AQTESOLV can use any consistent set of length and time units to solve for aquifer and leakance parameters. Field measurements were made in feet for drawdown and gallons per minute for pumping rate. Conversions were made to these measurements in a spreadsheet program to obtain equivalent values for pumping rate in cubic feet per minute.

It should be pointed out that the drawdown data utilized in this analysis were those measurements taken using the data logger and downhole pressure transducers. Although periodic drawdown measurements were taken in the same wells using an electric tape, these were not used to calculate aquifer parameters.

Because the field data are plotted on logarithmic graphs within AQTESOLV, each log cycle bad different numbers of data points. To prevent the program from biasing the curve match toward those parts of the curve having the most closely spaced data points when the nonlinear least-squares minimization algorithm was used, weighting factors were incorporated into the data file for each measurement based upon the number of data points that occurred within each log cycle. Within AQTESOLV, a weighting factor is required for each measurement that is input to the program. Such a mechanism allows for more realistic curve matches when the "least-squares" algorithm is applied to unevenly spaced data points.

For purposes of comparison, an alternative analysis methodology was employed to calculate $\mathbf{T}$ for situations when water level declines in observation wells are no longer changing. This methodology is attributed to Thiem $(1906)^{5}$. The approach is well documented in Lohman (1979)6. In this approach

$T=\left[2.3 Q \log \left(r_{2} / r_{1}\right)\right] / 2 \pi\left(s_{1}-s_{2}\right)$, where: 
$r_{1}$ and $r_{2}$ are the radial distances of two observation wells from the pumping well, [L] and

$s_{1}$ and $s_{2}$ are the drawdowns observed at these two wells [L]

$T$ and $Q$ are as defined previously

Hydraulic conductivity $(K)$ of the formations within which the well screens of RWM-12 were completed was also estimated using an independent metholology. This approach utilized analysis of grain size distribution and was conducted using the method described by Masch and Denny $(1966)^{7}$ and the sieve analyses of core samples obtained from the two zones. The approach takes into account the spread of grain sizes about the median by use of an inclusive standard deviation parameter. Information relevant to this analysis, including the grain size distribution plots, are presented in Appendix $\mathrm{C}$. Using the following equation which relates $\mathrm{K}$ to $\mathrm{T}$, comparisons can be made to estimates of $\mathrm{T}$ that were made using other methods.

$\mathrm{T}_{\text {core sample }}=\mathrm{Kb}$ where:

$\mathrm{K}=$ hydraulic conductivity of the core sample material, and

$b=$ length of the core sample

In this approach, the $\mathrm{T}$ estimates for individual core sections from within each of the upper and the lower aquifer units are summed to give an estimate of the aquifer unit $T$ so that the comparisons can be made with estimates of $\mathrm{T}$ obtained with the previously described hydraulic methods. The following equation is used:

$T_{\text {equifer }}=\sum_{i=1}^{n} K_{j} b_{i}$

where $\mathrm{n}$ is the number of core samples from an individual aquifer unit.

\section{Results}

\section{Water Level Responses to Pumping at RWM-12}

Hydraulic responses to pumping at RWM-12 are illustrated using hydrographs, or charts of water levels measured in a well versus time. True responses to pumping at the monitor wells can be seen after corrections are made for atmospheric pressure variation during the monitoring period. The method previously described in this report was used to accomplish this. Corrections were made for wells monitored both by electric tape as well as those monitored by transducers. Hydrographs for transducer monitored wells contain both the raw and corrected water level graphs, and are found in Appendix A. The darker, smoother line is the corrected hydrograph. Hydrographs for the electric tape monitored wells are found in Appendix B, and each chart contains the hydrographs for all cluster wells that are finished within the same hydrostratigraphic unit. Only corrected water levels are presented on these charts.

Responses to pumping at RWM-12 were observed in three wells monitored with dedicated transducers, MSB-47B, MSB-68C, and MSB-67C. All three of these wells are finished in the lower Lost Lake aquifer zone, the same horizon of the lower screen in RWM-12. All other wells monitored with pressure transducers, including the only monitor well finished in the upper Lost Lake aquifer zone, MSB-47C, did not exhibit 
any hydraulic response during the 10,000 minutes the well was monitored following the initiation of pumping at RWM-12.

All three wells that responded did so in a similar fashion. MSB-47B and $-68 \mathrm{C}$ exhibited drawdown practically instantaneously when pumpirig commenced, while MSB-67C responded within 2 minutes. MSB-47B and -68C experienced maximum drawdown of $2.5 \mathrm{ft}$, while MSB-67C had a maximum drawdown of $2.0 \mathrm{ft}$. All three reached a new equilibrium at approximately 800 minutes following initiation of pumping. These characteristics are apparent on the hydrographs for these wells.

Of the wells monitored with electric tapes, responses were detected only in certain wells finished in the lower Lost Lake aquifer zone at the MSB-69, $-82,-85$, and ASB8 clusters. This is the formation in which the lower screen zone in RWM-12 is finished. No wells finished in other aquifer units exhibited a hydraulic response. Wells monitored with electric tapes are at greater distances from the pumping well; hence, the magnitude of bydraulic response is less than for the wells monitored with pressure transducers. Because of the smaller magnitude of response, atmospheric pressure corrections must be made to determine the amount of water level drawdown attributable to pumping at RWM-12. Drawdown was in the 0.7 to $0.8 \mathrm{ft}$ range for MSB- $69 \mathrm{C},-82 \mathrm{C}$, and ASB-8C, while only $0.2 \mathrm{ft}$. at MSB-85C. At these wells the new equilibrium level was attained in the 1400 to 1600 minute range following the initiation of pumping at RWM-12. The timing of re-equilibration at MSB-82C is masked due to anomalous readings, probably measurement errors, taken on the second day after pumping was initiated. MSB-85C is located several hundred feet farther away from RWM-12 than the other three wells; hence, the smaller magnitude of drawdown is explainable. The described characteristics are apparent on the bydrographs for electric-tape monitored wells, presented in Appendix B.

\section{Analysis of Water Level Response Data}

Hydraulic analysis was conducted using the data from those wells monitored with a pressure transducer for which there was a clear response to pumping at RWM-12. These wells were MSB-47B, MSB-68C, and MSB-67C. All of these are all finished in the lower Lost Lake aquifer zone as is the lower screen of RWM-12. The primary analysis methodology is by the use of the Theis and Hantush approaches described earlier. For purposes of comparison, several other approaches to estimating hydraulic parameters are utilized, but are not regarded as providing estimates that are as representative of the hydrologic setting as is the Theis and Hantush approaches. Of these, the Hantush method is the most appropriate for the hydrogeologic setting near RWM-12.

Response at MSB-47C, which is finished in the upper Lost Lake aquifer zone (same as the upper screen in RWM-12), was conspicuously absent. Since no hydraulic response was seen in this zone, an assumption was made in the analysis that all pumped water was obtained from the lower screen zone, exclusively. Although some pumped water probably originated in the upper Lost Lake aquifer, only a small portion could have come from there without inducing a response at MSB-47C, thus the assumption that all flow originated in the lower Lost Lake aquifer zone is reasonable. 
Data from each of the responding wells was first evaluated using the transient-state solution methodologies described in Theis $(1935)^{3}$ and Hantush and Jacob (1955) ${ }^{4}$ Graphs showing the "fit" of the measured data with the type curves are shown in Appendix D. Manual fitting of field and analytical curves was employed for the Theis (1935) analysis to match the early-time portion of the curve, when leakance from adjacent layers was minimal. Poor fits were obtained for these analyses with the leastsquares algorithm because the later portion of the field data curve deviated from the theoretical curve, as expected, when leakance occurred. Examination of the Theis match curves, found in Appendix D, show good correspondence in the early time, but progressively greater deviation from one another after approximately 100 minutes. For the Hantush and Jacob (1955) analysis the nonlinear least-squares method was employed to match the field data curves with the type curves, since the theory of the methodology is more representative of this hydrogeologic setting; therefore, the response curves more closely corresponded to the analytical solutions, and very good fits could be obtained with the least-squares method.

Values of $T$ estimated using the Theis method were 8.01E-01, 1.16E +00 , and $8.28 \mathrm{E}-01 \mathrm{ft}^{2} / \mathrm{min}$ for MSB $-47 \mathrm{~B},-68 \mathrm{C}$, and $-67 \mathrm{C}$, respectively. Likewise, values of $\mathrm{S}$ estimated with this method were 7.54E-05, 1.67E-04, and 8.67E-05 for MSB-47B, $-68 \mathrm{C}$, and $-67 \mathrm{C}$, respectively. Values of $\mathrm{T}$ estimated using the Hantush method were $7.83 \mathrm{E}-01,1.13 \mathrm{E}+00$, and $6.36 \mathrm{E}-01 \mathrm{ft}^{2} / \mathrm{min}$ for $\mathrm{MSB}-47 \mathrm{~B},-68 \mathrm{C}$, and $-67 \mathrm{C}$, respectively. Likewise, values of $S$ estimated with this method were $7.39 \mathrm{E}-05,1.68 \mathrm{E}$ 04, and 8.02E-05 for MSB-47B, $-68 \mathrm{C}$, and $-67 \mathrm{C}$, respectively. Additionally, leakance $(\mathrm{r} / \mathrm{B})$ values were determined to be 2.19E-01, 1.04E-01, and 4.32E-01 for MSB-47B, $-68 \mathrm{C}$, and $-67 \mathrm{C}$, respectively.

The values of $r / B$ can be used to calculate an "averaged" value for $K^{\prime}$ (vertical hydraulic conductivity) for the low permeability unit separating the two aquifer zones, assuming that all leakage into the lower Lost Lake aquifer zone is induced from the upper Lost Lake aquifer zone. Estimates of $K^{\prime}$ (or $K_{v}$ ) can be calculated at each well by using the formula $B=\left(\mathrm{Tb}^{\prime} / \mathrm{K}^{\prime}\right)^{1 / 2}$, rearranging the terms and substituting the appropriate values for $B, b^{\prime}$, and $T$. This analysis gives values of 1.99E-06, 1.03E-06, and $2.27 \mathrm{E}-06 \mathrm{~cm} / \mathrm{sec}$ at MSB $-47 \mathrm{~B},-68 \mathrm{C}$, and $-67 \mathrm{C}$, respectively, and fall within the range expected for silty clays or clayey silts.

Table 2 presents a summary of the estimates of $T, K, S, r / B$, and $K$ ' obtained using the Theis and Hantush methods for calculation of these parameters at monitor wells MSB47B, $-68 \mathrm{C}$, and $-67 \mathrm{C}$. 
Table 2. Summary of Calculated Hydraulic Parameter Values

\begin{tabular}{|c|c|c|c|c|c|}
\hline & $\begin{array}{c}T \\
\left(\mathbf{f t}^{2} / \min \right)\end{array}$ & $\begin{array}{c}\mathbf{K} \\
(\mathrm{f} / \mathrm{min})\end{array}$ & $\underset{\mathbf{S}}{\mathbf{S}}$ & $\begin{array}{l}\mathbf{r} / \mathbf{B} \\
(*)\end{array}$ & $\begin{array}{c}\mathbf{K}^{\prime} \\
(\mathrm{cm} / \mathrm{sec})\end{array}$ \\
\hline \multicolumn{6}{|l|}{ MSB $47 B$} \\
\hline Theis & 8.01E-01 & $3.91 \mathrm{E}-02$ & $7.54 \mathrm{E}-05$ & & \\
\hline Hantush & $7.83 \mathrm{E}-01$ & $3.82 \mathrm{E}-02$ & $7.39 \mathrm{E}-05$ & $2.19 \mathrm{E}-01$ & $1.99 \mathrm{E}-06$ \\
\hline \multicolumn{5}{|l|}{ MSB-68C } & . \\
\hline Theis & $1.16 \mathrm{E}+00$ & $5.67 \mathrm{E}-02$ & $1.67 \mathrm{E}-04$ & & \\
\hline Hantush & $1.13 E+00$ & $5.50 \mathrm{E}-02$ & $1.68 \mathrm{E}-04$ & $1.04 \mathrm{E}-01$ & $1.03 \mathrm{E}-06$ \\
\hline \multicolumn{6}{|l|}{ MSB $-67 C$} \\
\hline Theis & 8.28E-01 & $4.04 E-02$ & 8.6TE-05 & & \\
\hline Hantush & $6.36 \mathrm{E}-01$ & $3.01 \mathrm{E}-02$ & 8.02E-05 & $4.32 \mathrm{E}-01$ & 2.27E-06 \\
\hline
\end{tabular}

Two alternative methods for estimating $T$ are utilized to obtain values to compare to the estimates obtained from the Theis and Hantush methods. These are the steadystate, or Thiem $(1906)^{5}$ method, and a grain size analysis approach described by Masch and Denny (1966) ${ }^{7}$.

Since pumping water levels at the observation wells reached a new equilibrium within the monitored period, the steady-state methodology described by Thiem (1906) has some applicability. The Thiem model is similar to the Theis model in that it also fails to account for leakage from adjacent layer(s), but cannot be used to obtain an estimate of storage capacity. This method uses water level drawdowns and radial distances from the pumping well for two separate observation wells to estimate values of $T$. The Theis and Hantush methods, by comparison, utilize drawdown responses and radial distance from a single well to obtain estimates of $T$. This difference should be noted when comparing the estimates.

Using the formula $T=\left[2.3 Q \log \left(r_{2} / r_{1}\right)\right] /\left[2 \pi\left(s_{1}-s_{2}\right)\right]$ and substituting in the appropriate values yields the following results:

for MSB-68CMSB-67C:

$T=\left[2.3 \times\left(7.35 \mathrm{ft}^{3} / \mathrm{min}\right) \times \log (514.9 \mathrm{ft} 245.4 \mathrm{ft})\right] /[2 \pi(2.5 \mathrm{ft}-2.0 \mathrm{ft})]$

$=1.73 \mathrm{ft}^{2} / \mathrm{min}$

Similarly for MSB-47B/MSB-67C:

$T=\left[2.3 \times\left(7.35 \mathrm{ft}^{3} / \mathrm{min}\right) \times \log (514.9 \mathrm{fv} / 309.3 \mathrm{ft})\right] /[2 \pi(2.5 \mathrm{ft}-2.0 \mathrm{ft})]$

$=1.19 \mathrm{ft}^{2} / \mathrm{min}$ 
The wells used in this analysis are those close in to the pumping well. The formula can also be applied to a near-in well and a distant well to give an estimate of $T$ that is representative of a much broader area. These estimates are as follows:

for MSB-68C/ASB-8C

$$
\begin{aligned}
T & =\left[2.3 \times\left(7.35 \mathrm{ft}^{3} / \mathrm{min}\right) \times \log (797.8 \mathrm{fv} 245.4 \mathrm{ft})\right] /[2 \pi(2.5 \mathrm{ft}-0.65 \mathrm{ft})] \\
& =0.75 \mathrm{ft}^{2} / \mathrm{min}
\end{aligned}
$$

for MSB-47B/MSB-82C

$$
\begin{aligned}
T & =\left[2.3 \times\left(7.35 \mathrm{ft}^{3} / \mathrm{min}\right) \times \log (846.4 \mathrm{f} / 309.3 \mathrm{ft})\right] /[2 \pi(2.5 \mathrm{ft}-0.8 \mathrm{ft})] \\
& =0.69 \mathrm{ft}^{2} / \mathrm{min}
\end{aligned}
$$

for MSB-47B/MSB-69C

$$
\begin{aligned}
T & =\left[2.3 \times\left(7.35 \mathrm{ft}^{3} / \mathrm{min}\right) \times \log (902.4 \mathrm{f} / 309.3 \mathrm{ft})\right] /[2 \pi(2.5 \mathrm{ft}-0.8 \mathrm{ft})] \\
& =0.74 \mathrm{ft}^{2} / \mathrm{min}
\end{aligned}
$$

The estimates calculated using measurements from closer wells are approximately twice the estimates obtained when using the more distant wells. The higher estimates may reflect a bias related to the inability of the method to account for the effect of vertical leakage.

The grain size method for estimating $\mathrm{K}$ and $\mathrm{T}$ values for aquifer units represents an independent, methodology for determining these parameters on a local scale where core material is available from a borehole. This approach can be utilized when sieve analyses can be conducted on core material, and can provide supplemental knowledge of aquifer properties when field instrumentation is not available to conduct in situ hydraulic estimates. In this investigation it serves to corroborate other estimates of $\mathrm{K}$ and $\mathrm{T}$ and to demonstrate the utility of the approach.

In applying the grain size method a value for $\sigma_{1}$ is calculated using the formula provided by Masch and Denny (1966), where $\sigma_{1}$ is defined as follows:

$\sigma_{1}=\left[\left(d_{16}-d_{84}\right) / 4\right]+\left[\left(d_{5}-d_{95}\right) / 6.6\right]$

In this equation, the " $d_{x}$ " notation represents the grain-size diameter at which $x \%$, by weight, of the sample particles are finer and 100-x\% are coarser. Masch and Denny (1966) use Phi $(\varphi)$ units, where $\varphi=-\log _{2} d$, and where $d$ is the grain size diameter in mm.

The $\sigma_{1}$ value is then utilized, along with the $d_{50}$ value (in Phi units) and the empirically derived charts in Appendix $\mathrm{C}$ to pick a $\mathrm{K}$ value for the sample. Table 3 presents a summary of the information that is utilized in the calculation of $K$ and $T$ values using the charts provided by Masch and Denny (1966) ${ }^{7}$. These graphs and grain size distributions charts for each core sample from RWM-12 are presented in Appendix $C$. Values of $K$ were converted to values of $T$ by multiplying $K$ by the thickness of the core sample. Summation of $T$ values for the lower Lost Lake aquifer 
zone provides an estimate that can be compared to previously calculated hydraulic estimates. Estimates of $\mathrm{T}$ for the lower screen zone was $9.44 \mathrm{E}-01 \mathrm{ft}^{2} / \mathrm{min}$ and is similar to the Theis estimates from MSB-47B, $-67 \mathrm{C}$, and $-68 \mathrm{C}$, of $8.01 \mathrm{E}-01,8.28 \mathrm{E}-01$, and $1.16 \mathrm{E}+00 \mathrm{ft}^{2} / \mathrm{min}$, respectively.

Table 3. Grain Size Information Summary

\begin{tabular}{|c|c|c|c|c|c|c|c|c|c|c|}
\hline \multirow{2}{*}{$\begin{array}{l}\text { Depth } \\
\text { from }\end{array}$} & \multirow{2}{*}{$\begin{array}{c}\text { Depth } \\
\text { to }\end{array}$} & \multicolumn{6}{|c|}{ Phi $(\varphi)$ Unit Size - \% finer than } & \multirow{2}{*}{$\begin{array}{c}K \\
\mathrm{~cm} / \mathrm{sec}\end{array}$} & \multirow{2}{*}{$\begin{array}{c}\mathrm{K} \\
u_{\min }\end{array}$} & \multirow{2}{*}{$\begin{array}{c}\mathbf{T} \\
\mathbf{n}^{2 / \min }\end{array}$} \\
\hline & & ds & $d_{16}$ & $d_{50}$ & d $_{84}$ & d95 & $\boldsymbol{\Omega}_{1}$ & & & \\
\hline 148.0 & 151.6 & 3.35 & 2.44 & 1.50 & 0.69 & 0.08 & 0.93 & $1.08 \mathrm{E}-02$ & $2.13 E-02$ & $7.68 \mathrm{E}-02$ \\
\hline 151.6 & 158.0 & 3.35 & 2.89 & 2.35 & 1.72 & 1.12 & 0.63 & $9.50 \mathrm{E}-03$ & $1.87 \mathrm{E}-02$ & $1.20 \mathrm{E}-01$ \\
\hline 158.0 & 163.0 & 3.50 & 1.97 & 2.47 & 2.05 & 1.66 & 0.25 & 1.47E-02 & $2.89 \mathrm{E}-02$ & $1.44 \mathrm{E}-01$ \\
\hline 163.0 & 168.0 & 3.44 & 2.95 & 2.46 & 1.89 & 1.26 & 0.60 & 8.83E-03 & $1.74 \mathrm{E}-02$ & $\frac{8.69 \mathrm{E}-02}{4.28 \mathrm{E}-01}$ \\
\hline 181.0 & 184.5 & 2.50 & 1.72 & 1.11 & 0.57 & 0.15 & 0.64 & $1.82 \mathrm{E}-02$ & $3.58 \mathrm{E}-02$ & $1.25 \mathrm{E}-01$ \\
\hline 184.5 & 188.0 & 3.60 & 2.43 & 1.69 & 1.05 & 0.62 & 0.80 & $1.35 \mathrm{E}-02$ & $2.66 \mathrm{E}-02$ & $9.30 \mathrm{E}-02$ \\
\hline 188.0 & 193.0 & 3.00 & 1.97 & 1.27 & 0.59 & 0.16 & 0.78 & $1.70 \mathrm{E}-02$ & 3.35E-02 & $1.67 \mathrm{E}-01$ \\
\hline 193.0 & 194.0 & 3.40 & 2.68 & 1.85 & 1.02 & 0.40 & 0.87 & $1.08 \mathrm{E}-02$ & 2.13E-02 & $2.13 E-02$ \\
\hline 194.0 & 197.0 & 2.97 & 2.49 & 1.84 & 1.05 & 0.53 & 0.73 & $1.50 \mathrm{E}-02$ & 2.95E-02 & $8.86 \mathrm{E}-02$ \\
\hline 197.0 & 201.0 & 3.00 & 2.49 & 2.03 & 1.36 & 0.75 & 0.62 & $1.32 \mathrm{E}-02$ & $2.59 \mathrm{E}-02$ & $1.04 \mathrm{E}-01$ \\
\hline 203.0 & 205.8 & 2.70 & 1.98 & 1.33 & 0.70 & 0.28 & 0.69 & 1.77E-02 & $3.48 \mathrm{E}-02$ & $9.74 \mathrm{E}-02$ \\
\hline 206.8 & 210.0 & 3.30 & 2.04 & 1.20 & 0.39 & 0.00 & 0.91 & $1.83 \mathrm{E}-02$ & $3.61 \mathrm{E}-02$ & $1.15 \mathrm{E}-01$ \\
\hline 211.0 & 216.0 & 2.98 & 2.54 & 1.68 & 0.83 & 0.33 & 0.83 & $1.35 \mathrm{E}-02$ & $2.66 \mathrm{E}-02$ & $\begin{array}{r}1.33 \mathrm{E}-01 \\
9.44 \mathrm{E}-01\end{array}$ \\
\hline
\end{tabular}

The depths from $148 \mathrm{ft}$ to $168 \mathrm{ft}$ (top 4 lines in Table 3) correspond to the upper Lost Lake aquifer zone, while depths from $181 \mathrm{ft}$ to $216 \mathrm{ft}$ (lower 8 lines in Table 3) correspond to the lower Lost Lake aquifer zone. Estimates of $T$ for each of the aquifer zones are comprised of individual $\mathrm{T}$ estimates from the core samples from that zone. In Table 3, the $\mathrm{T}$ estimates for each core sample are summed for each aquifer zone in the right hand column.

The estimates of $T$ for the lower Lost Lake aquifer zone using grain size analyses for samples from RWM-12 are representative of that location. Comparisons of these local scale estimates with the estimates representative of the observation well locations, and valid on a scale of hundreds of feet, should be similar but not identical. Differences can be attributed not only to the independent methodology, but also to possible lateral variation in aquifer properties. Considering these differences, the grain-size methodology estimates are remarkably similar to the Theis and Hantush methodology estimates. 


\section{Summary and Discussion}

Wells in the vicinity of RWM-12 were monitored at the time that it was brought online for groundwater remediation. Close-in wells were monitored with pressure transducers at relatively short intervals, while more distant wells were monitored with electric tapes at more infrequent intervals. All water level measurements were standardized to the baseline atmospheric pressure by correcting for variations in atmospheric pressure during the time that monitoring took place.

Of the close-in wells, only those finished in the aquifer unit of the lower screen zone in RWM-12 exhibited hydraulic responses. Of the wells monitored with electric tapes, only four exhibited slight responses. All were finished in the formation adjacent to the lower screen zone, the lower Lost Lake aquifer. All responses occurred relatively soon after pumping was initiated, even at the more distant wells. No responses were observed in wells finished in a subsurface zone other than the zone adjacent to the lower screen of RWM-12, even at the closest wells. This response pattern suggests that there is poor hydraulic connection between vertically separated zones, at least in the vicinity of RWM-12.

Estimates of transmissivity (T) and storativity (S) were obtained using several hydraulic methodologies and one method related to grain size distribution. One approach also provided a leakance factor $(r / B)$ that was later used to estimate vertical hydraulic conductivity $\left(\mathrm{K}^{\prime}\right)$ in the confining zone.

Estimates of $T$ for the lower Lost Lake aquifer zone ranged from a high of $1.73 \mathrm{ft}^{2} / \mathrm{min}$ using the Thiem method to a low of $6.36 \mathrm{E}-01 \mathrm{ft}^{2} / \mathrm{min}$ from use of the Hantush method at MSB-67C. The most reliable method of estimating $T$, of those used in this study, is thought to be the Hantush method because this analytical model is the most representative of field conditions at RWM-12. However, reasonable estimates were also obtained from the other methods. At the three wells for which Hantush analyses were conducted, estimates of $\mathrm{K}^{\prime}$ varied from $2.27 \mathrm{E}-06$ to $1.03 \mathrm{E}-06 \mathrm{~cm} / \mathrm{sec}$.

Estimates of $\mathrm{K}$ from the Hantush method at MSB-67C and -68C, 1.6E-02 and 2.8E-02 $\mathrm{cm} / \mathrm{sec}$, respectively, are similar but slightly higher than values of $\mathrm{K}$ calculated from slug tests conducted at these same wells at the time of their installation. The slug tests at MSB-67C and $-68 \mathrm{C}$ yielded estimates of $\mathrm{K}$ of $6.5 \mathrm{E}-03$ and $2.74 \mathrm{E}-02 \mathrm{~cm} / \mathrm{sec}$, respectively; hence, the Hantush estimates are higher by factors of 4.8 and 2.0. Slug tests estimates are valid for scales much smaller than the scales of aquifer tests, and are representative of the material immediately surrounding the well screen.

The range of estimates for hydraulic parameters from the different methodologies may serve as a useful guide in numerical model calibration for any later models that are developed to simulate groundwater flow in the vicinity of RWM-12. In the development of such models, hydraulic conductivity values are normally adjusted to obtain the best possible fit of simulated and measured hydraulic heads. Whether adjustments are made manually or through automatic estimation in an inverse model, the range of these field estimates can serve to define reasonable limits for parameter adjustments. Use of the grain-size method to estimate $\mathrm{T}$ or $\mathrm{K}$ of aquifer units can 
provide indirect information on hydraulic conductivity of aquifers when instrumentation to conduct in situ hydraulic testing cannot be installed or is cost prohibitive.

An interesting observation of the pattern of hydraulic responses to pumping at RWM-12 can be made. All observed responses occurred only in the lower Lost Lake aquifer zone, even at the close-in wells where the magnitude of hydraulic perturbation was greatest. This reflects the competency of the low permeability units in the vicinity of RWM-12, and possibly of their lateral extent in the direction of the more distant well clusters that exhibited slight responses exclusively in their " $\mathrm{C}$ " wells, which are finished in the lower Lost Lake aquifer zone.

The most surprising development during field testing was the lack of a hydraulic response to pumping of RWM-12 at MSB-47C. The lack of response is probably attributable to either naturally occurring heterogeneity within the upper Lost Lake aquifer or to a decrease in hydraulic conductivity $(K)$ in the aquifer material immediately surrounding the wellbore at RWM-12. Such a reduction in $K$ could occur during the well installation process if a clay-based drilling fluid is used, invasion of the formation material by the clay rich fluid occurs, and complete removal of this clay material from the formation material is not achieved during the well development process.

Electric logs from both RWM-12 and the MSB-47 cluster wells indicate higher electrical resistance in the upper Lost Lake aquifer zone, especially the 64-inch long normal log that provides a "deeper" look into the formation. High electrical resistance in borehole logs is usually reflective of clay-free, sandy formations when the hydrogeologic settings are near-surface and the water is relatively low in TDS, as is the case at RWM-12. The possibility of $\mathrm{K}$ reduction due to well installation processes appears to be a plausible explanation because a bentonite clay was used as the drilling fluid when RWM-12 was installed. A positive bydraulic head has to be maintained during the well installation process; hence, the drilling fluid can invade the aquifer material while a borehole is being drilled. The upper Lost Lake aquifer unit was exposed to this positive hydraulic head longer than the lower Lost Lake aquifer unit during the installation of RWM-12, and probably suffered a greater degree of invasion of the clay rich fluid.

Records of the development of RWM-12 following installation indicate that bailing, swabbing and pumping, and jetting of the screen zones with a dispersing agent all were employed. These records also indicate that sand content of the pumped water, and its turbidity, decreased during well development activities, but that the water remained "slightly cloudy" even after jetting with the dispersing agent. This suggests that some of the bentonite drilling fluid might not have been removed from the screened formations.

If the lower Lost Lake aquifer suffered a lesser degree of drilling fluid invasion during drilling it seems likely that it would be removed more rapidly during the development process than in the overlying aquifer zone. If this was the case at RWM-12, the first zone to develop would act to absorb any of the hydraulic impulses generated by the swabbing activity, and thus minimize any impact upon the other zone. In this fashion, 
the development of the lower Lost Lake aquifer probably "short-circuited" development in the upper Lost Lake aquifer.

It is not definitively known that the lack of hydraulic response at MSB $-47 \mathrm{C}$ is due to formation "damage" at RWM-12 during the well installation process; but, if that is the case, incomplete well development appears to be the most likely cause. The possibility that the upper Lost Lake aquifer does not contribute to the water pumped at RWM-12 is of critical concern because VOC analyses of core material taken from the original borehole indicated that the highest TCE concentrations at RWM-12 are in the upper Lost Lake aquifer zone. Also, analyses of pumped water samples taken at different times during periods of operation indicate that TCE concentrations are decreasing through time, further reducing the efficiency with which this well is extracting TCE from the subsurface. Additional development of this well, and the upper screen zone in particular, could significantly enhance this efficiency.

\section{References}

1. Lewis, S. E., and Aadland, R. K., 1992, "Hydrogeologic Setting of A/M Area: Framework for Groundwater Transport", WSRC-TR-92-355, Westinghouse Savannah River Co., Aiken, SC 29808.

2. Ferris, J.G., Knowles, D. B., Brown, R. H., and StalIman, R.W.,1962, "Theory of Aquifer Tests", U.S.G.S. Water Supply Paper 1 536-E.

3. Theis, C. V., 1935, "The Relation Between the Lowering of the Piezometric Surface and the Rate Duration of Discharge of a Well Using Ground-Water Storage", American Geophysical Union Transcript, Vol 16, pp 519524.

4. Hantush, M.S., and Jacob, C.E., 1955, "Non-Steady Radial Flow in an Infinite Leaky Aquifer", Transactions of the American Geophysical Union, Vol 36, pp 95-100.

5. Thiem, Gunther, 1906, "Hydrologische Methoden": Leipzig, J. M. Gebbhart, 56 p.

6. Lohman, S.W., 1979, "Ground-water Hydraulics": U.S. Geological Survey Professional Paper 708, 70 p.

7. Masch, F.D., and K.L. Denny, 1966, "Grain Size Distribution and its Effect on the Permeability of Unconsolidated Sands", Water Resources Research 2(4), pp. 665-677. 
This page intentionally left blank. 
Appendix A. Well Hydrographs (Transducer Wells) 
This page intentionally left blank. 


\section{HYDROGRAPHS FOR MSB-47B}

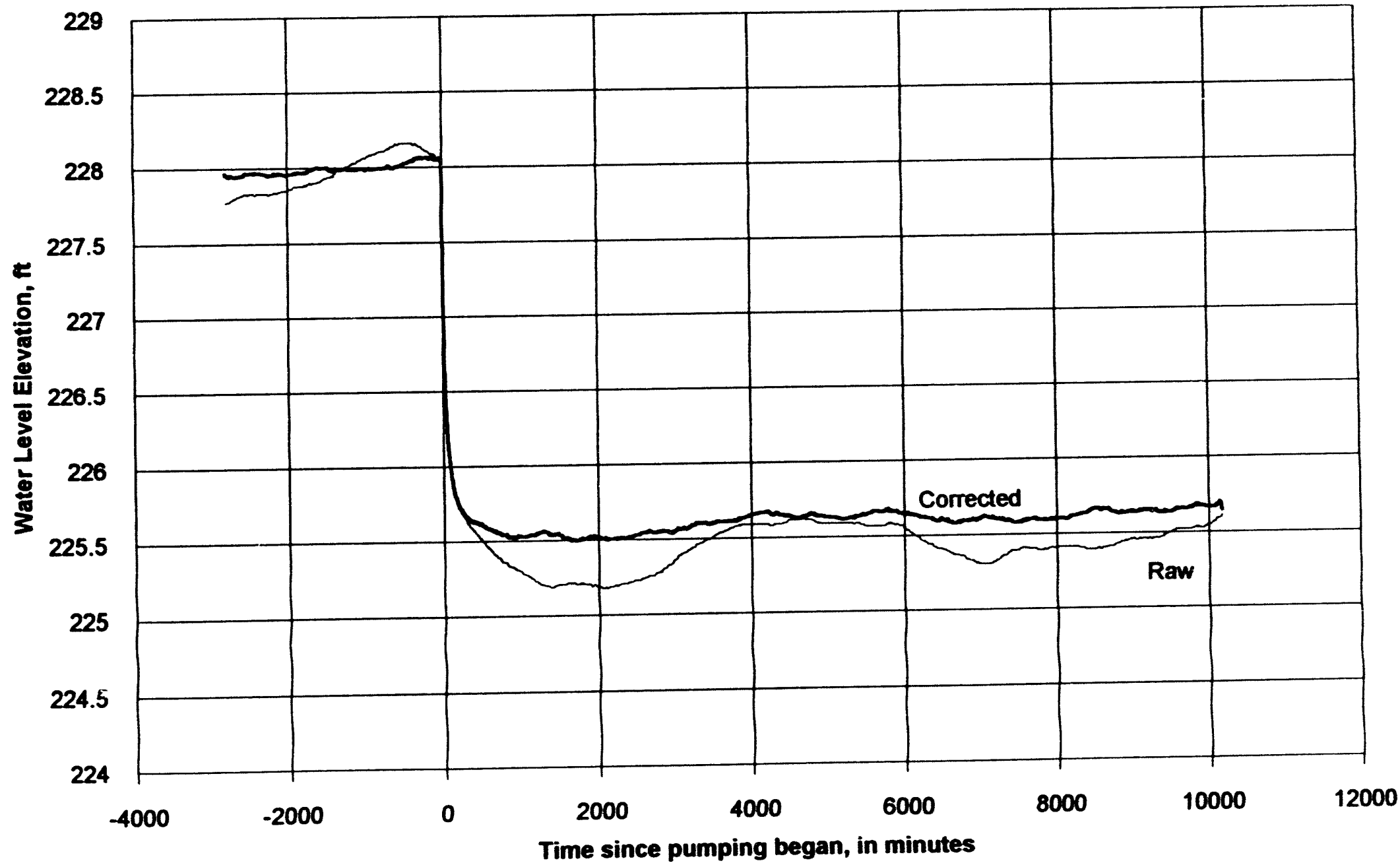


HYDROGRAPHS FOR MSB-67C

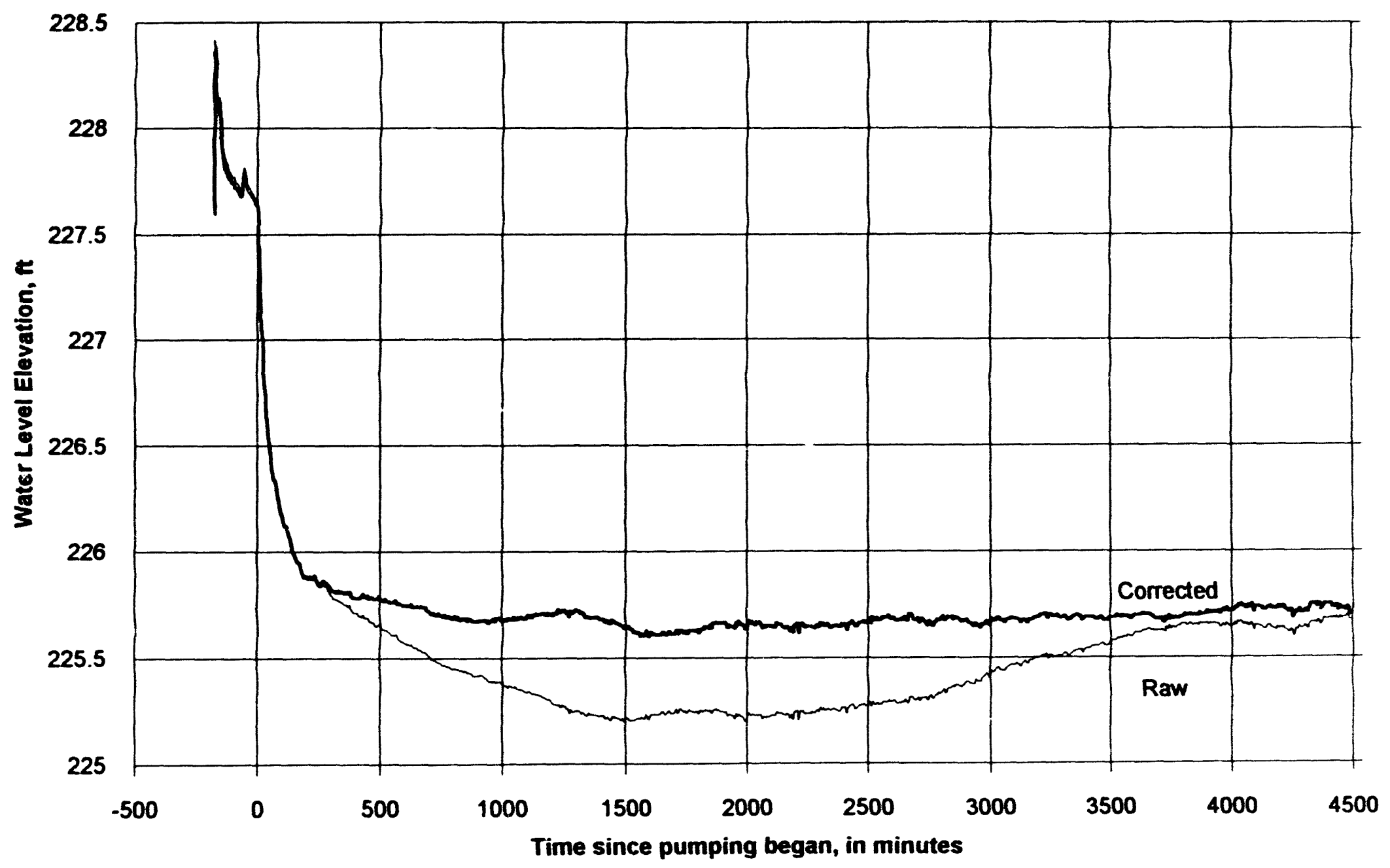




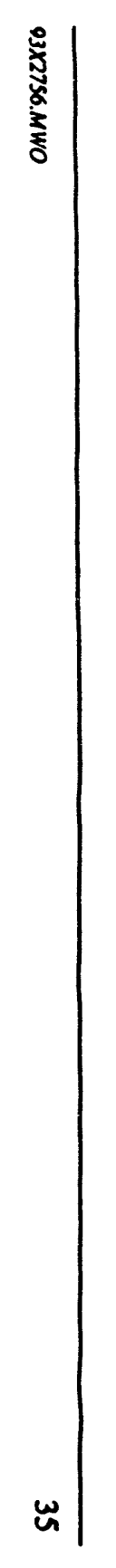

HYDROGRAPHS FOR MSB-68C

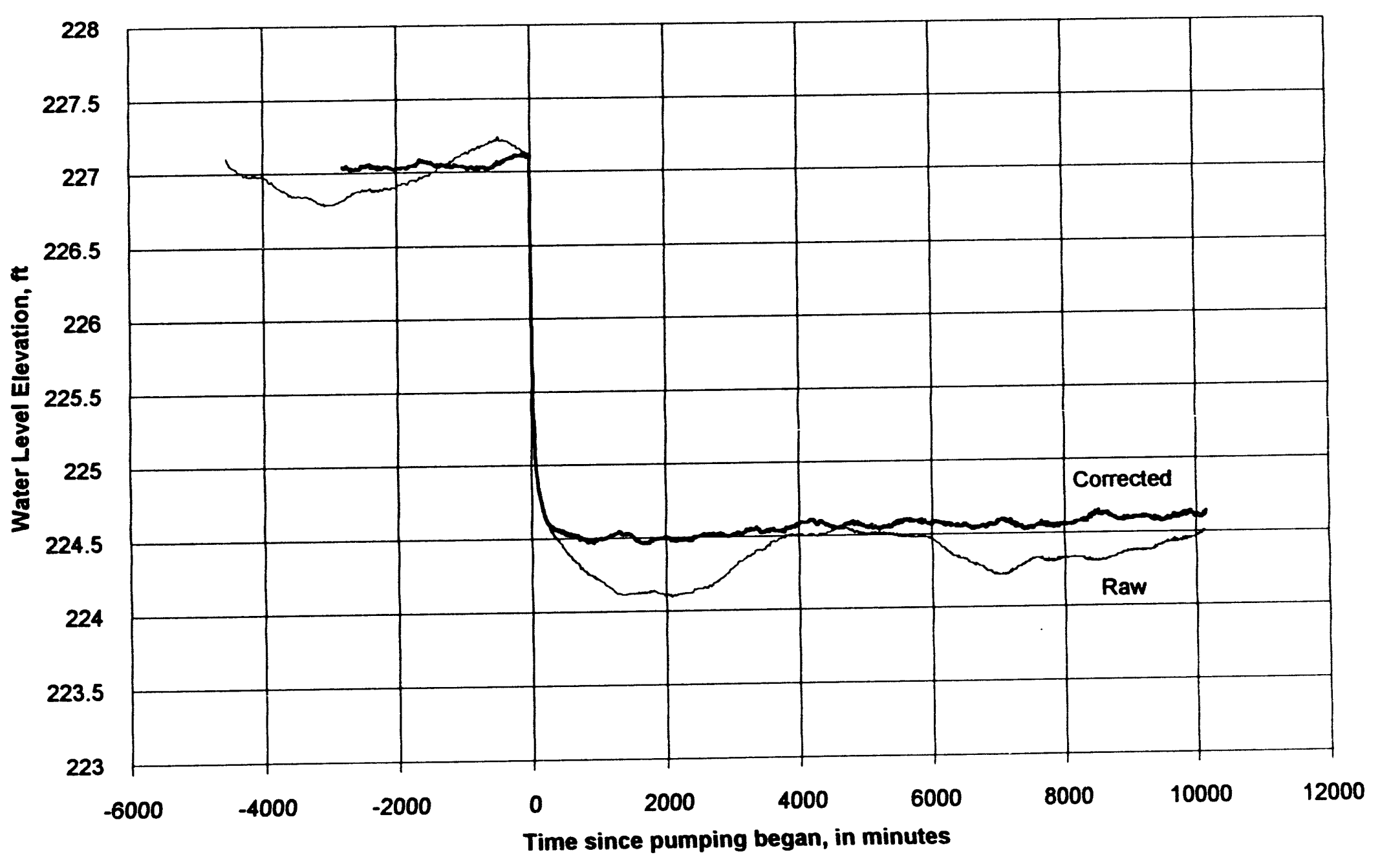


HYDROGRAPHS FOR MSB-47C

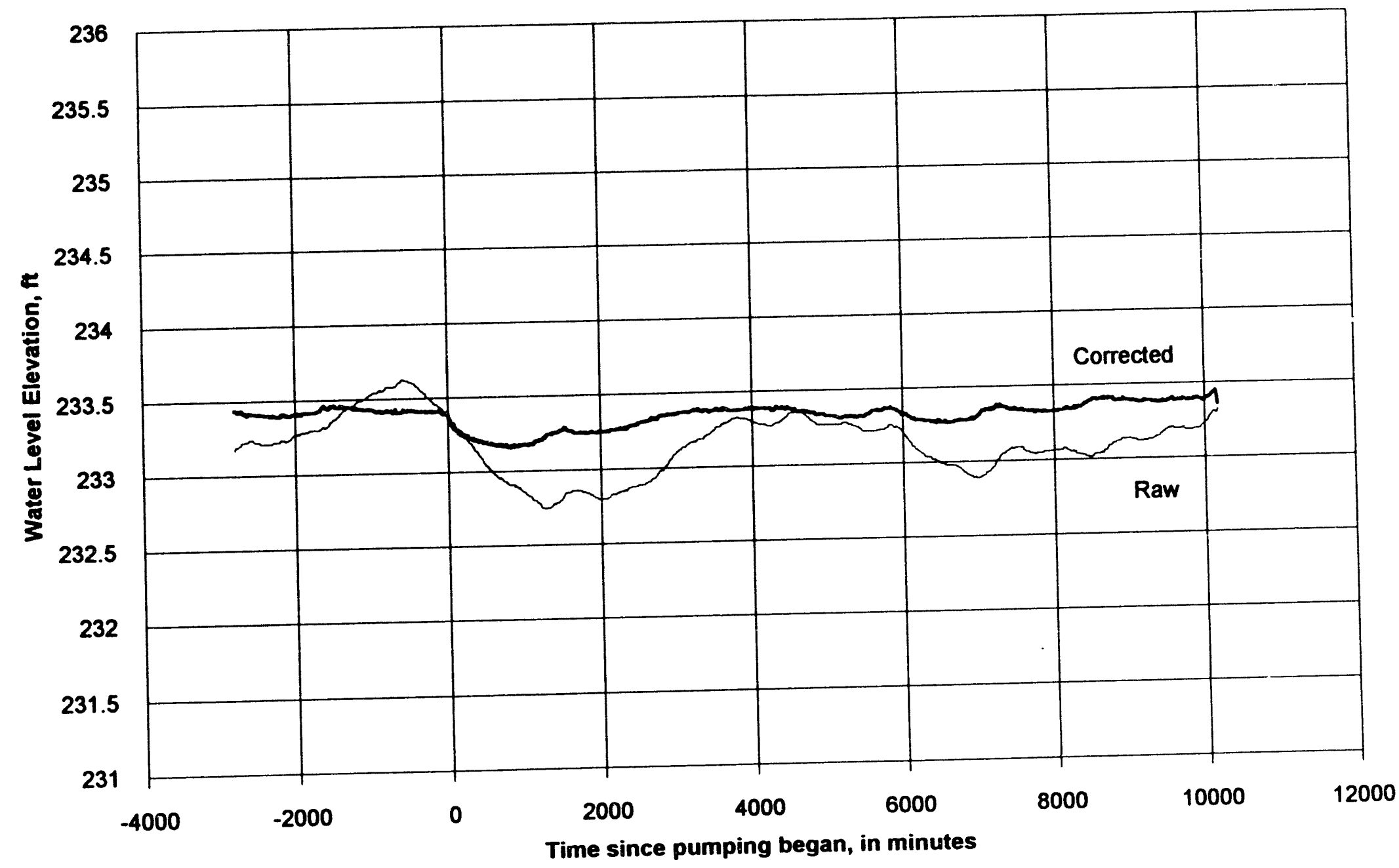


Appendix B. Well Hydrographs (Electric Tape Wells) 
This page intenionally left blank. 


\section{ELECTRIC TAPE HYDROGRAPHS FROM "C" WELLS}

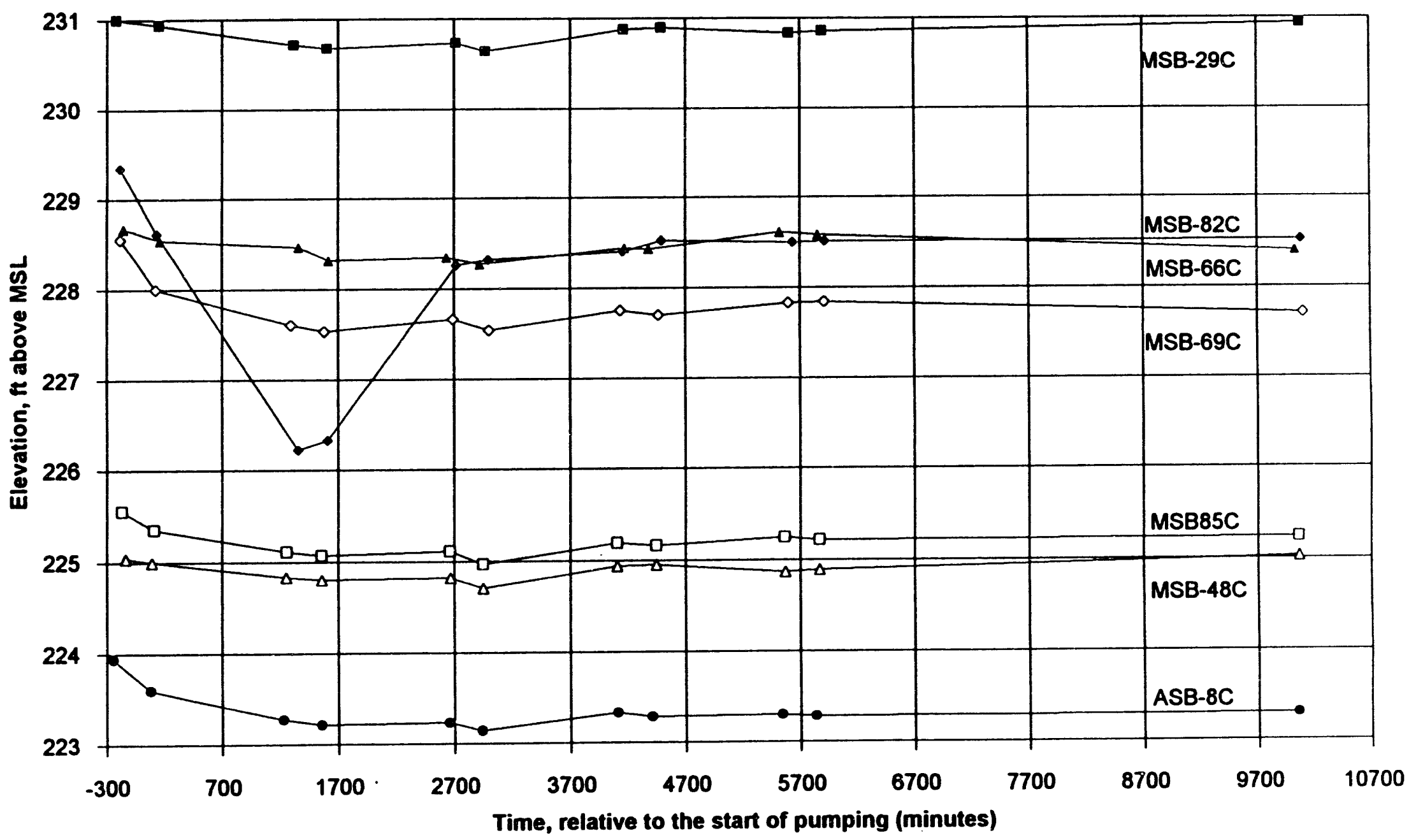




\section{ELECTRIC TAPE HYDROGRAPHS FROM "D" WELLS}

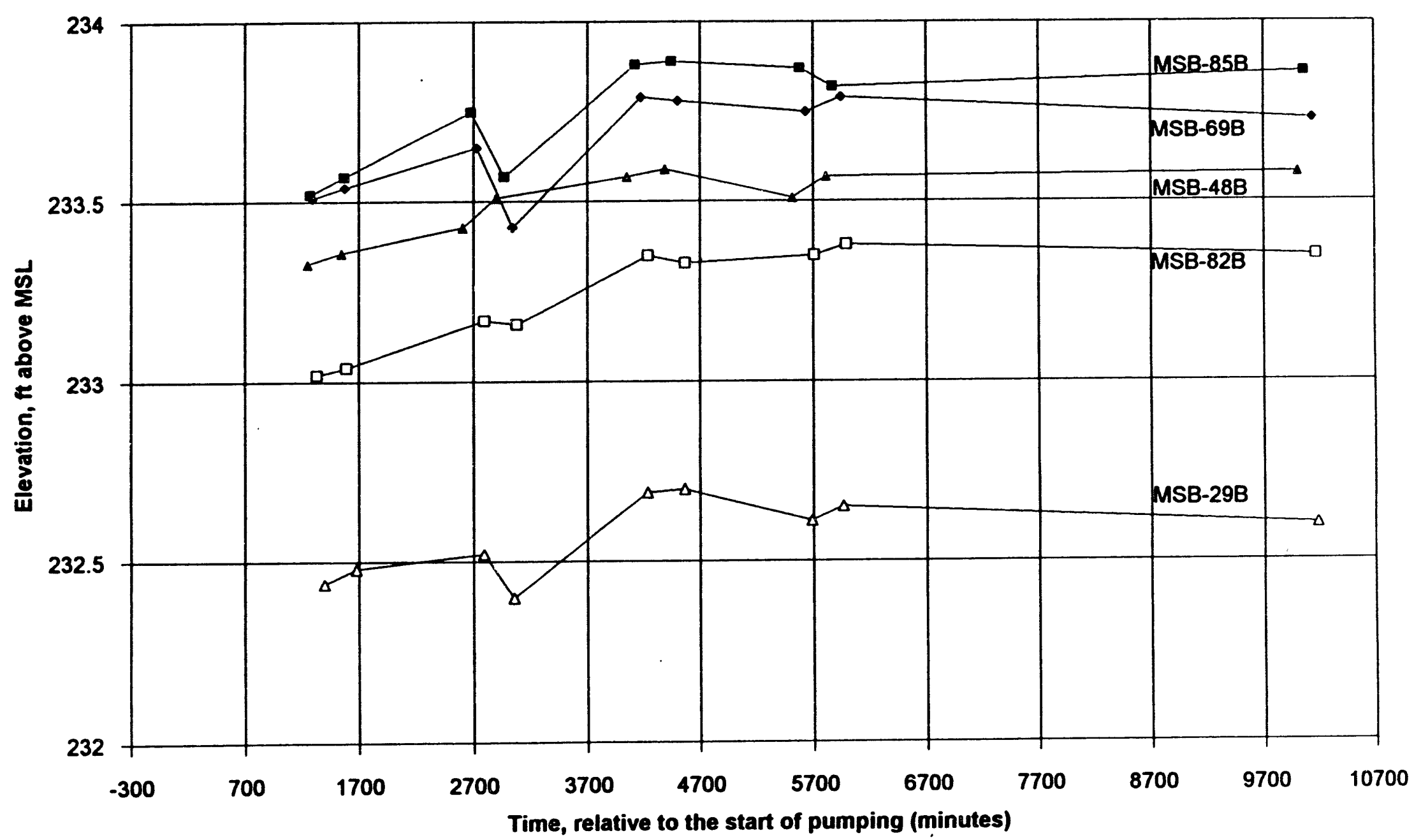




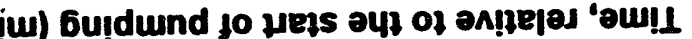

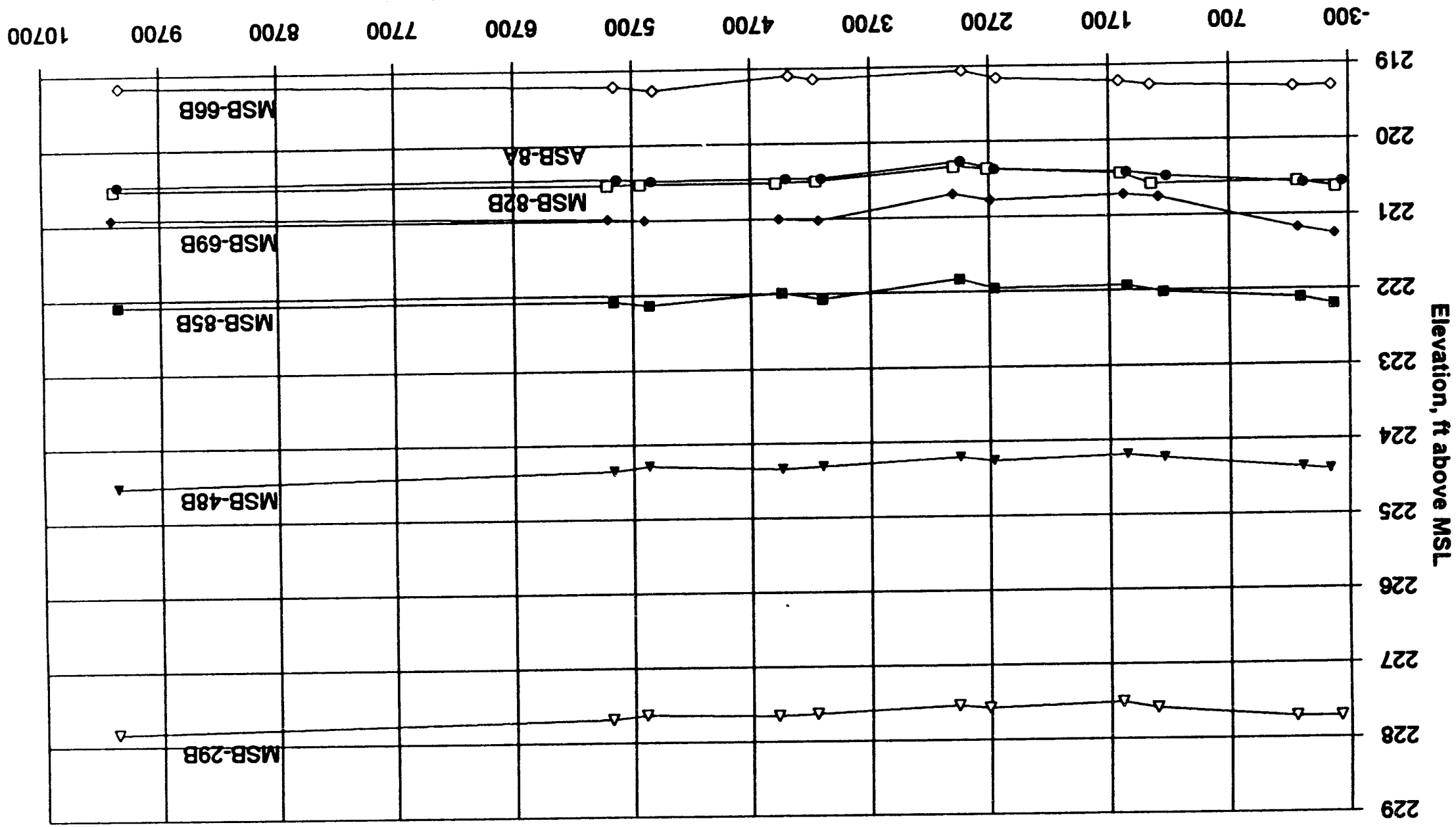

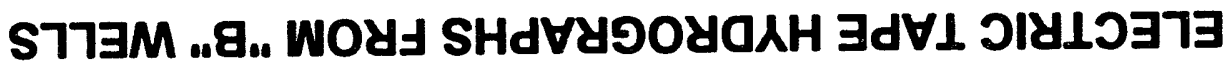


ELECTRIC TAPE HYDROGRAPHS FROM "A" WELLS

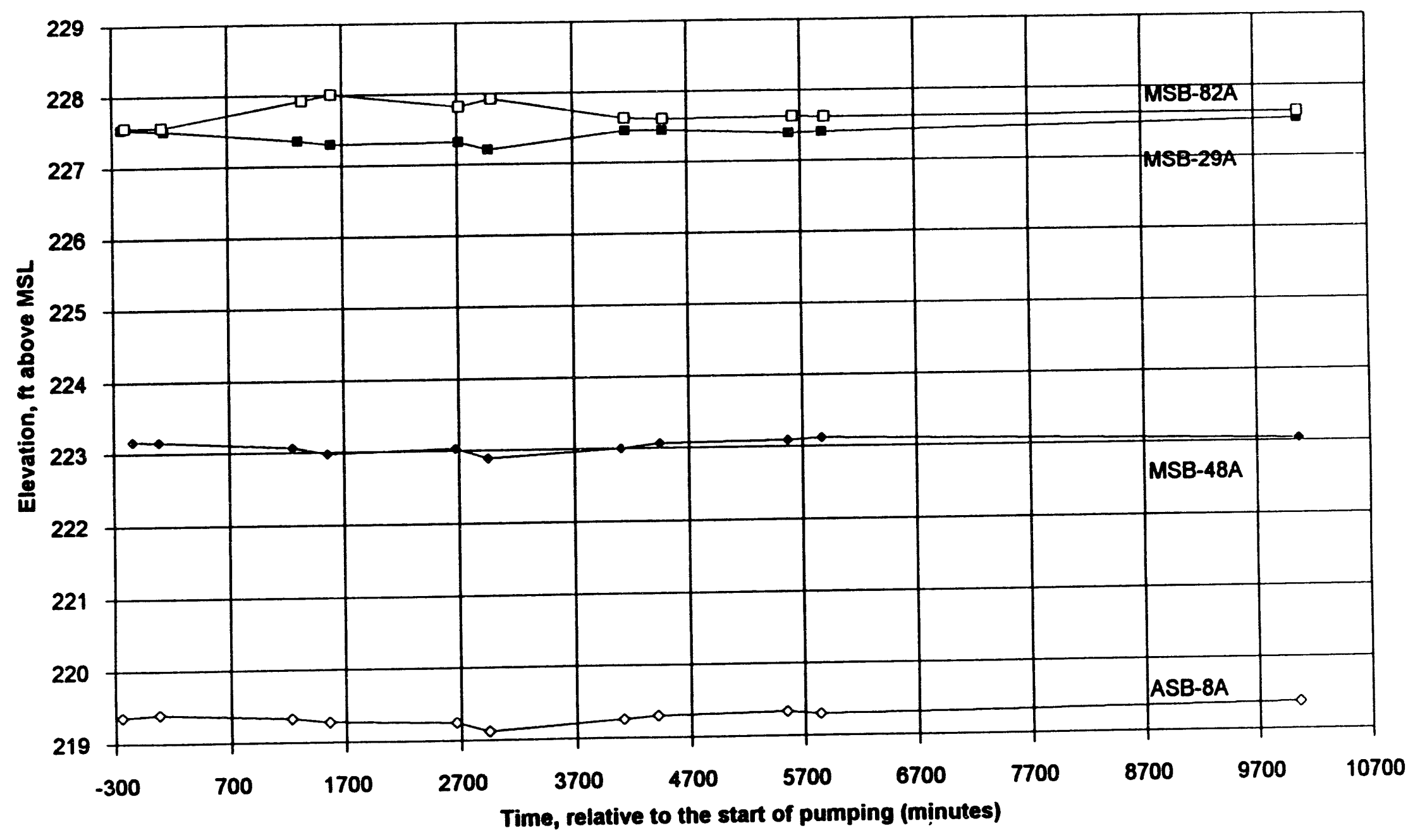




\section{ELECTRIC TAPE HYDROGRAPHS FROM "TA" WELLS}

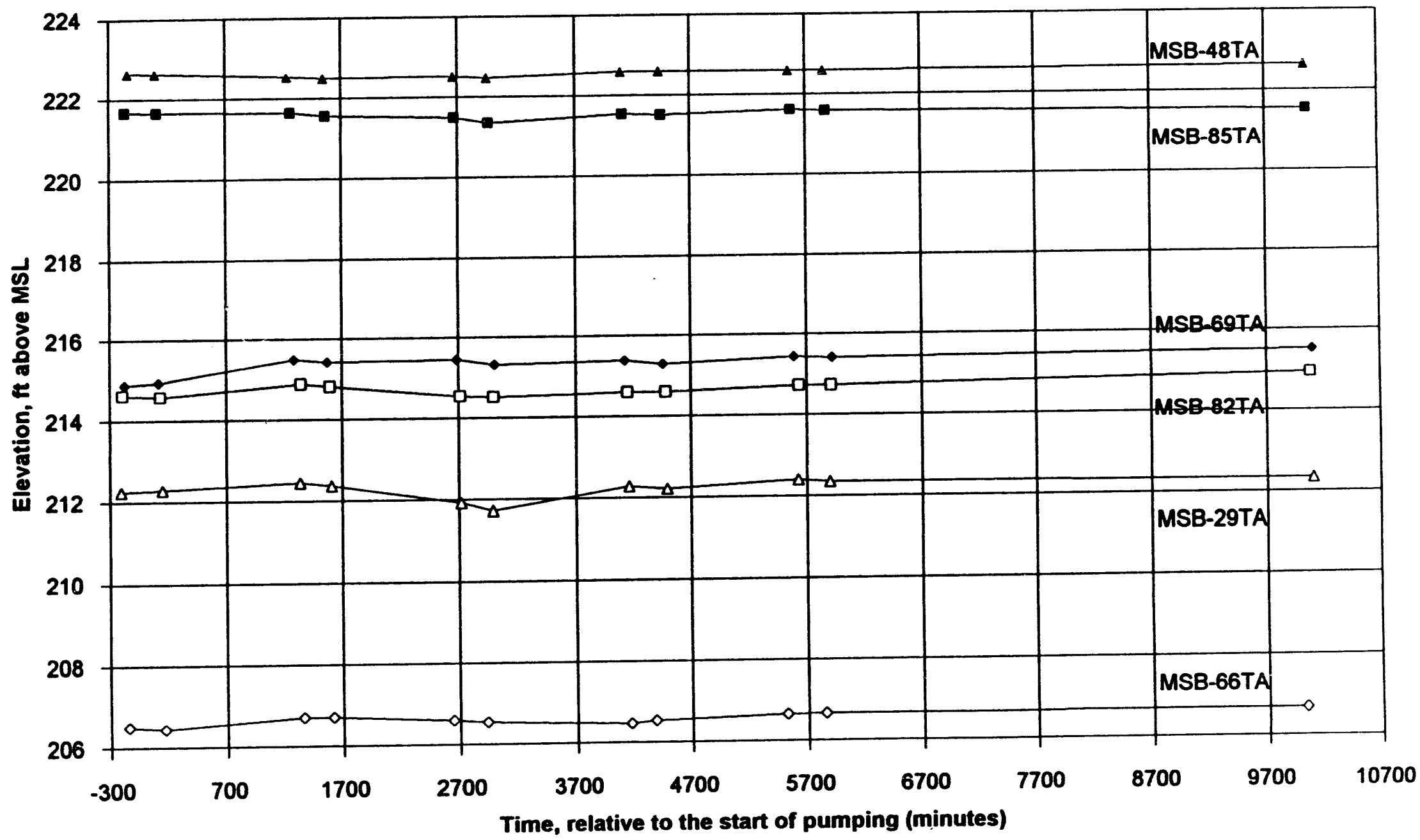


This page intentionally left blank. 
Appendix C. Grain Size Analysis Data 
This page intentionally left blank. 
from Masch and Denny, 1966

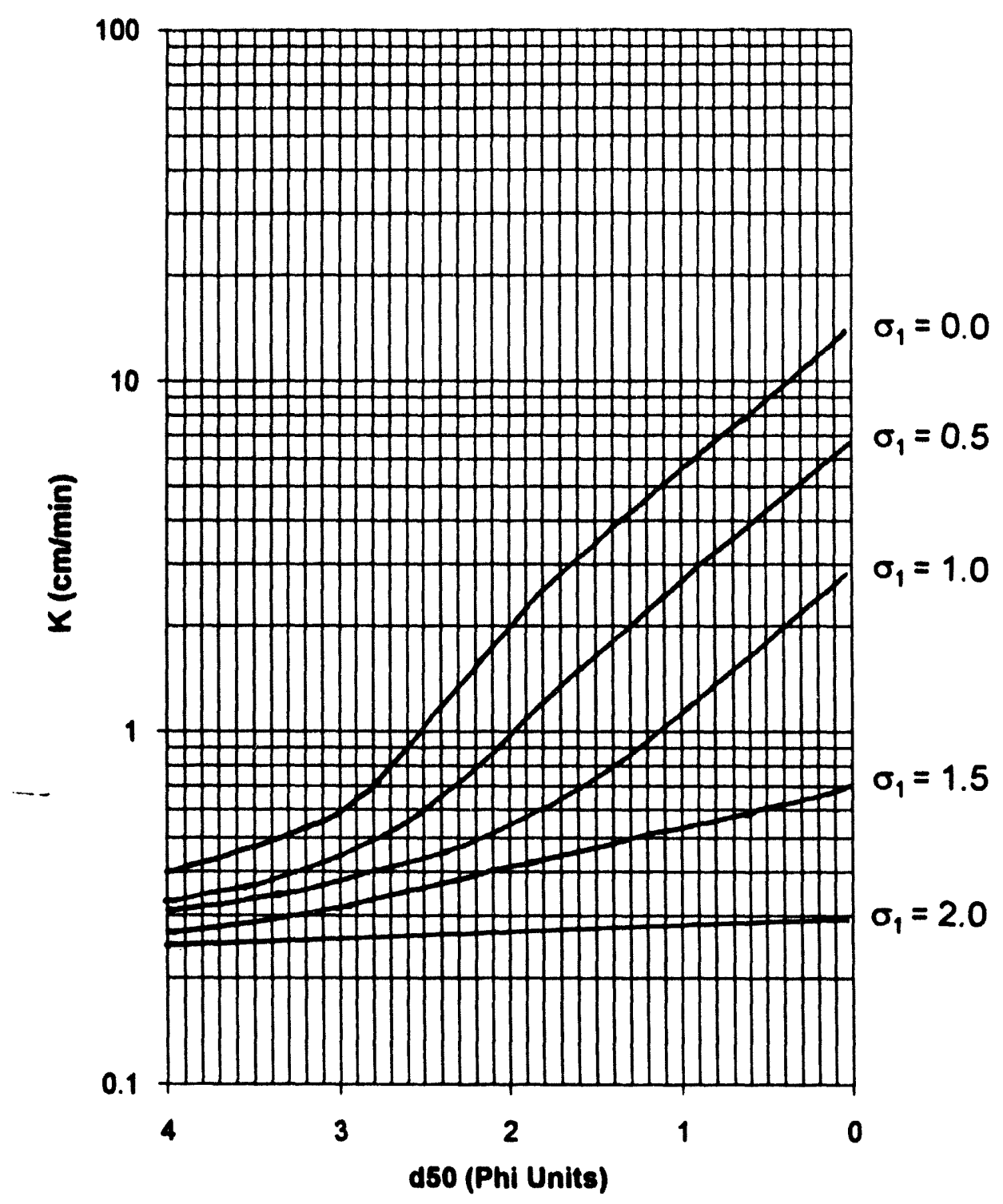




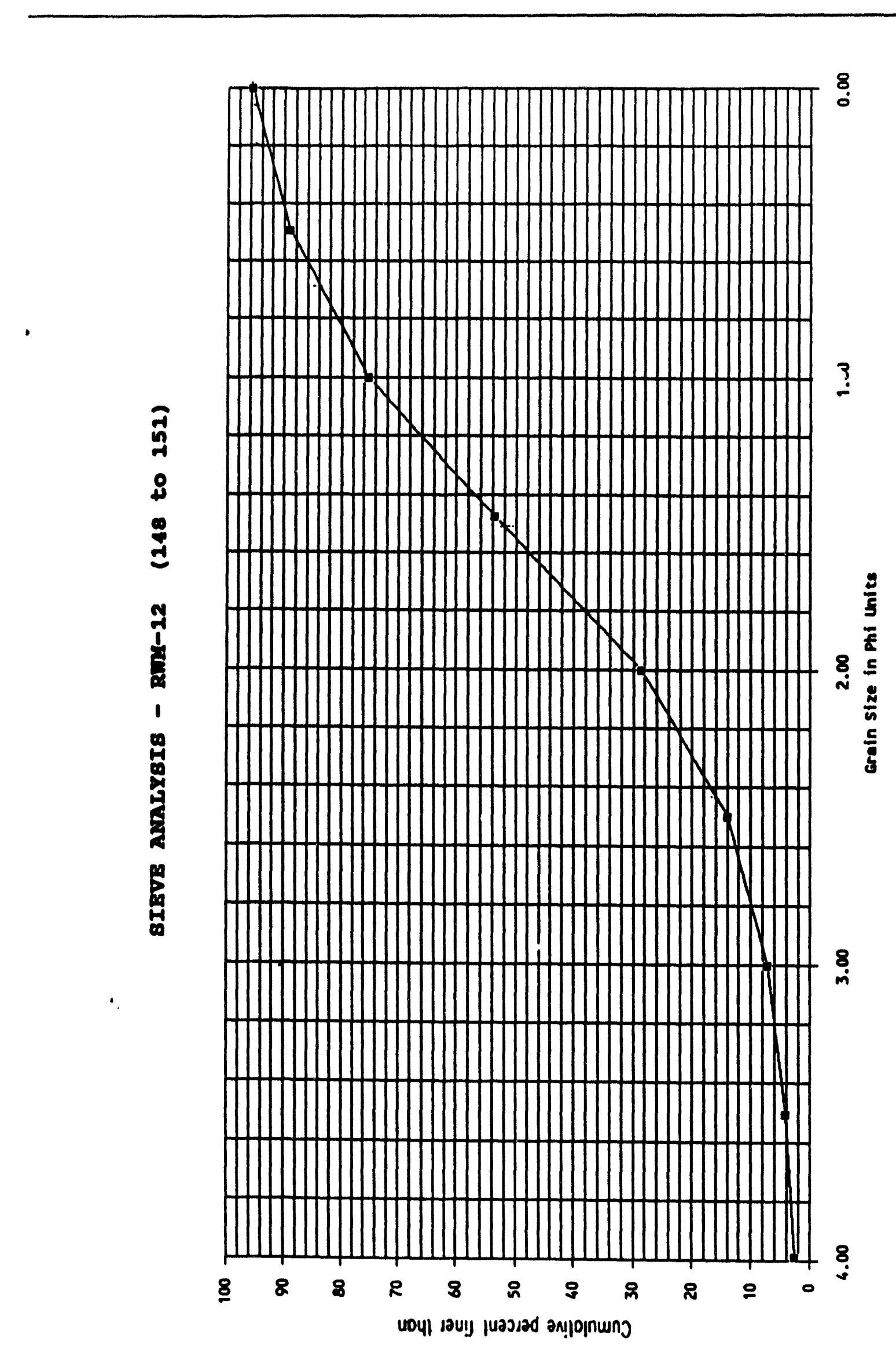




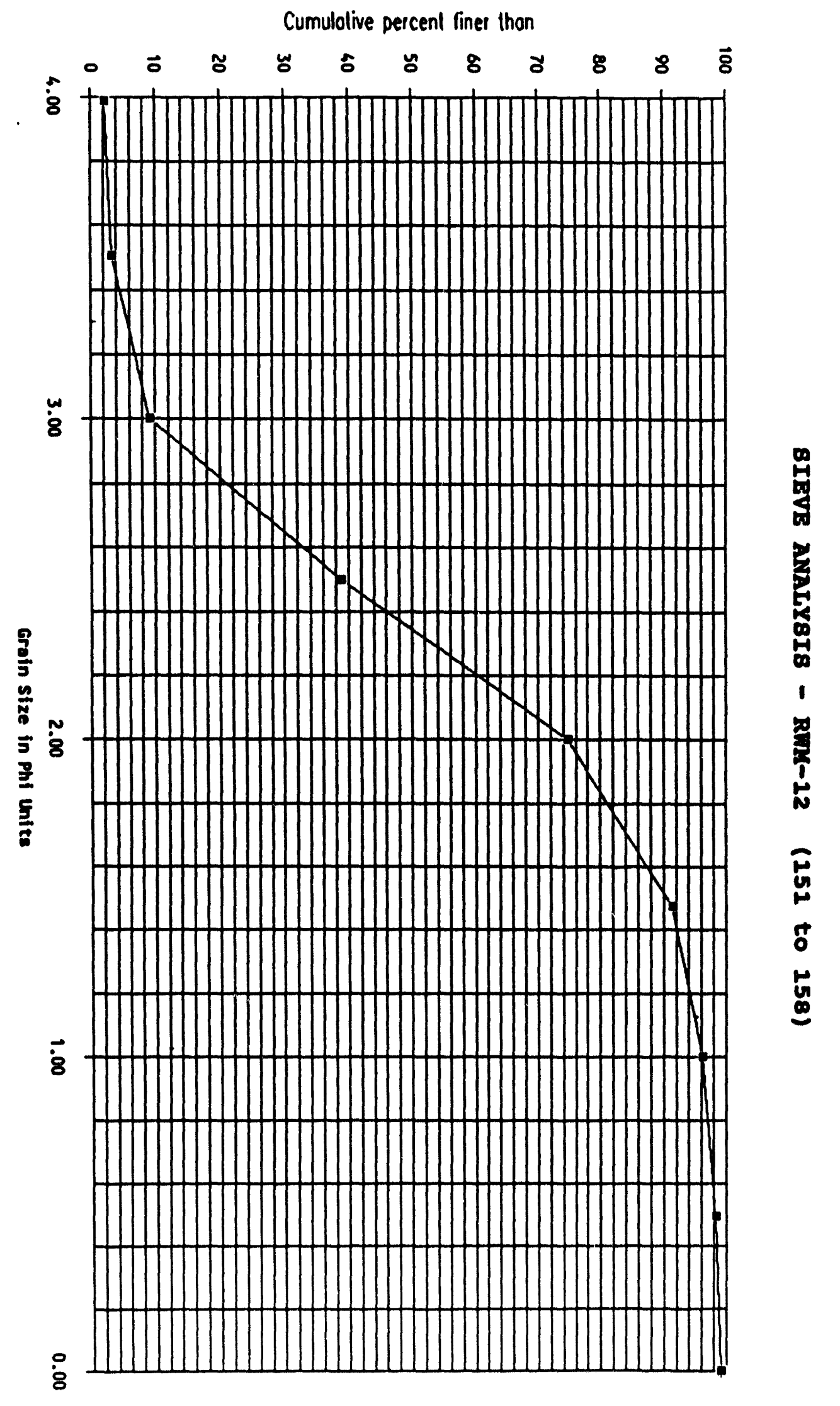


BIEVE ANALY8I8 - RIM-12 (258 to 163)

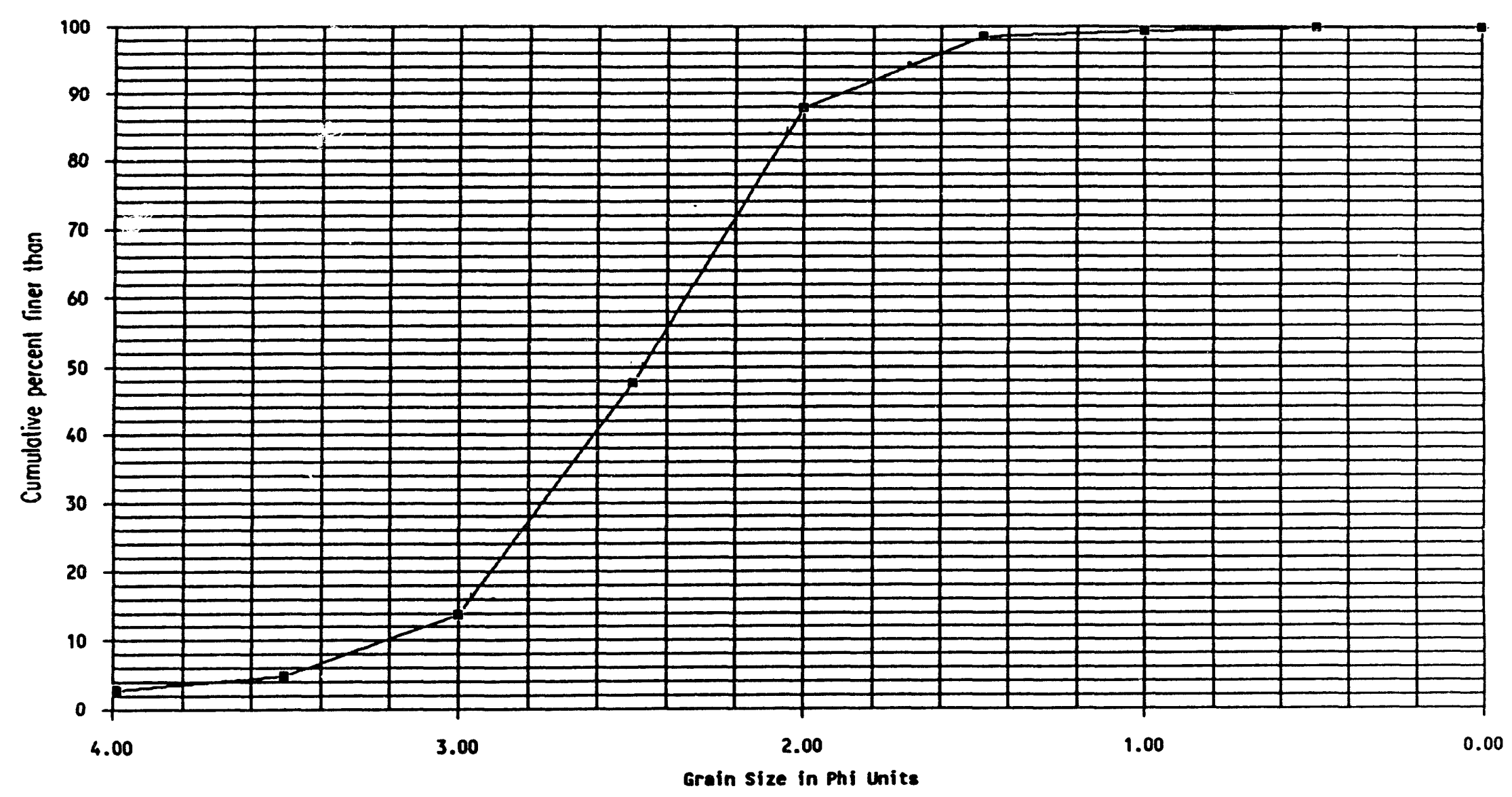


BIEVE ANATYBI8 - RNM-12 (163 to 168)

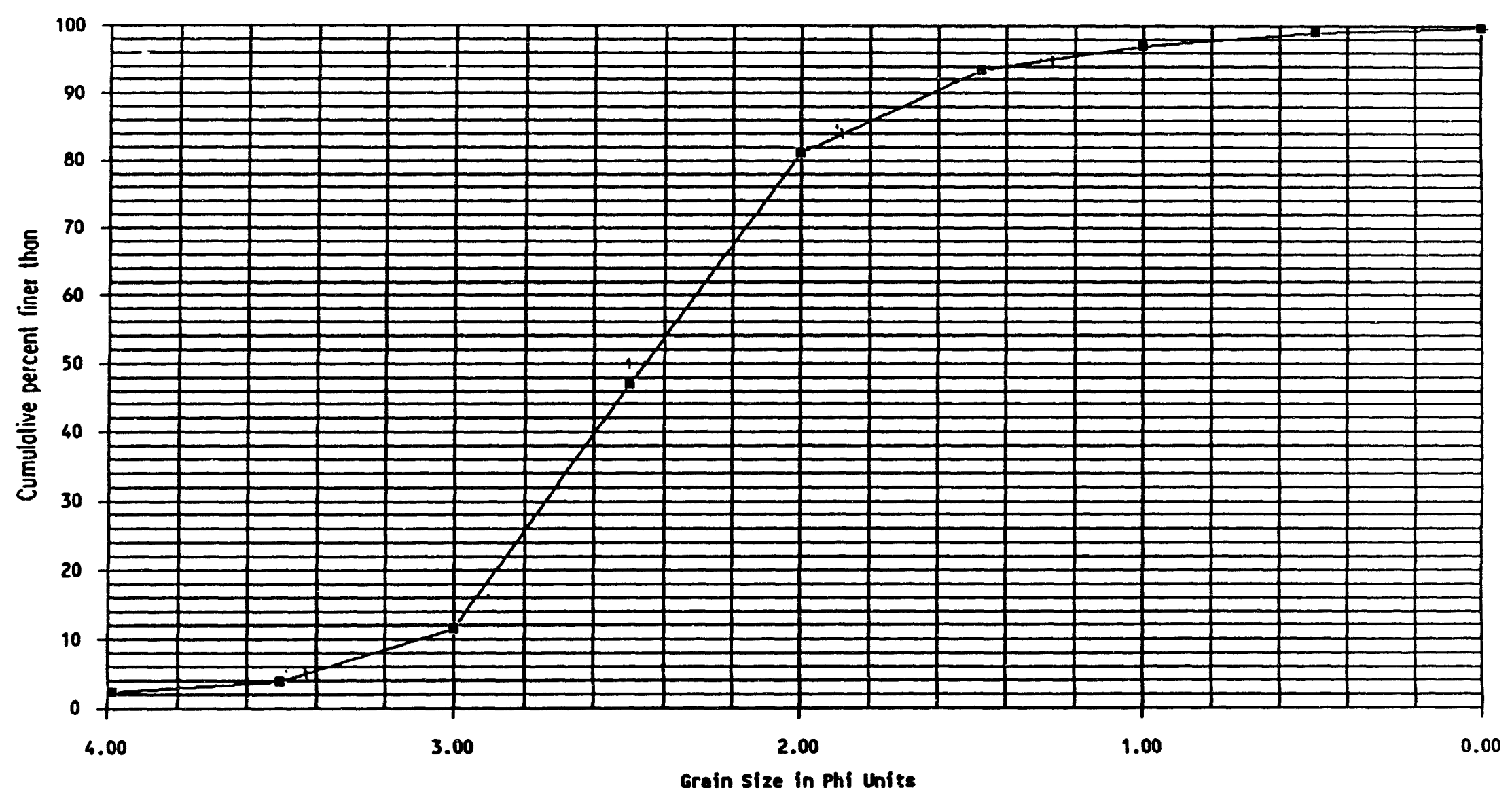


SIEVE ANALY8I8 - RWY-12 (181 to 184)

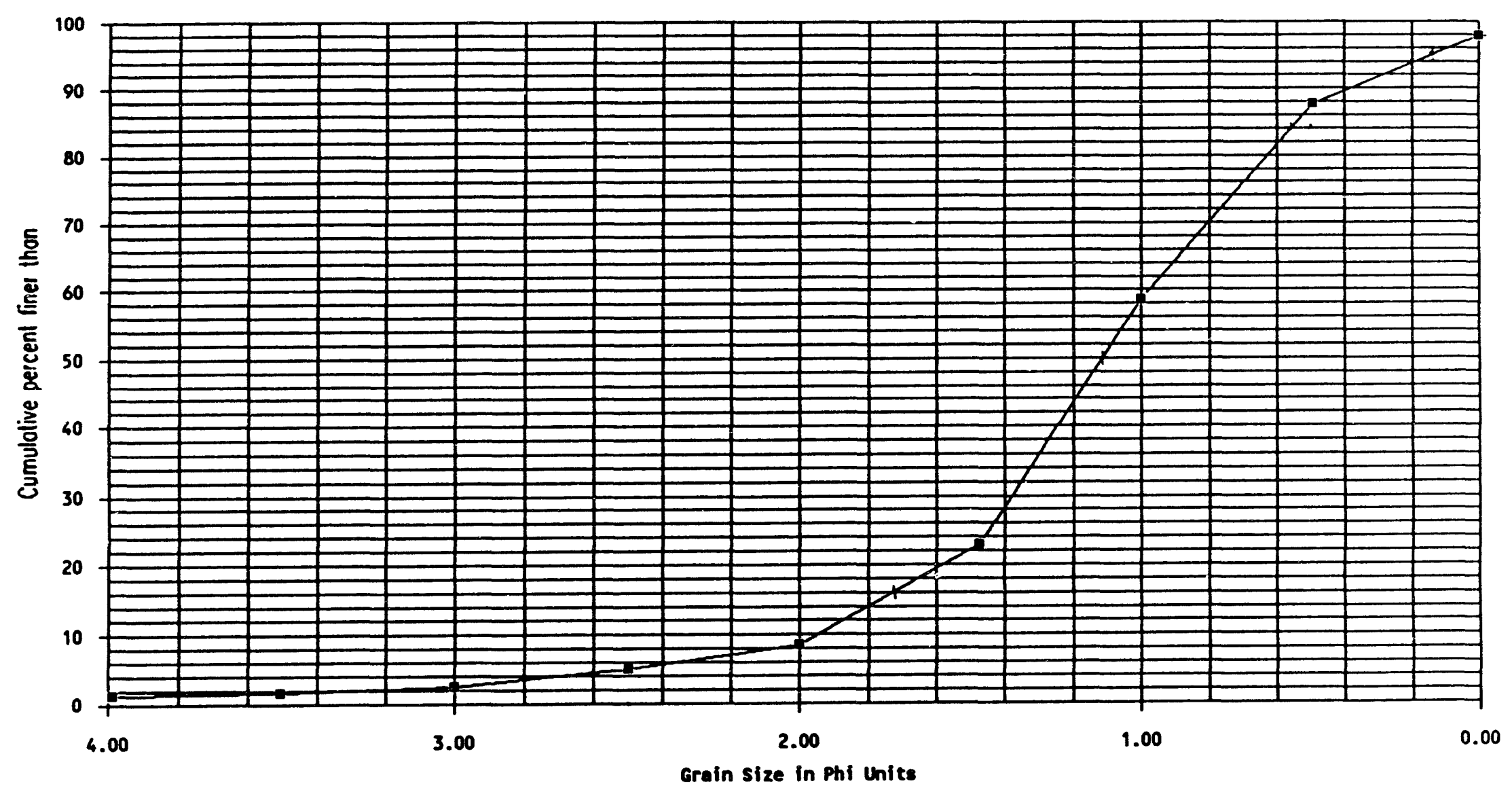




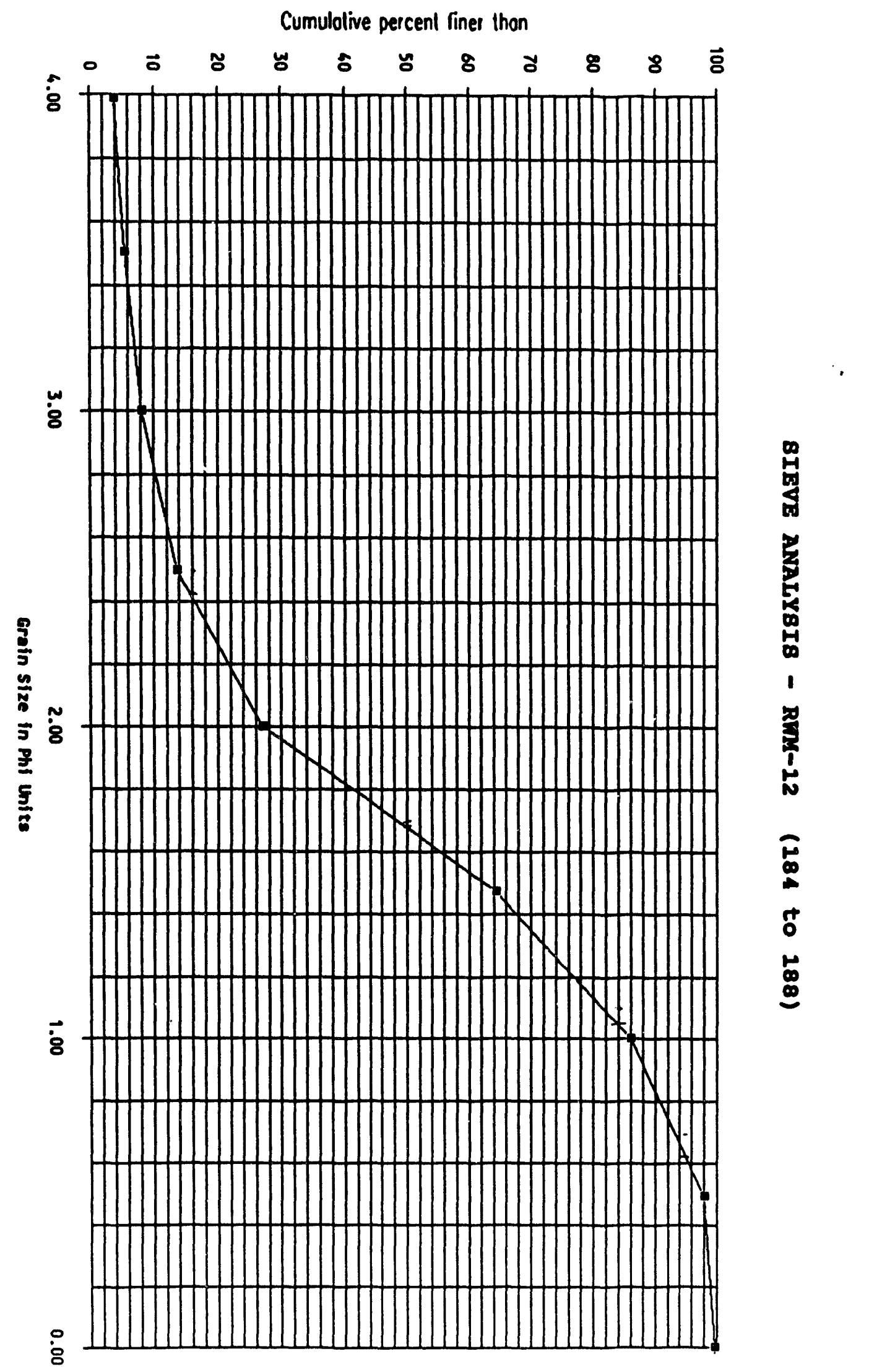


8IEVE ANALY8I8 - RWK-12 (188 to 193)

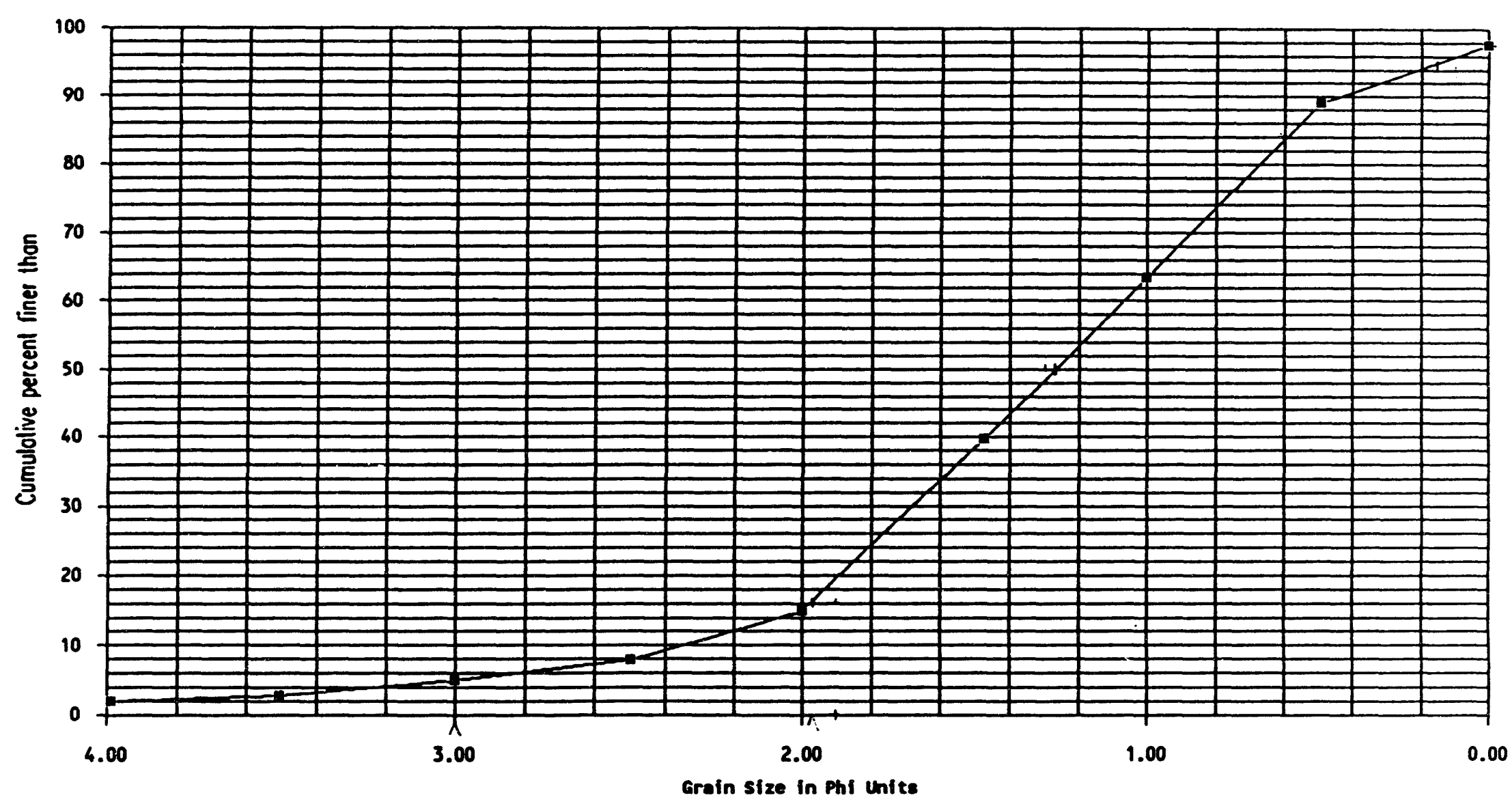


BIEVE ANAIYBIB - RIK-12 (193 to 194)

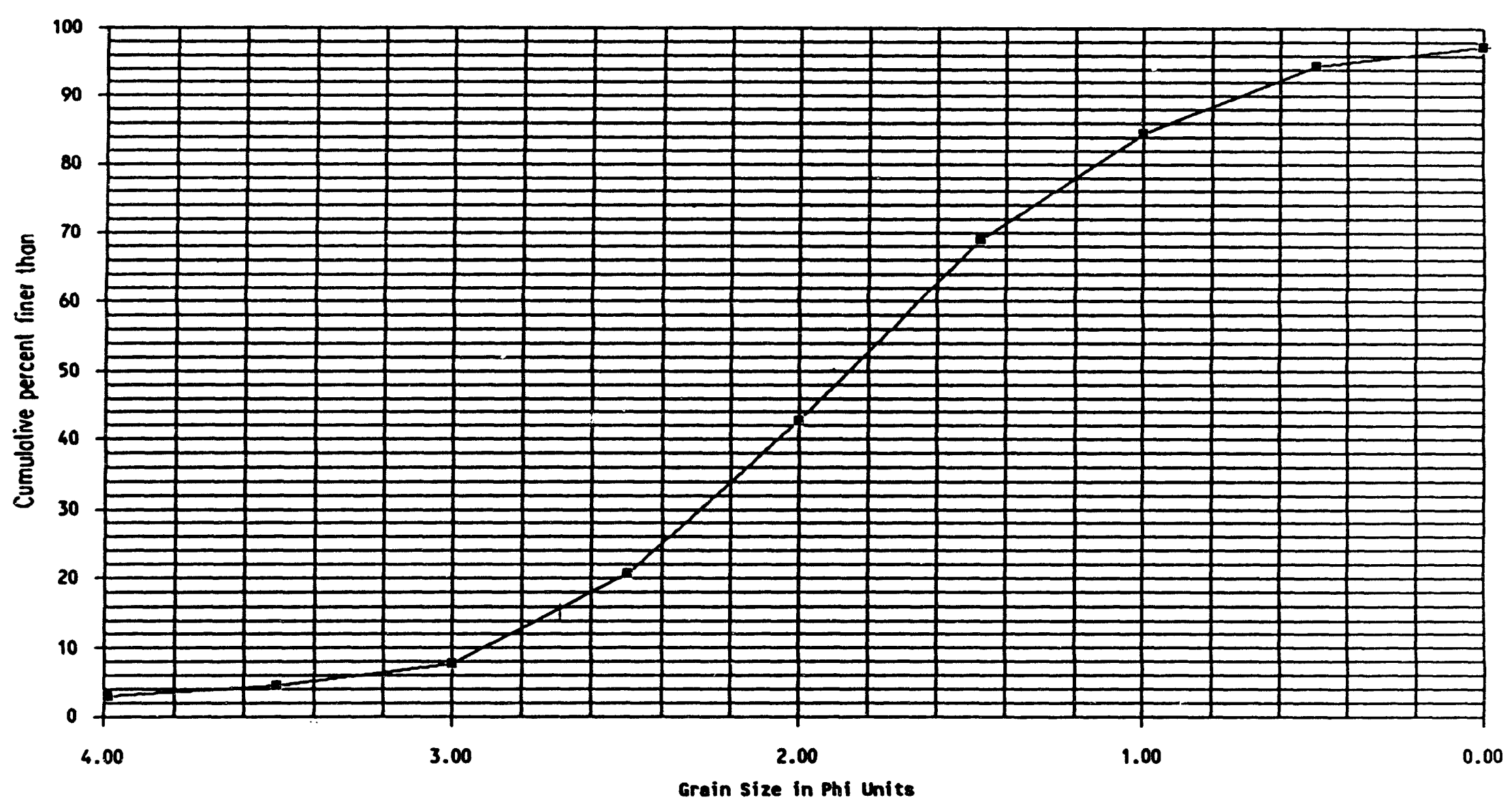


8IEVE ANALY8IS - RWI-12 (194 to 197)

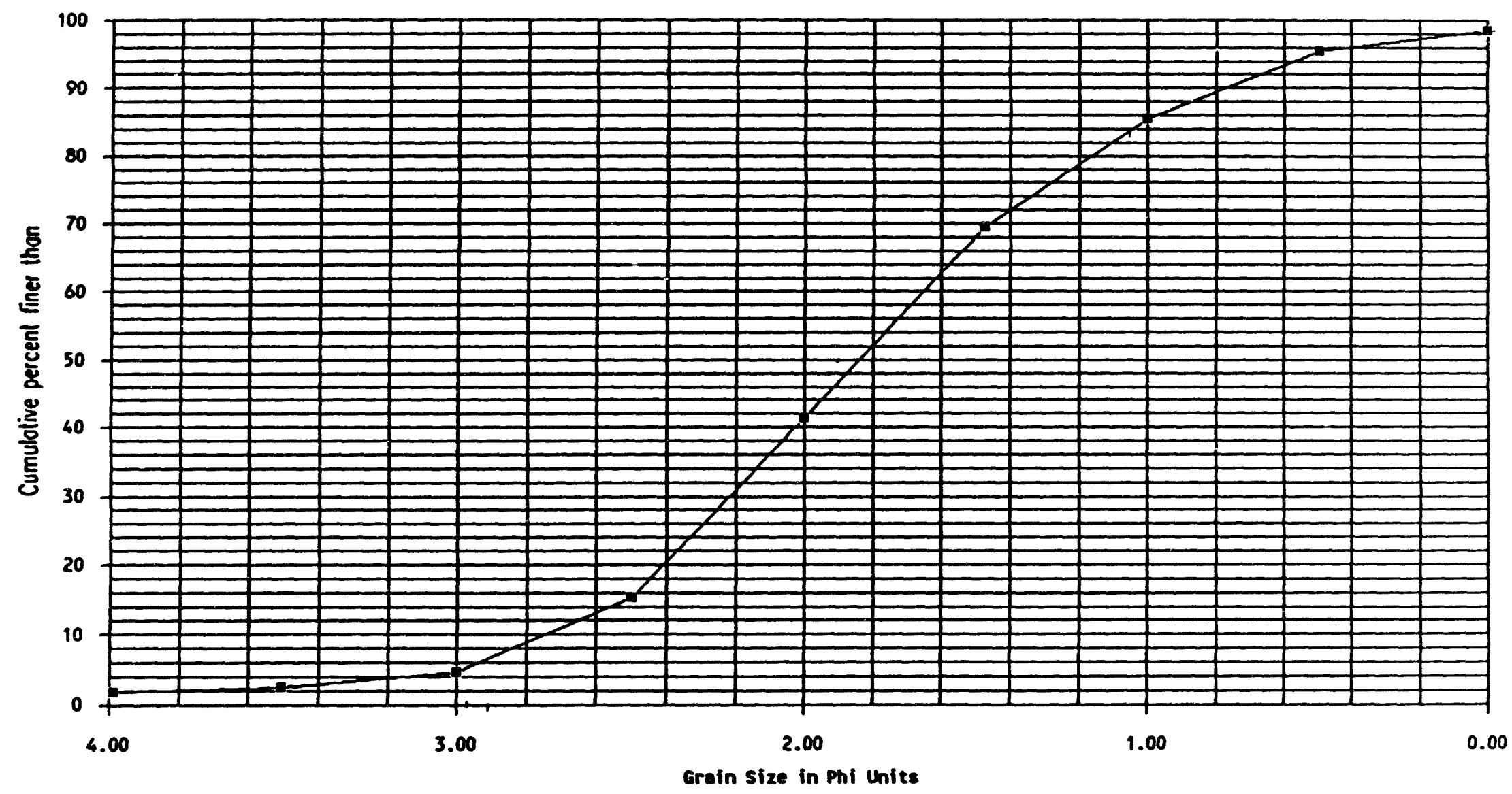




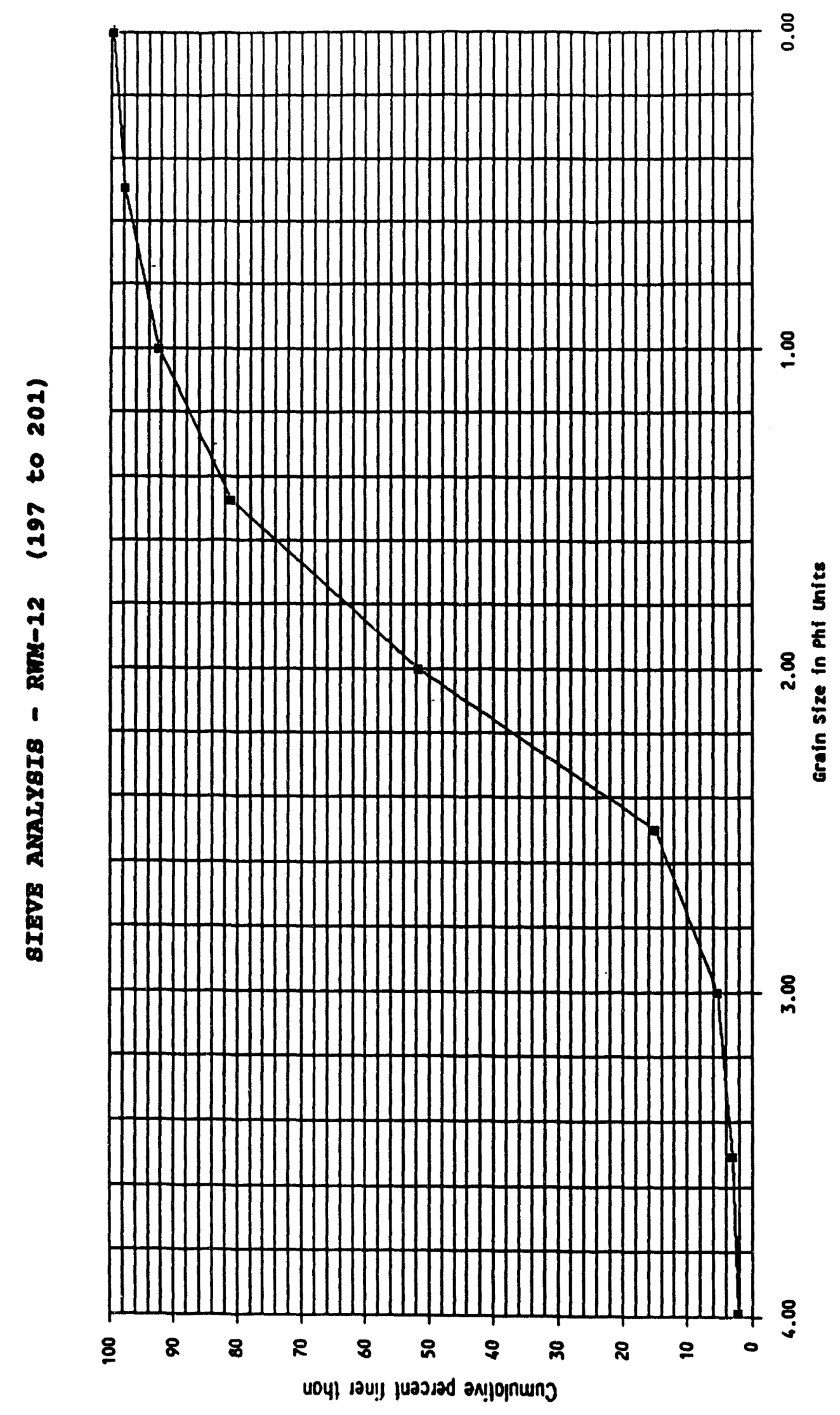


SIEVE ANALY8IS - RTI-12 (203 to 206)

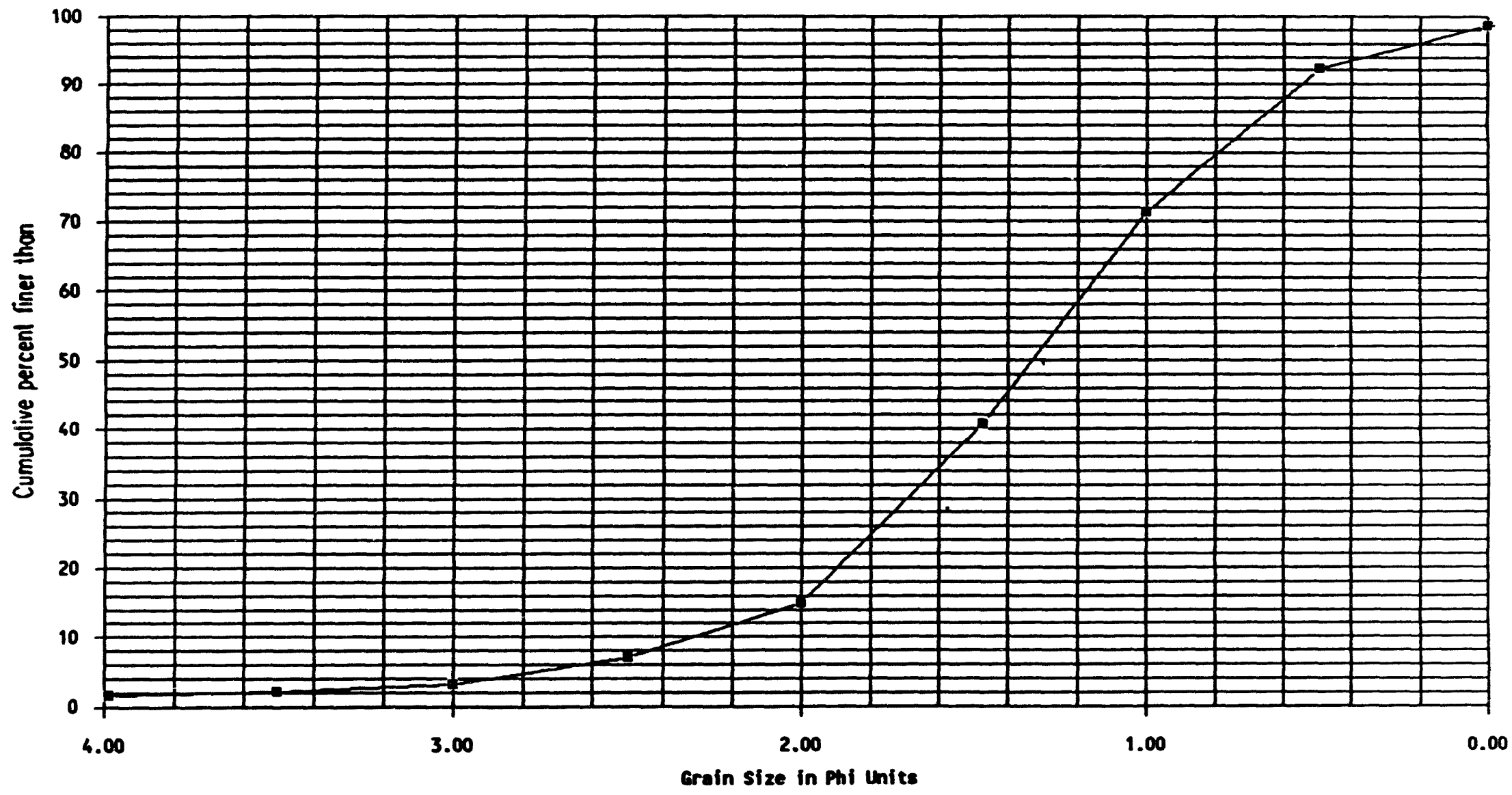


8IEVE AMAY8I8 - RWL-12 (207 to 210)

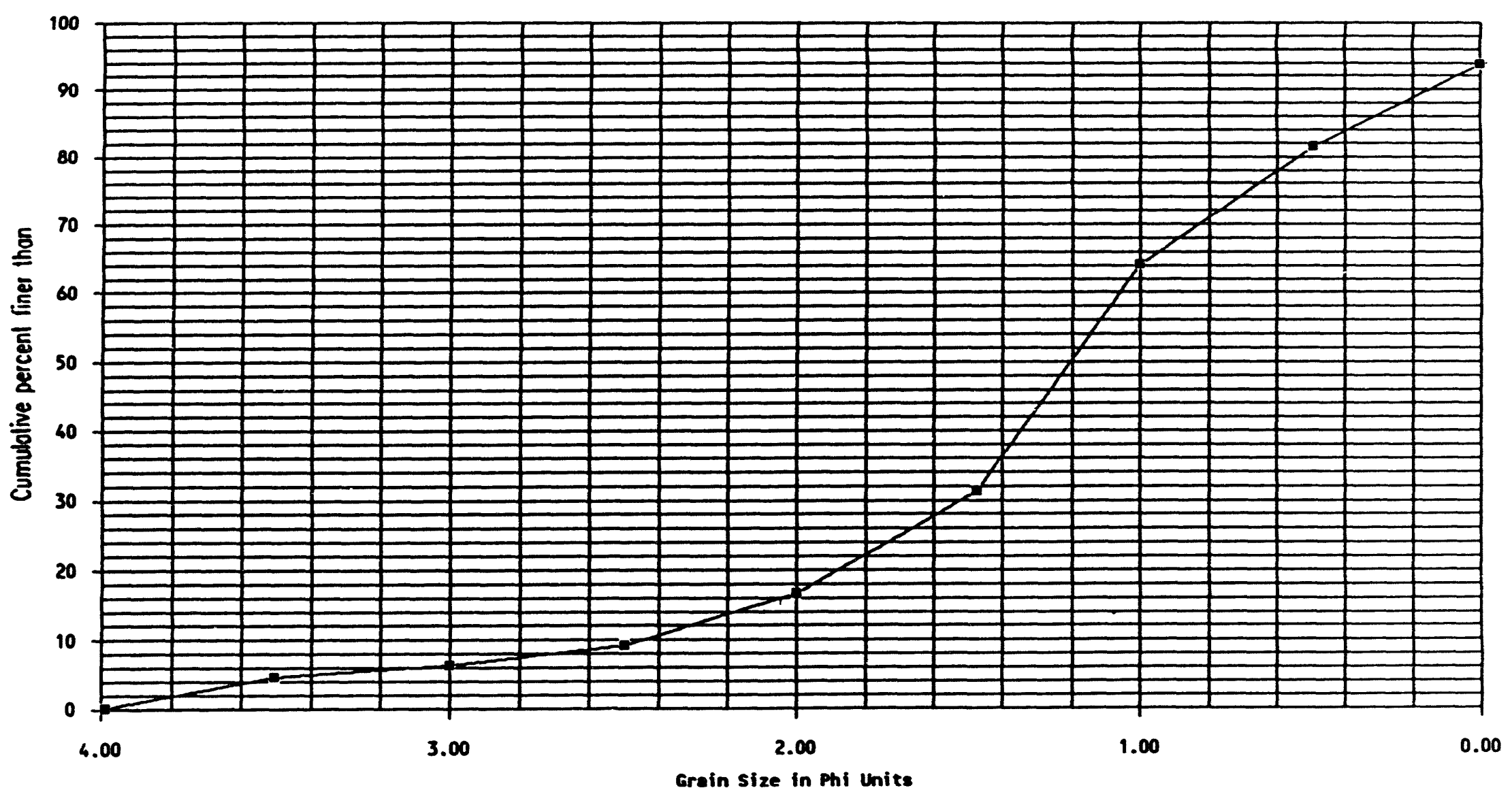




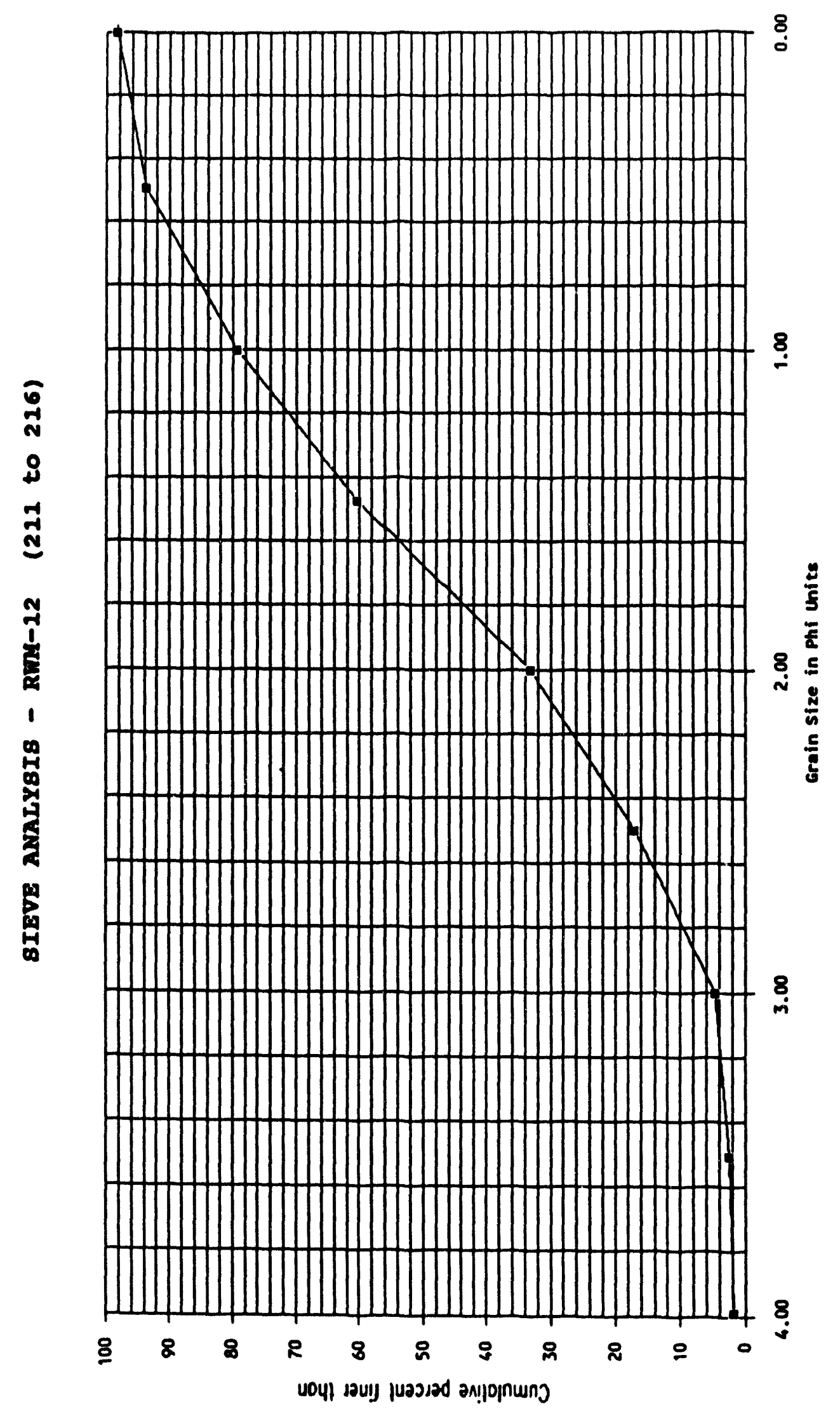


Appendix D. Type Curve Graphs 
OAnrosteres

29

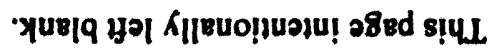




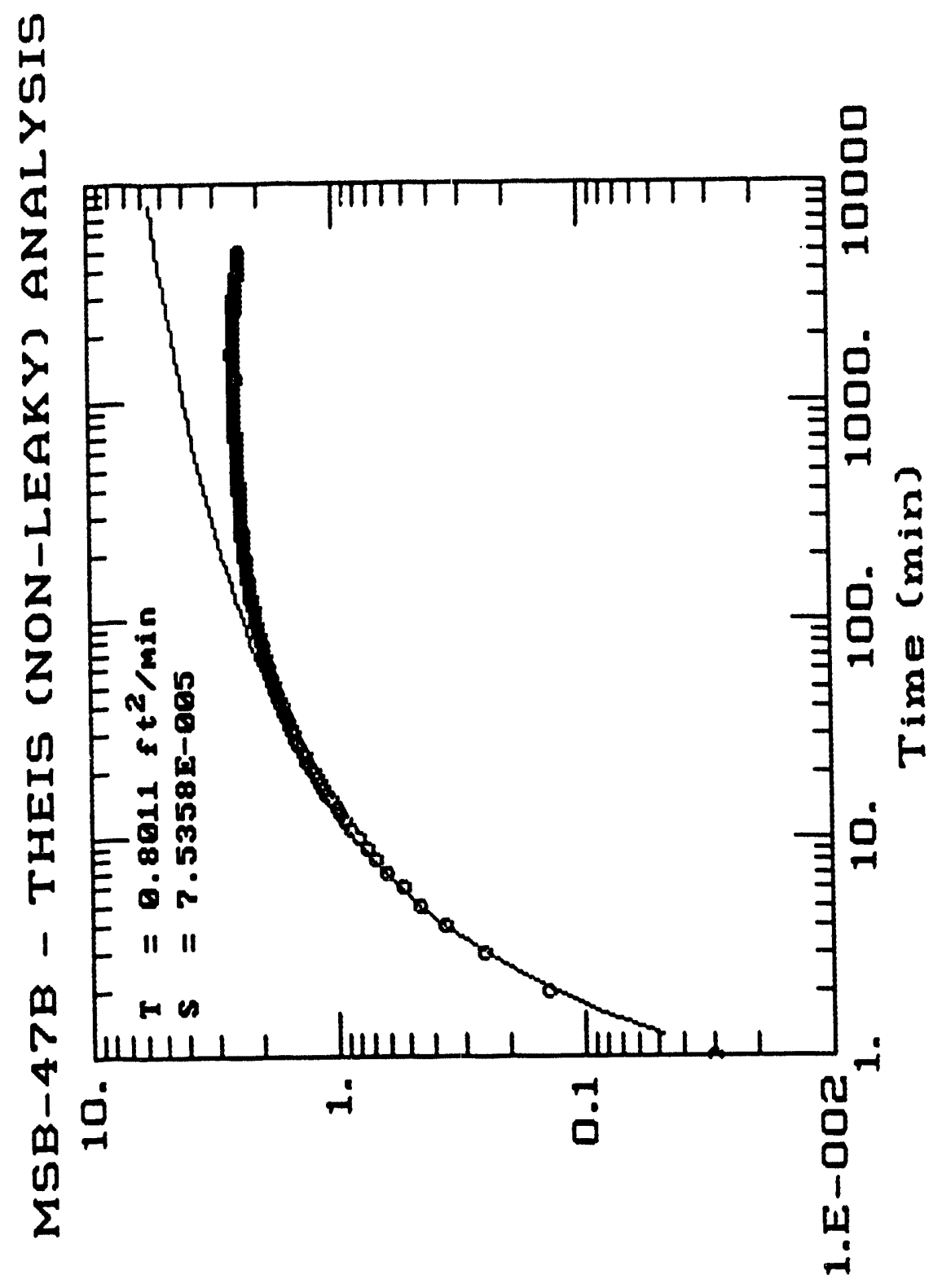

(7f) LMOPMExa 


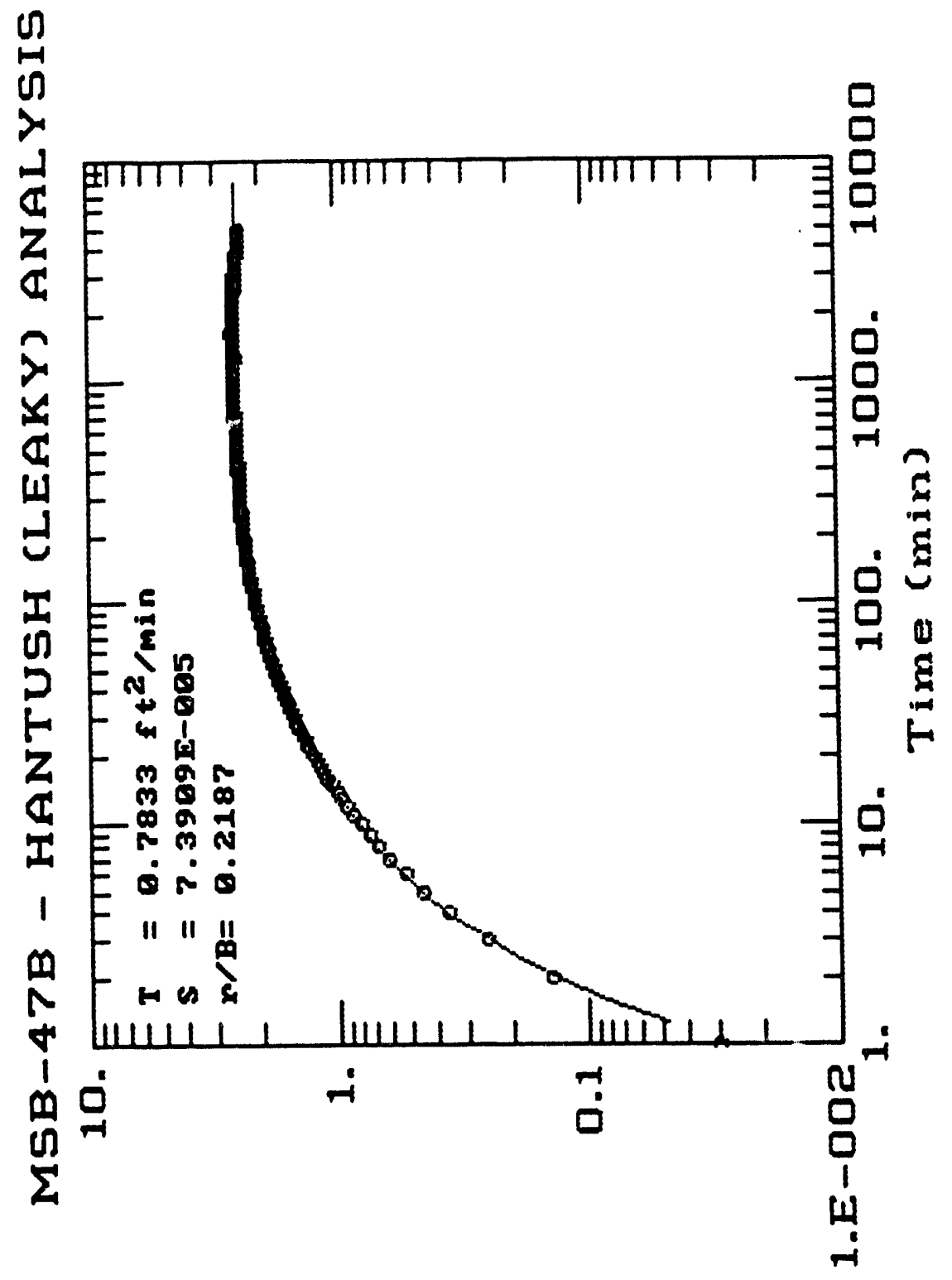

(7f) cxmopmex 
MSB-6BC - THEIS (NON-LEAKY) ANALYSIS

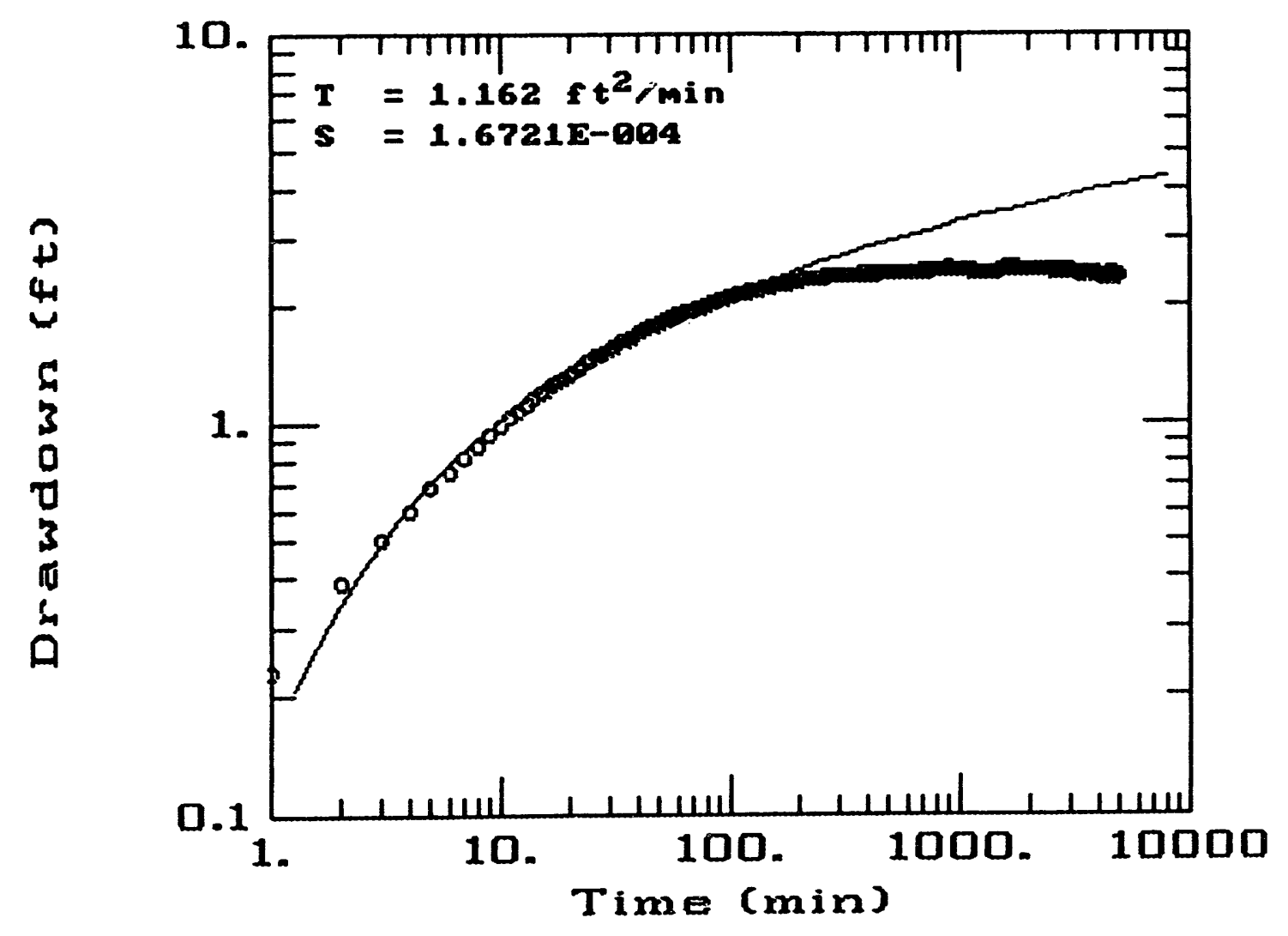




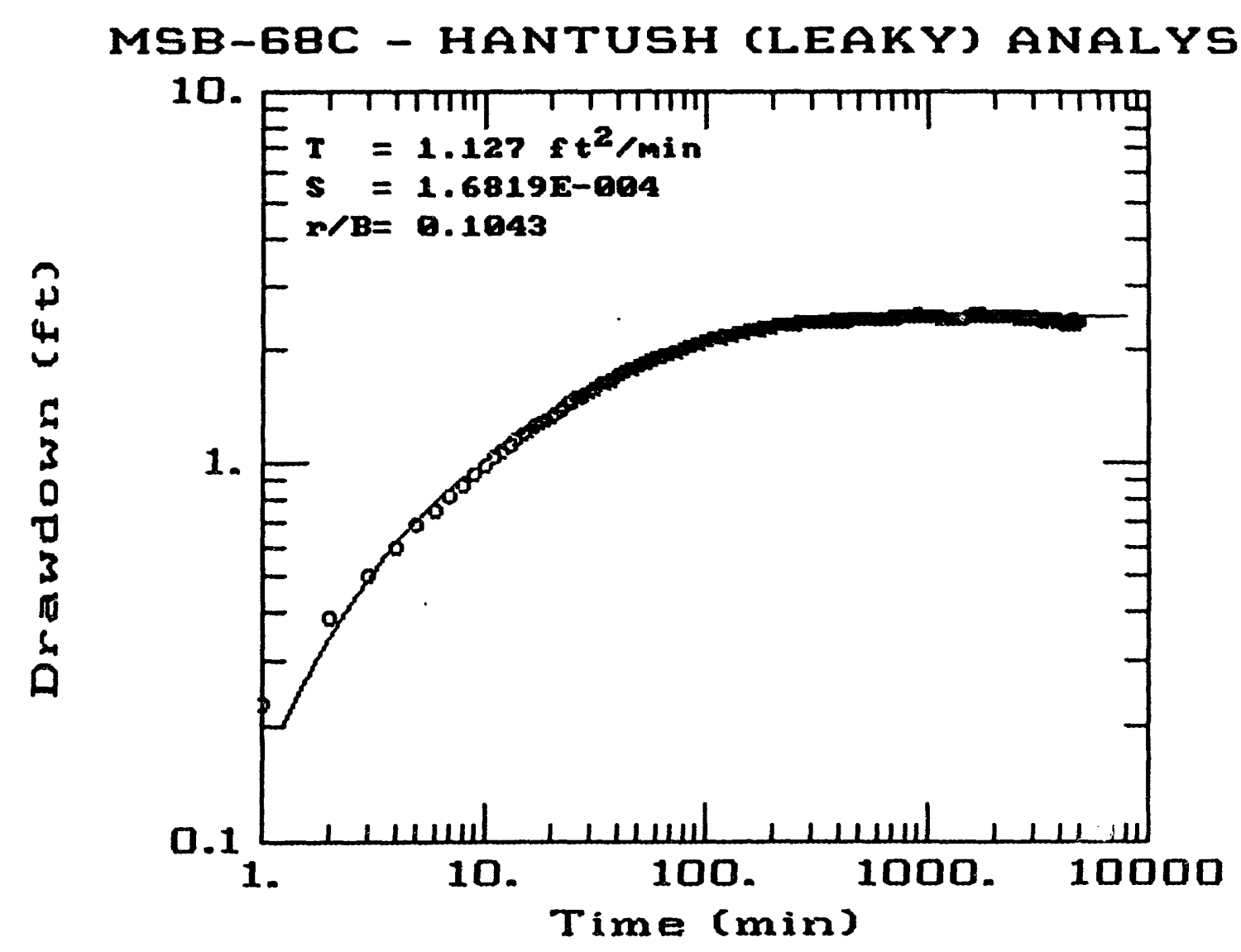




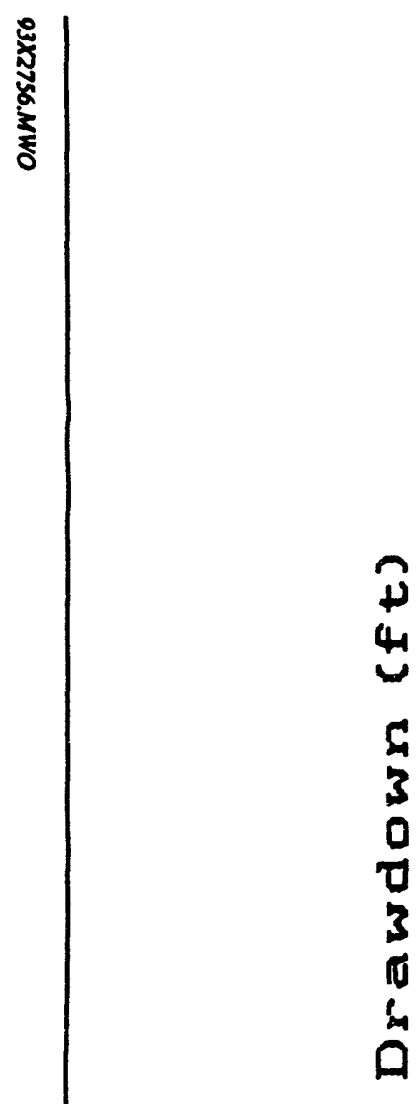

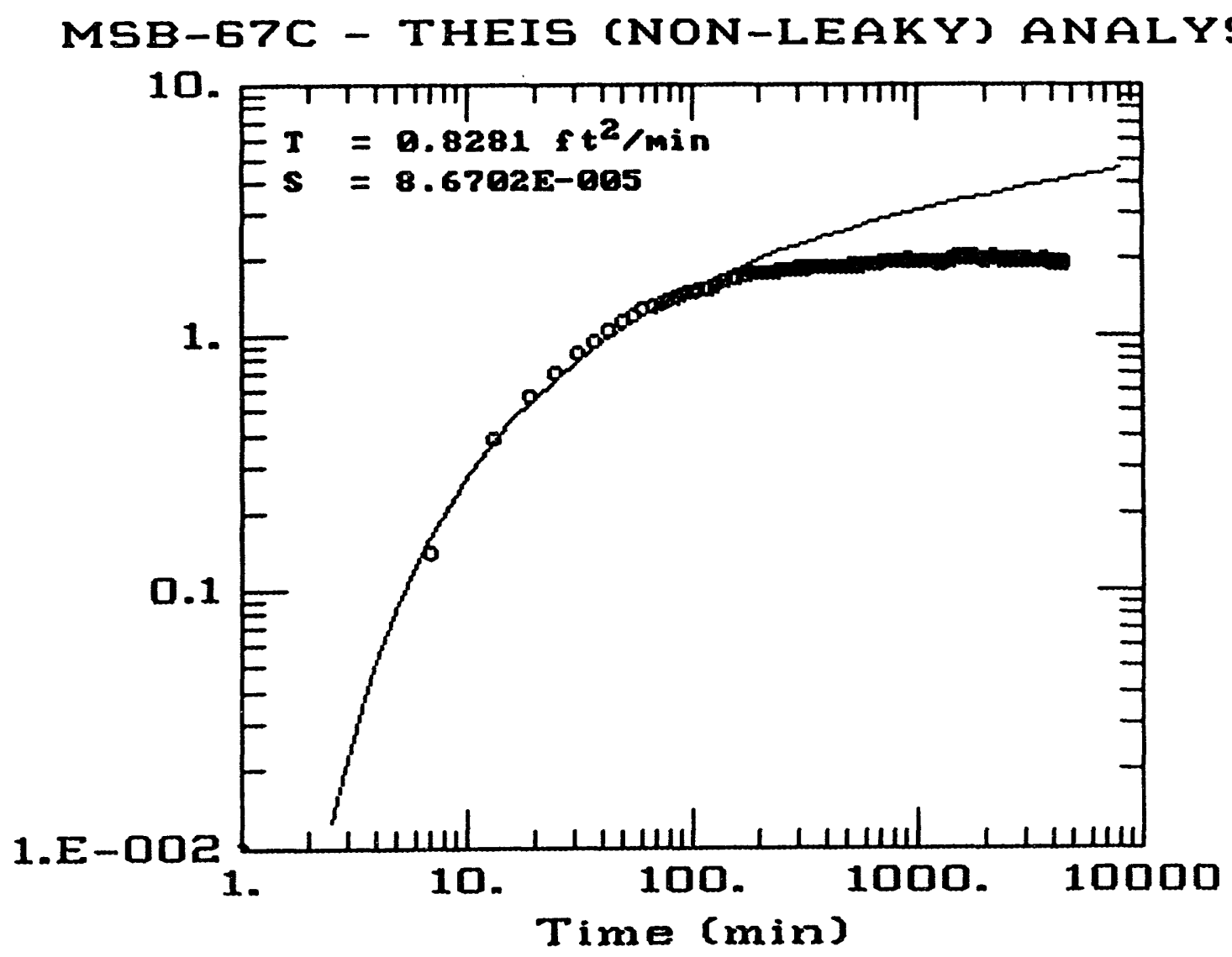

9 


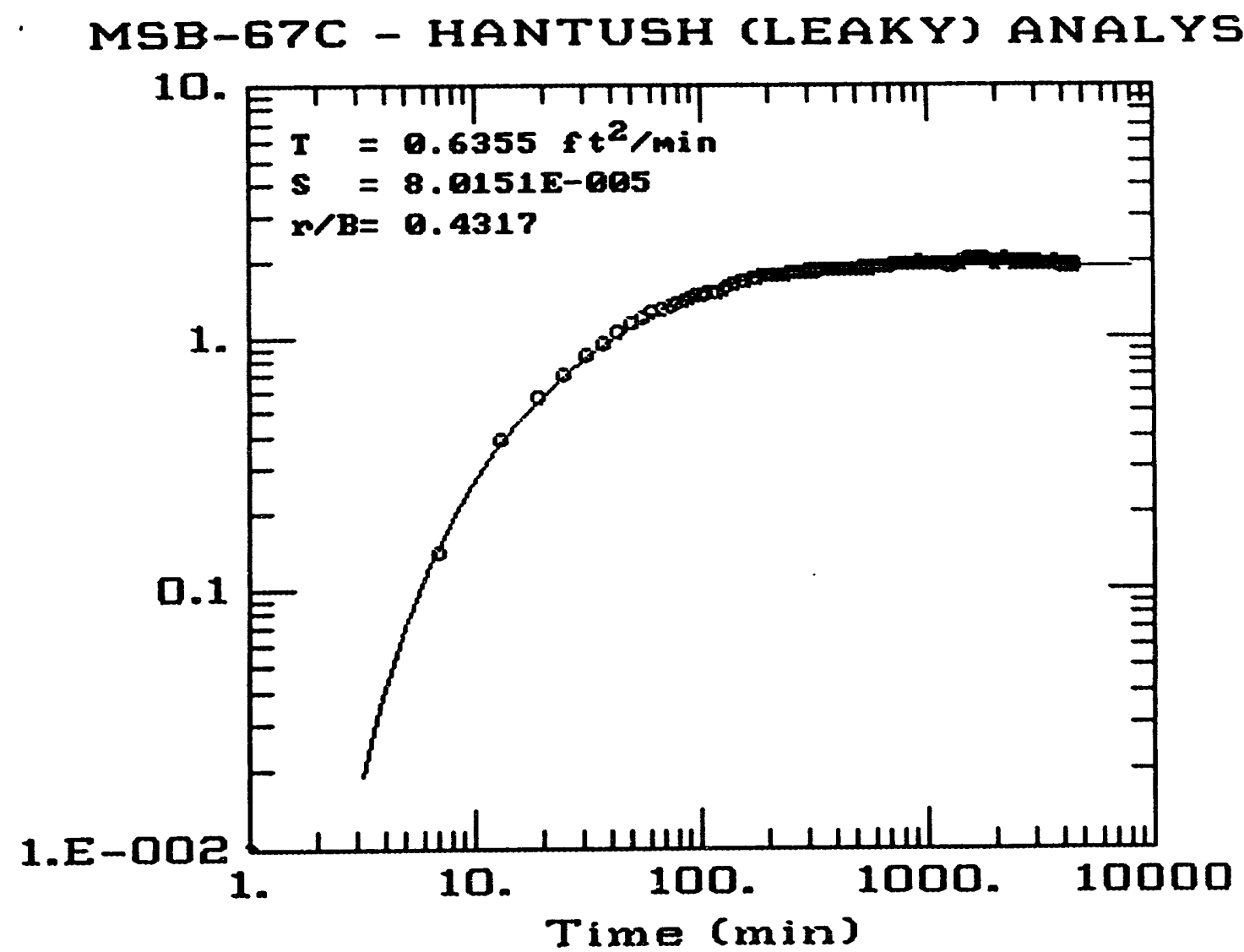



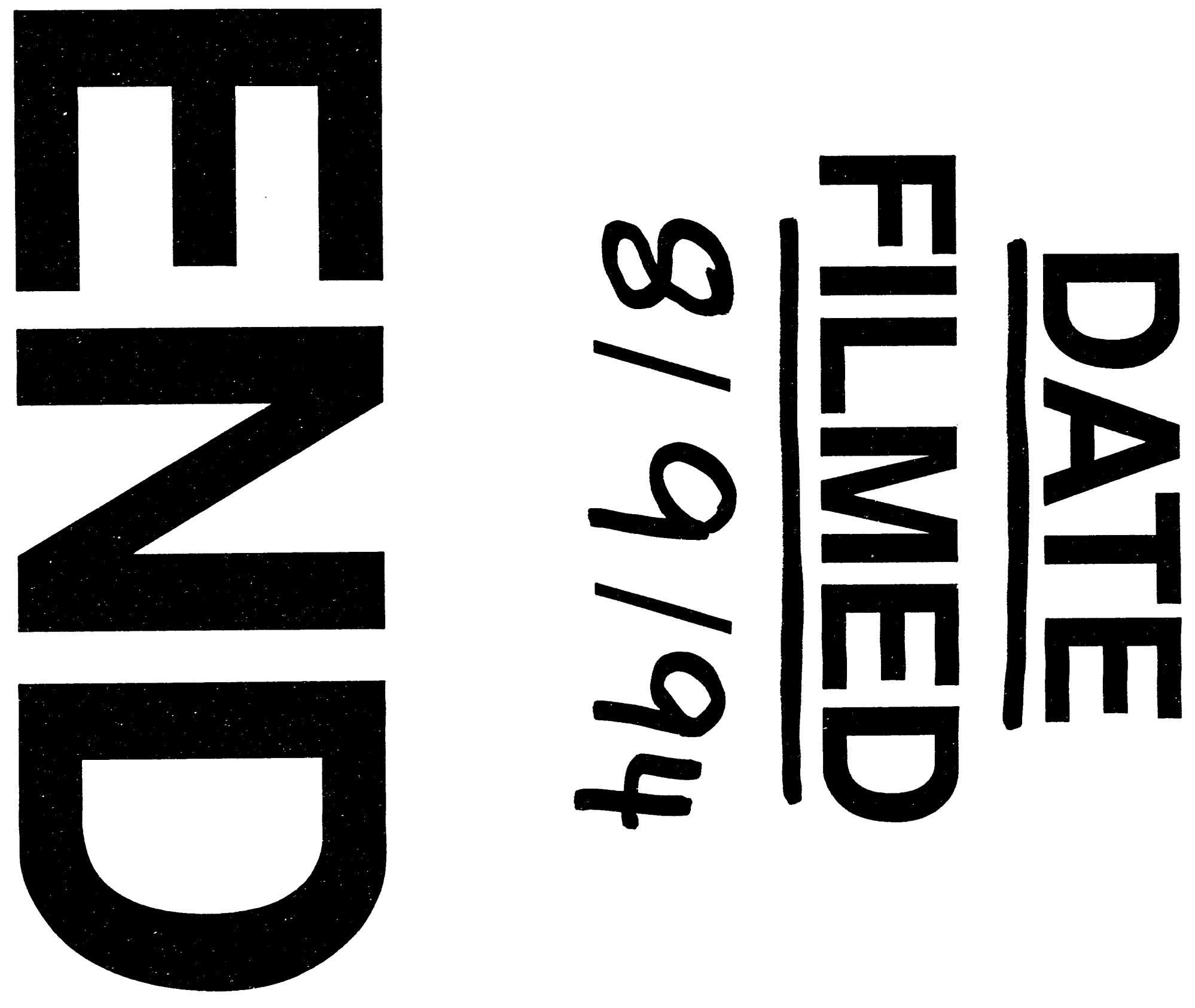
